Portland State University

PDXScholar

1989

\title{
Exploratory study : preparation by Japanese parents in the U.S. for their children's reentry to Japan from an intercultural communication perspective
}

Noriko Nakagawa

Portland State University

Follow this and additional works at: https://pdxscholar.library.pdx.edu/open_access_etds

Part of the International and Intercultural Communication Commons

Let us know how access to this document benefits you.

\section{Recommended Citation}

Nakagawa, Noriko, "Exploratory study : preparation by Japanese parents in the U.S. for their children's reentry to Japan from an intercultural communication perspective" (1989). Dissertations and Theses. Paper 4102.

https://doi.org/10.15760/etd.5986

This Thesis is brought to you for free and open access. It has been accepted for inclusion in Dissertations and Theses by an authorized administrator of PDXScholar. Please contact us if we can make this document more accessible: pdxscholar@pdx.edu. 
AN ABSTRACT OF THE THESIS OF Noriko Nakagawa for the Master of Arts in Speech presented April 4, 1989.

Title: Exploratory Study: Preparation by Japanese Parents in the U.S. for Their Children's Reentry to Japan from an Intercultural Communication Perspective

APPROVED BY MEMBERS OF THE THESIS COMMITTEE:

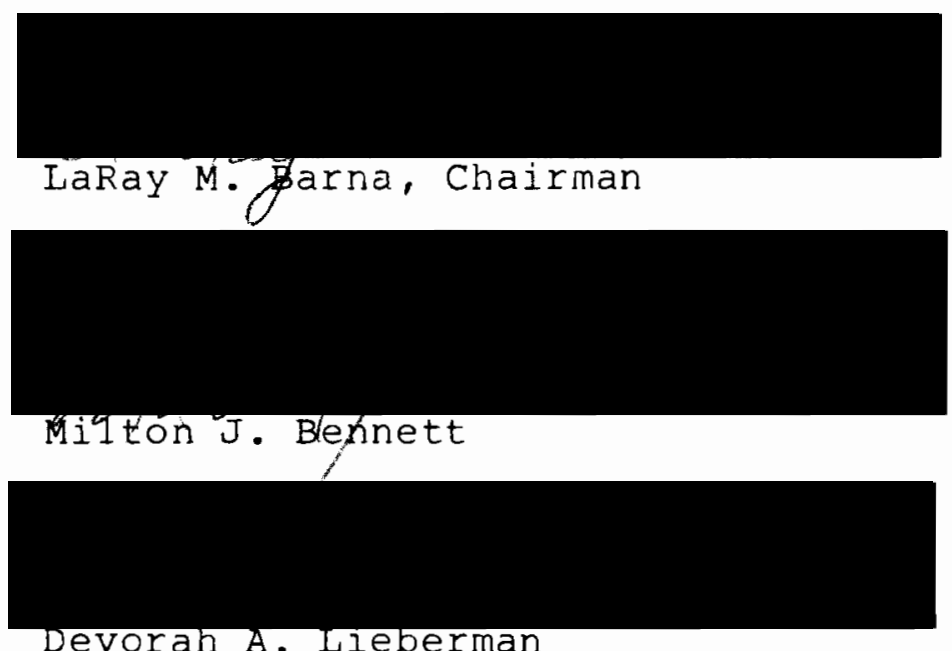

Devoran A. Lleberman

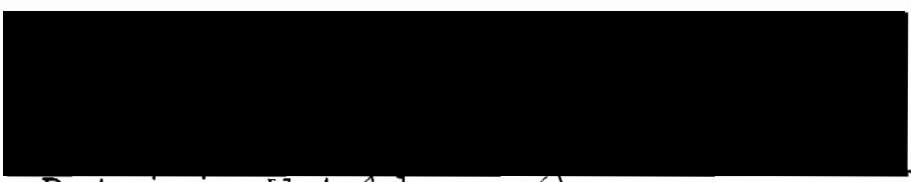

Patricia wetzel

The purpose of this thesis was to discover whether or not the Japanese parents who are temporarily staying in the U.S. with their children are anticipating the possibility of 
psychological and communicative problems their children may face as returnees, and to what extent the Japanese parents discuss these potential problems with their husbands and/or with their children. The question also asked whether or not the Japanese parents are doing anything to prepare themselves and/or their children to cope with the potential problems which their children may face as returnees.

A literature review revealed the potential problems of Japanese returnee children. Those were "returnee children's advanced English proficiency over their peer group in Japan," "their reduced Japanese language ability," and "loss of their 'Japaneseness' caused by the changes in terms of their values, ways of thinking, behavioral patterns and communication styles that happened to the children during their sojourning abroad." A survey questionnaire was constructed and the Portland Japanese School was selected as representative of a suitable population of the Japanese children now in the U.S. Who will be returning to Japan in the future. The questionnaire was sent to all the mothers of these children, and 57 were returned. Forty-one of these met the stated criteria in the present study, and were subjected to data analysis. The data obtained from the closedended questions was tabulated by percentage, and content analysis was used for the open-ended questions, suggesting themes which emerged from the open-ended questions. The interrater reliability coefficient for clusters within the themes in this research was strong $(+0.83)$. 
It was found that the Japanese mothers in this study anticipated the following potential effects of their children's sojourn in the U.S. on their reentry to Japan: "Changes could occur to their children during their sojourn in the U.S.," "These changes are serious enough to make them appear different from their peer group in Japan," and "These differences may cause some difficulty for their children's reentry to Japan." However, they did not realize the importance of maintaining the children's "Japaneseness" for their reentry, and the reasons why the changes that occurred to their children will become a barrier for their readjustment to the Japanese society. The results of the data also indicated that they did not discuss the issue of the children's reentry within the family as much as was recommended in the literature. This was explained by the general disinclination of the Japanese to verbalize their feelings. Even though many mothers believed in the necessity of preparation for their children's reentry in additional ways to simply helping their children keep up with their studies, there were few mothers who reported any specific kind of preparation which they were actually doing. The subjects in this research did not regard discussion of the problem of reentry as one method of preparation.

In the discussion, the importance of not using the common or generic definition of the term "reentry" was stressed since it does not fit the Japanese cultural context. 
The designing of reentry orientation programs specifically for Japanese returnee children was suggested. 
EXPLORATORY STUDY: PREPARATION BY JAPANESE PARENTS IN THE U.S. FOR THEIR CHILDREN'S REENTRY TO JAPAN FROM AN INTERCULTURAL COMMUNICATION PERSPECTIVE by NORIKO NAKAGAWA

A thesis submitted in partial fulfillment of the requirements for the degree of

\author{
MASTER IN ARTS \\ in \\ SPEECH
}

Portland State University

1989 
TO THE OFFICE OF GRADUATE STUDIES:

The members of the committee approve the thesis of Noriko Nakagawa presented April 4, 1989.

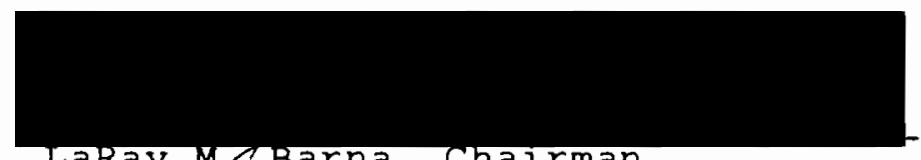

Lakay Mfi Barna, Chairman

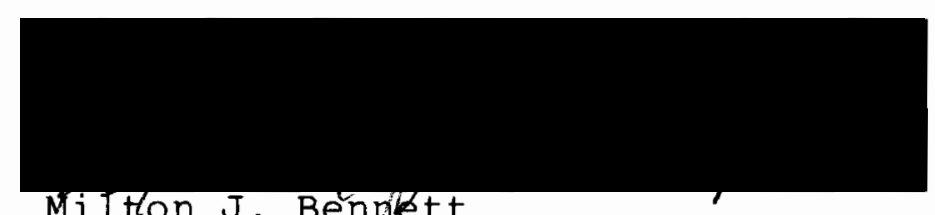

Milton J. Benniett

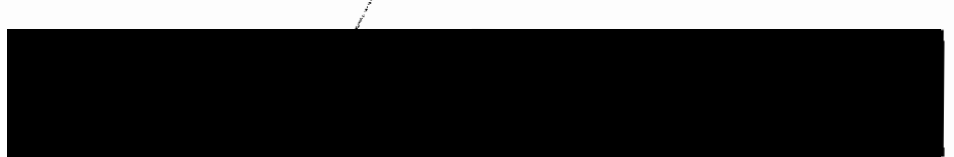

Devorah A. Lieberman

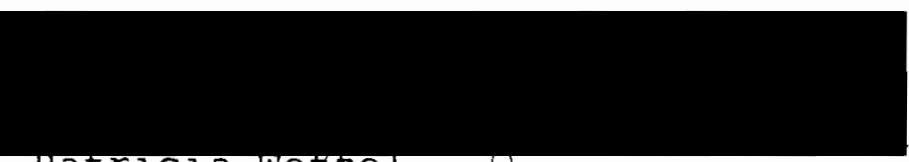

patricia wetzel

APPROVED :

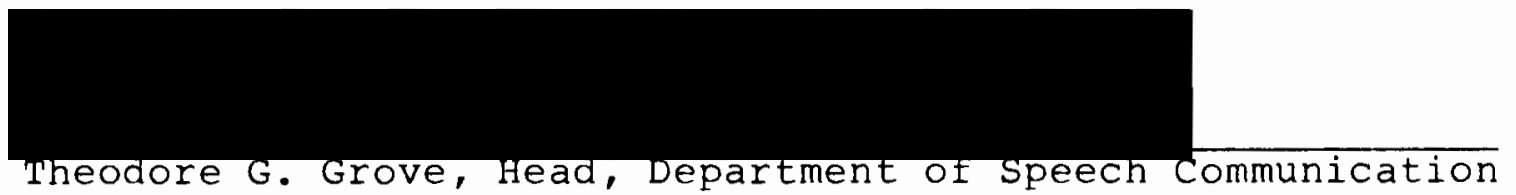

Bernara Ross, Vice provost for Graduate studies 


\section{ACKNOWLEDGMENTS}

I would like to take this opportunity to express my appreciation and gratitude to those who offered me support and encouragement in completing this thesis. I especially give my heartfelt appreciation to Professor LaRay Barna, my academic adviser and chairperson for my thesis, for the hours she spent helping me, and for the encouragement she gave me to pursue this thesis topic. Without her endless support, expertise, and love I would not have completed my studies at Portland State University. I am grateful to Dr. Bennett for his enthusiasm in teaching, and for his valuable advice which helped shape the final form of this research. I would like to thank Dr. Lieberman, especially for her contribution to the methodology for my thesis, for endless encouragement, and for making me laugh when I had a rough time. I am thankful to Dr. Wetzel for her warmth and encouragement. I would also like to express my gratitude to Dr. Ehrenhaus, although not a committee member, for the encouragement and support he gave me through my academic years. I am also grateful to the Speech Communication Department as a whole for providing me with a great academic and personal experience.

There are some other people who deserve my special gratitude. I am indebted to Shinobu and Atsuko for their careful translating, and cooperation with content analysis, 
respectively. I would like to give great thanks to my best friend in the Speech Communication Department, Elees, for the caring she has given me since I came to the U.S. I wculd also like to express my appreciation to my friends, Donna, Anne, and Hyla for their endless encouragement in completing my thesis.

I would like to give a great appreciation to Mr. Kumashiro, a chairperson of the Educational Board at Portland Japanese School, for showing his understanding of my research, and his cooperation in selecting the subjects. I also appreciate the cooperation given by each person who participated in this study. The completion of this thesis could not have been accomplished without these people's help. Most of al1, I would like to express my deepest gratitude to my family who have provided assistance, encouragement, and love throughout my academic years in the U.S. 
TABLE OF CONTENTS

PAGE

ACKNOWLEDGMENTS

LIST OF TABLES

viii

CHAPTER

I INTRODUCTION . . . . . . . . . . . . 1

Background and Justification . . . . . . 1

Purpose of the Study . . . . . . . . . 9

Plan of the Thesis............ 9

II LITERATURE REVIEW: BACKGROUND INFORMATION • 11

Introduction . . . . . . . . . . . . 11

PART I: DIMENSION OF REENTRY SHOCK . . . . . 12

Reentry Shock (Reverse Culture Shock) . . 12

Changes that May occur to the Home culture and Within the Individual . . . . . 16

Unawareness of Reentry Problems . . . . . 22

Expectations of People in the Home

Culture............. . 23

Indifferences of People in the Home

Culture . . . . . . . . . . . 24

Positive and Negative Aspects of

Cross-Cultural Experience . . . . . 26

PART II: U.S. CULTURAL INFLUENCE ON

JAPANESE RETURNEE CHILDREN • . . . . . . . 33

Communication Styles......... . . 33 
Cultural Assumptions (Values) . . . . .

Thought Patterns . . . . . . . . . . 43 43

Role Behavior . . . . . . . . . . 49

Conclusion . . . . . . . . . . . . . 54

III LITERATURE REVIEW: THE ISSUES OF JAPANESE RETURNEE CHILDREN • • • • . . . • • . • . • 55

Problems Facing the Japanese Returnee Children . . . . . . . . . . . 55

School Phobia . . . . . . . . . 61

The Japanese Educational System . . . . 66

Particularism of the Japanese Culture . . 68

The Significance of Preparation and the Parental Role in Children's Reentry . . 80

Conclusion . . . . . . . . . . . 86

IV METHODS • . . . . . . . . . . . . . . 89

Purpose of the Study . . . . . . . . . 89

Research Questions . . . . . . . . . . 89

Research Method . . . . . . . . . . 90

Operational Definitions . . . . . . . . 93

Population . . . . . . . . . . . . 95

Questionnaire Development . . . . . . . 96

Translation . . . . . . . . . . . 104

Pilot Study . . . . . . . . . . . 104

Mailing . . . . . . . . . . . . . 105

V RESULTS AND INTERPRETATIONS . . . . . . . . 107

Research Question One . . . . . . . 109

Research Question Two . . . . . . . . 129 
Research Question Three . . . . . . . 142

VI DISCUSSION, LIMITATIONS, AND SUGGESTIONS

FOR FUTURE RESEARCH . . . . . . . . . . . 152

Discussion . . . . . . . . . . . . 152

Limitations of the Present Study . . . . 160

Suggestions for Future Research . . . . 163

Summary and Conclusion . . . . . . . 165

REFERENCES • • . . . . . . . . . . . . . . . . . . . 166

APPENDIX

A Anxieties Held by Japanese Families Overseas - 174

B Problems Faced by Returnee Children . . . . . 176

C List of Potential Problems from the Review of Literature which Will be Faced by the Japanese Returnee Children . . . . . 178

D Themes Which Emerged from Subjects'

Responses................ . 181

E Human Subjects Research Review Committee

Approval . . . . . . . . . . . . . 184

F Questionnaire . . . . . . . . . . . . . 186

G Pilot Study Questionnaire . . . . . . . . . 199

$\mathrm{H}$ Letter of Introduction . . . . . . . . . . 212

I Permission Letter . . . . . . . . . . . 215

J Approval Letter . . . . . . . . . . . . 218

K Follow-Up Letter . . . . . . . . . . . . 221 


\section{LIST OF TABLES}

TABLE

PAGE

I People's Perceptions . . . . . . . . . . .

II Children's English Proficiency . . . . . . . . 110

II Percentage of Subjects Who Reported Themes

Regarding Japanese Returnee Children's

Potential Problems in Question 9. . . . . 115

IV Subjects' Anticipation of the Importance of

the Japanese Language for Their Children . . 116

$V$ Results of the Demographic Data Analysis in

Question 10a . . . . . . . . . . . . 117

VI Percentage of Subjects Who Reported Themes

Regarding Japanese Returnee Children's

Potential Problems in Question $10 b . . . .$.

VII Subjects' Anticipation of the Importance of

"Japaneseness" for Their Children . . . . .

VIII Results of the Demographic Data Analysis in

Question 18 . . . . . . . . . . . . . 124

IX Percentage of Subjects Who Answered "Yes"

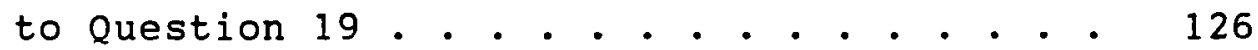

$\mathrm{X}$ Percentage of Subjects Who Answered "Yes"

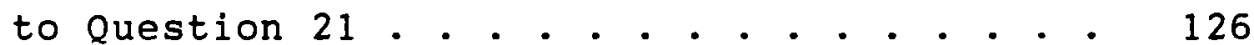


XI Percentage of Subjects who Reported Themes

Regarding Japanese Returnee Children's

Potential Problems in Question 17 . . .

XII Subjects' Communication with Their Husbands

in Regard to the Language Issue concerning

Children's Reentry . . . . . . . . . . 130

XIII Results of the Demographic Data Analysis in

Question 12 . . . . . . . . . . . . 131

XIV Subjects' Communication with Their Children in

Regard to the Language Issue Concerning

Children's Reentry . . . . . . . . . . 133

XV Results of the Demographic Data Analysis in

Question 13 . . . . . . . . . . . . . 134

XVI Subjects' Communication with Their Husbands

in Regard to Children's Reentry . . . . .

XVII Results of the Demographic Data Analysis in

Question 22 . . . . . . . . . . . . 138

XVIII Subjects' Communication with Their Children in

Regard to Children's Reentry . . . . . . . 140

XIX Results of the Demographic Data Analysis in

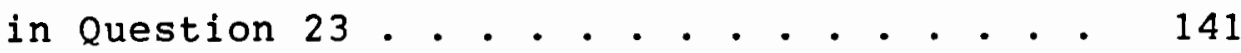

XX Language Used by the Subjects' Children at

Home in the U.S. . . . . . . . . . . . . 143

XXI Percentage of Subjects Whose Children Speak

Only Japanese at Home in the U.S. . . . . . 144 
XXII Percentage of Subjects Who Encourage Children

to Speak Japanese at Home in the U.S. . . . 146

XXIII Percentage of Subjects Who Answered "Yes"

to Question 15 . . . . . . . . . . . 147

XXIV Percentage of Children's Preparation Done

by the subjects . . . . . . . . . . . . 148

XXV Percentage of Subjects Making Preparations for

Their Children's Reentry . . . . . . . . 149 


\section{CHAPTER I}

\section{INTRODUCTION}

\section{BACKGROUND AND JUSTIFICATION}

Due to Japan's economic and industrial advancement, the number of children who live overseas with their parents and then return to Japan is increasing every year. It is estimated that in 1987 there were approximately 220,000 Japanese adults who worked for Japanese companies and organizations (and over 50,000 school-age children) who temporarily lived overseas. This number of returnee children (over 9,500 in the Tokyo area alone) represents an increase of $300 \%$ in ten years (Enloe and Lewin, 1987, pp. 223-224). It is estimated that more than 17,000 school children lived in the United States during 1987 (Ministry of Education, 1988, p. 6). The increasing number of Japanese families overseas is a sign of the international affiliation of the Japanese economy .

The point is that the returnees are a growing phenomenon, and it is not always easy for them to go home. Sussman, a psychology professor at City University of New York who has conducted an extensive survey of about 300 Japanese businessmen who worked in the U.S. before returning to Japan, says the great differences between American and Japanese 
societies make for acute adjustment problems even after the journey back home to Japan (Ota, 1985, p. 2).

Among the returnees, those who are likely to be the most affected are the children, who are generally called kikoku shijo. Children are likely to suffer from more severe "reverse culture shock" after returning to Japan. Horio Teruhisa, Professor of Comparative Education at Tokyo University, points out that children's reentry can be tough and introduces the results of a 1982 survey by the Ministry of Education showing that more than $80 \%$ of the children who have lived abroad experience problems on return (Read, 1988, p. D8). The Oregonian introduces some examples of the problems faced by the returnee children. For example, the daughter of the former manager of the Bank of Tokyo in Portland, who is 24 years-old now, recalls her "terrible time" upon reentry, saying, "The kids really hated me. I suppose because they were jealous. I almost got beaten up. Japanese kids like you to be the same as them." In order to escape from the school bullies (ijime), children are forced to make an effort. Some decide to go to the American school in Japan, and others seek to avoid teasing by keeping their foreign experience a secret from schoolmates (Read, 1988 , p. D8). Not only does their peer group not understand their situation, but teachers also do not often understand the returnee children's situation. Hoshino, cited by White (1988), says: 
- . these children are neither immigrants nor of an ethnic or political minority, and yet they are thorns in the side of the native group. Teachers may ignore these children, or may single them out as bad examples. In some cases, teachers may even show some antagonism towards these students ( $p .60)$.

Kazuya Kawazoe, an after-school juku tutor and a former visitor of Portland, said:

- . students who have studied abroad later have difficulties with the Japanese language and culture and may even find it hard to communicate with friends. - . In a sense many of the students have become Americans--used to voicing their independence-and this poses a conflict with the Japanese culture. - . That sense of independence makes it hard for students who have studied abroad to cooperate as part of a group, such as at work or in extracurriculum activities. . . such cooperation is a vital part of the Japanese culture (Blackmun, 1988, p. $2 \mathrm{Mp} 4 \mathrm{M}$ ).

Pointing out that foreign-educated students are becoming more attractive to multinational Japanese companies, some people state that the situation of the returnee children is getting better. Some say that more and more companies are now willing to hire people who have received some or all of their education abroad, and others say that more Japanese colleges are allowing students educated overseas to take different entrance exams, which more heavily emphasize the advantages of a foreign education (Rooks, 1988, p. D7). Although these show improvement in Japan's attitude towards returnee children, they do not necessarily ease the psychological and communication problems experienced by the children upon reentry. As Domoto (1987) states, the failure to adapt to the Japanese school situation may be due more to the exclusionist nature of the Japanese students (and/or 
teachers), than to the inflexibility of the returnees ( $p .35)$. However, without help how will children overseas be able to anticipate such potential problems, and prepare to cope with them? This kind of basic question motivated the present study .

While there has been extensive research on the cultural adjustment of sojourners abroad, up until 10 years ago no research had been done concerning the adjustment of returning sojourners to their home cultures and little since then (Sussman, 1986, pp. 235-236). Some authorities feel that readjustment to one's own home culture may be more difficult than adjusting to a foreign culture (Adler, 1975; Brislin and Pedersen, 1976; Gullahorn and Gullahorn, 1963; Werkman, 1986). Brislin and Pedersen (1976) describe this problem as the reentry crisis.

The readjustment back home is likely to be even more difficult than going abroad in the first place, aj.1 the more so since this adjustment is frequently unexpected. Not only has the returnee changed, but back-home culture has likewise changer, making it doubly difficult to readjust. People's expectations for returning may have been distorted in an unrealistically, favorable direction by their very absence. When they find themselves unable to pick up where they left off or even to start from scratch to some new endeavor, they are likely to experience a reentry crisis (p. 16).

Several scholars also emphasize that preparation can help minimize the reentry crisis of the returnee (Cantrell, 1974; Harrell, 1986; Sobie, 1986; Wallack and Metcalf, 1981; Werkman, 1986). Brislin (1974) states that "when people prepare for unpleasant, aversive events that could occur in

the future, the impact of those aversive events is much less 
severe than if the people did not prepare" (p. 3). In connection with the children overseas, it is their parents who must play an active role to minimize potential problems which their children will encounter after returning to their home country (Harrell, 1986; Sobie, 1986; Wallack and Metcalf, 1981; Wallack and Metcalf, 1982). Wallack and Metcalf (1981) point out the significance of the parental role by encouraging parents to be "aware of some of the predictable problems your child may encounter and assist him/her in coping" (p. 13). Their point is that this parental role should be pursued through communication with the children. It is important for the parents to encourage each child to "share his or her feelings, fears, and frustrations about going home and help children to develop a realistic view of what to expect" (Wallack and Metcalf, 1982, p. 23).

Sussman (1986) mentions that most sojourners who are prepared to make a cultural adjustment in their host country rarely anticipate having any problems upon their return home. A notable exception is the Japanese, who consider reentry to be a significant issue and explore reentry problems prior to the sojourner's departure (p. 236). However, the type of problems they anticipate and whether preparation is being done concerning children's reentry is not clearly described in this article.

The researcher of this study has been able to find only a few sources that tackle this subject. First, Kaigai Shijo Kyoiku Shinko Zaidan (The Foundation for the Education of 
Children Overseas), which was established in 1971 by the Ministry of Education and of Foreign Affairs and Corporations, issues a monthly magazine for the Japanese families who are newly assigned for overseas service, and/or those who came back to Japan after their assignment. Through review of this magazine for the last 10 years, it was found that in addition to giving information about schools available for returnee children, this magazine also deals with the issue of returnee children's readjustment to the Japanese school system and society. However, the articles mainly deal with the issue from the curative point of view, not from the preventive viewpoint. Some scholars conducted research specifically on Japanese children and/or families who came back from the U.S. and/or those who were still in the U.S. (Enloe and Lewin, 1987; Farkas and Kono, 1987; White, 1988). However, no research was reported that dealt with the issue of Japanese parents' preparation for their children's reentry.

One book, entitled Kaigai Shijo Kyoiku Manyuaru (Parents' Manual for Educating Children Overseas) (Hasebe, 1985), does deal with parents' preparation of children's reentry. It presents the results of a survey conducted in 1982 by the Ministry of Education concerning Japanese families overseas, and those who returned to Japan. It included the parents' and children's anxiety about returning to Japan, and the problems that returnee children had after their return. The listing of the problems was helpful and will be detailed later. This book also states the importance of 
the parental role in connection with the children's readjustment to the school system, and it emphasizes parental roles in helping the children maintain their Japanese language ability. However, it does not recount the parent's preparation for the children's readjustment to any other facet of reentry. This seems to support the following statement by Enloe and Lewin (1987):

The problems which have received the largest amount of attention concerning the readjustment issue of the returnee children is that of the returnee's reentry into the Japanese educational system, and the necessity of being able to compete successfully in the rigorous university entrance examination ordeal (pp. 224-225).

This statement makes the researcher speculate that a large number of the subjects in this study may be concerned with their children's readjustment to the Japanese educational system.

A main assumption in current intercultural communication theory is that effective intercultural communication depends on having the assumption that people in different cultures are likely to be different in matters of perception, behaviors, values, and thought patterns. Barna (1985) mentions :

- - many of us naively assume there are sufficient similarities among people of the world to enable us to successfully exchange information and/or feelings, solve problems of mutual concern, cement business relationships or just make the kind of impression we wish to make (p. 330).

As she points out, such aura of similarity is a serious stumbling block to successful intercultural communication. 
Unlike the assumption of similarity held by Americans as stated above, Japanese people tend to view people in other cultures as very different from themselves (Tai, 1986); however, they are likely to see similarity among the Japanese. People in some cultures may tend to view similarity among themselves, but because of the homogeneous characteristics of the country, Japanese people strongly tend to assume that even if they are exposed to a foreign culture, they can retain the Japanese way of thinking, their values, and communicative behavior. Unfortunately, the literature negates this Japanese notion. It has been shown that experiencing a new culture can cause returnees to experience conflict of role behavior (Bochner, Lin, and McLeod, 1980; Lundstadt, 1963), and attitudinal change (Becker, 1968; Martin, 1986). According to the literature, it is essential, therefore, for parents to prepare for their children's reentry based on an assumption of difference. Their children could be different from the peer group in Japan.

In summary, the literature states that as the number of Japanese returnee children is increasing, reentry has become a serious problem for these children. The literature also points out the importance of preparing children for their reentry; however, there seems to be no previous research as to what kind of preparation is being given by parents for their children's readjustment to Japan. 
PURPOSE OF THE STUDY

The purpose of the present study is to discover whether Japanese parents in the U.S. anticipate and are preparing themselves and/or their children to cope with the possibility of psychological and communicative problems which their children may encounter as returnees in Japan. This can be broken down into the following three research questions:

1. Are the Japanese parents who are temporarily staying in the U.S. with their children anticipating the possibility of psychological and communicative problems their children may face as returnees?

2. To what extent do the Japanese parents discuss these potential problems with each other and/or with their children?

3. Are the Japanese parents doing anything to prepare themselves and/or their children to cope with the potential problems which their children may face as returnees?

PLAN OF THE THESIS

A survey will be conducted via questionnaires to determine whether a selected group of Japanese parents anticipate the potential problems mentioned in the literature, and what, if anything, is being done to prepare themselves and/or their children to cope with these problems. Chapter II is a review of the literature to provide background information on the 
reentry process in general, including what is commonly referred to as "reentry shock" and the positive and negative dimensions of cross-cultural experiences. This will be followed by a discussion of U.S. and Japanese cultural contrasts which could directly affect returnee children. Chapter III deals with the problematic issues faced by the Japanese returnee children through a review of the current research and literature. At the same time, significant characteristics of Japanese culture which hinder Japanese people's smooth reentry will be discussed. Reports of the importance of preparation and the parental role for children's reentry will also be discussed. Chapter IV describes the method which is used in this research, including the explanations of operational definitions, population, questionnaire development, translation, and pilot study. Chapter $V$ presents the results and their interpretation obtained from the present research, and in the final chapter, the researcher will discuss the study's results in relation to the literature review, limitations of the study, and suggestions for future research. 
CHAPTER II

LITERATURE REVIEW: BACKGROUND INFORMATION

INTRODUCTION

This chapter will be divided into two parts. The first part will examine reentry shock in contrast to culture shock, and discuss several significant dimensions of reentry shock based on the following aspects: (1) changes in the home culture, and within the returnees; (2) returnees' unawareness of the potential problems; (3) expectations of people in the home culture; and (4) indifference of people in the home culture. Positive and negative aspects of cross-cultural experiences will also be described regarding language and other cultural aspects. An extended overseas experience has a significant effect on the returnee's cultural aspects. Since the focus of this study is Japanese children who returned from an extended period in the United States, the second part of this chapter will describe potential U.S. cultural influences on the returnee children, including different aspects of communication styles, cultural assumptions (values), thought patterns, and role behavior in the U.S. and Japan. The interrelationship of these and language use will also be emphasized. 


\section{PART I: DIMENSION OF REENTRY SHOCK}

REENTRY SHOCK (REVERSE CULTURE SHOCK)

Regarding the definition of reentry shock, Adler (1981) defines reentry as the readapting of the individual to the home environment after an extended stay in another culture. Based on the research conducted by Adler (1981) and Gama and Pedersen (1977), Martin (1984) points out that,

- . while reacculturation is the specific anthropological term, "reentry" has been used by scholars in a variety of disciplines investigating the readjustment of sojourners to their home environment (p. 116).

Martin (1986) argues for the necessity of considering the processual nature of reentry. She points out that in order to pursue this objective, reentry should be viewed as one phase of the total intercultural experience (pp. 2-3). Therefore, before discussing the dimension of reentry shock, the researcher will explain briefly the general concept of "culture shock." Brislin (1981) explains that "culture shock is a summary term [referring] to the accumulated stresses and strains which stem from being forced to meet one's everyday needs . . In unfamiliar ways" (p. 13). Culture shock is considered to be an adverse reaction which most individuals have to experience during a sojourn. Condon and Yousef (1975) describe it as follows:

If one is living in another culture quite different from his own, sooner or later he will experience a period of frustration, anger, alienation, depression, and other such reactions that have come to be labeled "culture shock" . . . . It seems that no matter how 
well a person has prepared himself, some degree of "shock" is inevitable and some would say, necessary for better adjustment ( $p .262$ ).

Barna (1983) argues that specific factors, such as ambiguity, uncertainty, and unpredictability, cause a reduced ability to interact within an unknown social structure. The consequent frustration leads to a stress reaction ( $p .31$ ).

Some scholars explain culture shock as an "up-anddown" emotional cycle which is described in a U-curve:

- . on arrival, there is a "high" period lasting a week to a month or so, followed by a "low" period of two to three months characterized by irritability and hostility. Under optimal circumstances, that is followed by gradual psychological adjustment to the cultural differences (Fontaine, 1986, p. 43).

Much has been written about the original experience of culture shock, but the dimension of the "other culture shock" tends to be ignored (Sobie, 1986, p. 96). Koehler (1986) defines reentry shock as "the often unexpected and sometimes painful experience of readjusting to life in one's home country after living in a foreign country" (p. 90). Meintel (1973) defines "reverse culture shock" as the disorientation which sometimes characterizes the sojourner's return home, stating that "most of the informants emphasized they felt it more abruptiy and acutely than any shock upon entering the strange environment" (p. 52). Meintel says that the returnee's new perspectives of the people in his/her home culture and his/her own past may not be fully realized until rendered immediate by returning home (p. 52). 
Through research conducted on returned Americans, Gullahorn and Gullahorn (1963) explain reentry shock. They reported that people underwent a similar reacculturation process in their home culture to that experienced abroad (p. 39). Their hypothesis is explained in a W-shaped curve which describes not one but two up and down cycles of people's self-reported satisfaction from the beginning of the sojourn in their host culture, through readjustment in their home culture. In their model, reentry shock is described as the second down point at which people experience the same kind of feelings of alienation and confusion as they had at the time of sojourn in foreign environments.

Lowenthal and Renwick (1988) cite Asuncion-Lande as saying that there are four distinctive patterns of response to the reentry shock (pp. 1-2). First is the initial excitement of return. The returnee who has been away from his/her relatives, friends, and colleagues goes home with excitement and pride. Second, the initial excitement of coming back home fades away when they realize the necessity of readjusting to the home environments. At this point "feelings of ambivalence about the wisdom of returning home begin to surface" (Lowenthal and Renwick, 1988, p. 1). The third stage is marked by the need for a sense of control. The returnee tries to control the threat to his self-concept and to establish a sense of being in control over his environment. However, this attempt reinforces the returnee's feelings of frustration, and as a result, "an extreme reaction to such 
frustration and conflict is a complete rejection of his own culture and an attempt to go abroad once again" (p. 2). The last stage is a period of readaptation. At this stage, the returnee seriously begins to find ways to cope with the issues of readjustment:

- . they begin to realize that while they may not be able to change their own culture, they can attempt to understand and to respond to it in the light of the new knowledge about themselves and about their environment (Lowenthal and Renwick, 1988, p. 2).

Asuncion-Lande, cited by Lowenthal and Renwick (1988) mentions the relationship between "culture shock" and "reentry shock" as follows:

Readjustment is a challenge for individuals when they return home from a relatively long residence in another culture. In many ways it is very similar to the experience of a person who enters a new culture for the first time. The latter has been labeled as "culture shock" and the former as "reverse culture shock" or "re-entry shock" (p. 1).

Although an individual is likely to suffer from some psychological pain in both the adjustment and the readjustment processes, it is essential to notice that there are some factors which clearly distinguish reentry shock from culture shock. Sussman (1986) states that "the adjustment difficulties sojourners experience upon their return home differ from initial overseas adjustment on several significant dimensions..." (p. 236). She characterizes the following five major factors which distinguish reentry shock from culture shock: 
(1) The emerging adjustment difficulties are characterized (and exacerbated) by the unexpectedness of re-entry problems.

(2) Friends, family, and colleagues expect returnees to exhibit "normal" or pre-sojourn behavior and are not expecting new and different behaviors from the returnees.

(3) Changes occur within the individual as a result of the overseas experience of which the individual may often not be aware.

(4) Changes occur in the home culture (e.g., actual changes in politics, the economic system) and the returnee may not have accurate perceptions of these changes.

(5) The lack of significant interest of colleagues and friends in the sojourn experience is frequently a source of disappointment and frustration ( $p .236$ ).

In the following section, each dimension pointed out by Sussman will be discussed in more detail.

\section{CHANGES THAT MAY OCCUR TO THE HOME CULTURE AND WITHIN THE INDIVIDUAL}

In his article Schuetz (1945) distinguishes a stranger from the homecomer in a sense that a stranger is about to "join a group which is not and never has been his own" while "the homecomer expects to return to an environment. . which he always had" (p. 369). However, the situation does not remain the same as it used to be before the homecomer's overseas sojourn. Asuncion-Lande, cited by Lowenthal and Renwick (1988), says:

They may fail to realize that their outlook on life will have been changed by their intercultural experience, and that their old culture and environment may have changed also during their absence. These unexpected changes exert a strong influence on individual 
reactions to their home culture. Their reactions often occur at the level of "out-of-awareness." This fact contributes to the difficulty of determining the underlying cause of frustration or conflict during the re-entry period ( $p .2)$.

The main point is that changes could occur to both the returnees' home culture and the returnees themselves.

If changes that happen to the home culture are considered to be objective changes, changes which occur to an individual can be regarded as subjective changes. In other words, as Sussman (1986) mentions, "sojourners often return home holding different attitudes, beliefs, perceptions, and behaviors than they held at their initial departure" (p. 244). In his research Kagitcibasi (1978), who studied the effects of sojourners' experiences on the attitudes of young Turkish students who spent a year in the U.S., concludes that "through new culture contacts serving as a secondary socialization process, changes in important and earlylearned attitudes can, in fact, be produced" (p. 155). Through his research Kagitcibasi proved that changes which occurred during the overseas sojourn could persist after the sojourners returned.

Changes in attitudes and values tend to result in the behavioral changes in people. In order to describe the potential behavioral changes which occur to returnees, the following section will discuss the concepts of role behavior and the relationship between behavior and communication. The researcher feels that in the case of Japanese returnee children it is their behavior in their various roles (age 
role, student role, sex role, and so on) that causes many of their problems.

\section{Role Behavior}

Brislin (1981), quoting the statement of Sarbin and Allen in 1968, says that, "role, a term borrowed directly from the theater, is a metaphor intended to denote that conduct adheres to certain 'parts' (or positions) rather than to the players, who read or recite them" (p. 29). For example, regardless who occupies the position, certain behaviors are expected from the role of teacher or office clerk. In other words, this indicates a performative dimension of role. In the definition of "role" as performance, Rich cited by U1rich (1986), states that "it is 'a set of behaviors that is enacted'" (p. 10). Moreover, Condon and Yousef (1975) point out that "the view of communication as performance is extremely important in considering intercultural communication" (p. 17).

Based on Nadal's extensive research on role behavior in 1980, Ulrich (1986) defines role as follows:

In summary, roles are defined as an intricate part of the society allowing us to communicate with predictability within the context of our culture. Some regard roles as the backbone of the society holding together social order and control. Others define roles as concepts that require certain behaviors expected from a society (p. 12).

These role behaviors are obtained through social learning which means that "people within a culture acquire the knowledge of how to interact in their society through formal and informal learning" (Hall, 1959, p. 12). 
In terms of cross-cultural transitions, people are expected to be engaged in the role behaviors suitable to each culture. Moreover, in order to do so, they need to shift to a new reference group in the host culture. Brislin (1981) states that "once a person makes a commitment to a reference group in another country, (s)he often puts a great deal of effort into protecting the group's interest" (p. 128). Sojourners are often required to "protect such group's interest" by involving themselves in appropriate role behaviors in the host culture. As described previously, these roles are manifested through adopting behavioral norms of the host culture ranging from specific professional roles, such as teacher and doctor to everyday etiquette. Upon reentry "they may employ these behaviors in the home country, forgetting momentarily that the norms may be different" (Brislin, 1981, p. 132).

The results of the research show that the changed behavior of the returnees gives some influence to role relationships with people in the home culture. In a study in which she investigated reentry adjustment experiences of American students after an extended sojourn abroad, Uehara (1986) concluded that the degree of satisfaction of the relationship with family and friends is negatively correlated with readjustment problems. Martin (1986), studying perceptions of positive and negative changes in three types of reentry relationships (parent, sibling, and friend), states that while relationships with parents and siblings 
were perceived to have changed more positively than negatively, relationships with friends were perceived to have changed both negatively and positively ( $p .1$ ). Moreover, Martin (1986) reports that more than $50 \%$ of the returnees answered that these changes were due to their experience abroad.

Behavior and Communication

First, Condon and Yousef (1975) state that "we can say that there was COMMUNICATION if we are referring to any behavior that is perceived and interpreted by another, whether or not it is spoken or intended or even within the person's conscious awareness" (p. 2). Moreover, there is a meta communicational axiom of the pragmatics of communication, which reads that "one cannot not communicate" (Watzlawick et al., 1967, pp. 45-51). Watzlawick et al. state as follows:

First of all, there is a property of behavior that could hardly be more basic and is, therefore, often overlooked; behavior has no opposite. In other words, there is no such thing as nonbehavior, or, to put it even more simply: one cannot not behave. Now if it is accepted that all behavior in an interactional situation has message value, i.e., is communication, it follows that no matter how one may try, one cannot not communicate (pp. 48-49).

In regard to the issue of reentry the returnee's changed behavior will send messages to people in the home country that they may interpret adversely. Martin (1986) states that "recent literature has begun to emphasize the role of communication in the reentry process" (p. 1). For example, Gama and Pedersen (1977), who investigated former 
Brazilian graduates in the U.S., conclude that the returnees, especially women, had a hard time in readjusting themselves to their family expectations. Obviously their behaviors were communicating unacceptable change in these women.

Also, people categorize events in order to objectify their own subjective experience of reality. Berger and Luckman (1967) state:

- . the symbolic universe provides a comprehensive integration of all discrete institutional processes. The entire society now makes sense. Particular institutions and roles are legitimated by locating them in a comprehensively meaningful world (p. 103).

A symbolic universe constitutes one level of legitimation, and it is constructed by means of social objectivation (Berger and Luckman, 1967, pp. 95-96). In this kind of legitimation "institutional roles become modes of participation in a universe that transcends and includes the institutional order" (pp. 96-97). In connection with the returnees, they move to a new "symbolic universe" of the host culture during their sojourn abroad, first, and then they move back to the "symbolic universe" of their own home culture. The point is that the situation in the former home "universe" can hold problematic possibility. For example, if manifested behaviors indicate one of the institutional roles presented by people in one society, the returnee's changed behavior will be conceived as deviance from the institutional norms. Discontinuity between their overseas sojourn and the home would create unsharability with people in the home country, and as a result, the returnee finds it difficult to communicate 
his/her experience and/or feelings to others in the home society.

The present study will use this communication perspective throughout in examining the reentry process. It is through communication, as opposed to withdrawal, that adjustment occurs both to the culture and to reentry. Behaviors, verbal and nonverbal, are interpreted by all parties and attitudes formed. The process of communication is vital. By understanding this process and the factors that affect reentry, successful and comfortable transitions are more likely. The great variety of reported experiences and reactions to the reentry process is itself a result of the communication process.

\section{UNAWARENESS OF REENTRY PROBLEMS}

As described previously, culture shock is generally regarded as an inescapable experience which happens during sojourn in a foreign culture. Barna (1983) states:

From birth a child is formally and informally taught how to behave and what to expect from the environment and the people that surround him or her. A culture is a safe haven and forestalls the anxiety of dealing with differences ( $p .32$ ).

Barna then explains that culture shock is an expected aspect of overseas sojourn, to some extent, because the learned ways of coping with one's own cultural environments no longer work in the new setting. The difference with reentry shock is that people suffer from greater "shock" because of its total unexpectedness. Assuming that neither their home culture nor 
they have changed, they do not expect to have to deal with differences (Koehler, 1986; Brislin and Van Buren, 1986). However, as discussed previously, many changes could occur to the returnees because of their overseas sojourn.

\section{EXPECTATIONS OF PEOPLE IN THE HOME CULTURE}

A third factor of reentry is that returnees are expected to be very much the same by the people in the home culture. People in the home culture have no idea about what kinds of experiences the returnees had in the host culture. Nor do they realize that people cannot be the same after being exposed to foreign environments for a significant period of time. When the returnee does not live up to the expectations his old friends have for him, they have a sort of "shock" reaction as does the returnee when he notices their discomfort.

Freedman (1986) mentions the importance of comfort for human needs:

Comfort.. . is what we feel when the world and the people in it behave in ways that correspond with our expectations: our world is predictable, and we feel comfortable. When a discrepancy occurs and people act in an unpredictable manner, we become uncomfortable (p. 23).

Moreover, Brislin (1981) argues that "the product of a culture's influence. . Is a residue of behavior, ideas, and beliefs with which people are comfortable and which they consider 'proper' or 'the right way'" (p. 5). In addition, since "people develop the habit of making judgments in terms 
of what is acceptable and beneficial to their in-group" (Brislin, 1981, p. 76), the returnee's unpredictable behavior can cause conflict between people in the home culture.

\section{INDIFFERENCES OF PEOPLE IN THE HOME CULTURE}

As Austin (1986) points out, "one major expectation of most returnees is that people in the home country will be interested in their experience" (p. 125). Generally, the host country people tend to show a great interest in the customs, food, and way of life of sojourners from foreign countries. However, if the returnees expect the same kind of concern to be shown by the home country people, they will usually be disappointed. The fact is that "their joyful anticipation may quickly wilt into disappointment, frustration, and antagonism as they experience a 'reverse culture shock" (Guither and Thompson, 1986, p. 207). Guither and Thompson introduce one returnee's experience as follows:

We asked a philosophical university professor who had helped build a new university in East Africa if he felt people realized all of the efforts he and his colleagues had put forth in this project. He quickly responded, in effect, "People are not interested in all your wonderful experiences, but they will always be ready to tell you when their daughter is going to have a new baby" (p. 210).

Koehler (1986) describes the case of one of the service wives who returned from her husband's overseas assignment:

Beyond casual conversation, service wives often find that friends, neighbors, new acquaintances and even relatives are not really interested in hearing about their life overseas, and talking about it is often interpreted either as boasting or as criticism of the United States. Not being able to share their 
foreign experience at the same time that they are not yet feeling a part of life at home leads to confusion (p. 93).

Uehara (1986), who studied the nature of American student reentry adjustment and perceptions of sojourn experience, introduces a 25-year-old American male student's frustration as follows:

A lot of difficulty . . . . I find myself thirsting to share my experience with others who are interested in it. However, people generally aren't interested in my experience, but rather are mainly interested in filling me in on what I missed while absent from the U.S. . . Virtualiy no one wants to listen. It's damn frustrating, makes me feel very alienated, alone, powerless and confused (pp. 415-416).

Teenage returnees tend to hide their foreign experience. Sobie (1986) quotes one cross-cultural trainer's comments:

Some begin to feel that being overseas was a bad thing. Not many kids want to hear about their adventures in London or Naples, . . Instead of being able to process their years overseas, they have to pretend it didn't happen (p. 99).

This tendency of indifference to intercultural experiences of the returnees is called "Uncle Charlie" syndrome (Brislin and Van Buren, 1986, p. 221). Quoting a statement by Cleveland et al., Brislin (1981) says:

- . sojourners are excited about sharing their experiences, but none of their friends or family members want to hear about them. As one businessman put it, others would rather talk about Uncle Charlie's roses (p. 131).

Guither and Thompson (1986) argue that it is necessary to prepare for such indifferent attitudes shown by the home country people: 
People back home have continued to live their lives about the same as usual. The fact that you were gone has not really affected them and they will usually have only a casual or passing interest in your experience. Being prepared for this indifference may be just as important as preparing to live overseas (p. 207).

\section{POSITIVE AND NEGATIVE ASPECTS OF} CROSS-CULTURAL EXPERIENCE

Children who have been reared overseas are most likely to acquire languages, perspectives, behaviors, values, and developmental patterns which are distinct from the peer group in their home culture. An important point to remember is that there are both positive and negative dimensions in sojourning abroad.

\section{Language}

Foreign language acquisition is regarded as one of the positive aspects of cross-cultural experience. Lambert (1967) introduces the findings from the experiment conducted with Anisfeld on using 10-year-old monolingual and bilingual students as subjects. The results show that the bilingual children were markedly more favorable towards the "other" Ianguage group than the monolingual children were (p. 104). Moreover, pointing out that a bilingual person is in an excellent position to develop a totally new outlook on the social world, Lambert (1967) states:

- . bilingual[s], especially those with bicultural experiences, enjoy certain fundamental advantages which, if capitalized on, can easily offset the annoying social tugs and pulls they are normally prone to (p. 106). 
In another piece of research conducted with Klineberg, Lambert (1967) concludes that stereotyped thinking about in-group and out-group distinctions begins with preschool age, and parents tend to reinforce children to have this kind of distinctive differentiation of out-group people, which consequently forms ethnocentric attitudes in their children. In connection with bilingualism, Lambert states that "the child who was brought up bilingually and biculturally will be less likely to have good versus bad contrasts impressed on him when he starts wondering about himself, his own group and others" (p. 106). In other words, a bilingual child is likely to "become sensitive to and leery of ethnocentrism" (p. 107).

On the other hand, there could be negative aspects of bilingualism. Lambert (1967) summarizes his research findings as follows:

- . the bilingual encounters social pressure of various sorts: he can enjoy the fun of linguistic spying but must pay the price of suspicion from those who don't want him to enter too intimately into their cultural domains and from others who don't want him to leave his "own" domain (p. 105).

He goes on to mention that an ability to speak two languages can influence an individual's self-concept:

If he is progressing towards bilingualism, he encounters similar pressures that may affect his self-concept, his sense of belonging and his relations to two cultural-linguistic groups, the one he is slowly leaving, and the one he is entering. The conflict exists because so many of us think in terms of in-groups and out-groups, or of the need of showing an allegiance to one group or another . . . (p. 105106). 
In other words, because of social pressure, which stems from in-group/out-group distinction, a bilingual person could be in danger of losing his/her own stable self-concept.

\section{Other Cultural Aspects}

As discussed previously, cross-cultural experience could affect returnees in matters of attitudes, behaviors, and values. Several scholars describe that a tolerant attitude can be one of the positive acquisitions of crosscultural experience. Guither and Thompson (1986) point this out by stating that "both children and adults unconsciously develop a tolerance for other people that they never had before" (p. 215). Wallack and Metcalf (1981) state that "exposure to life in another culture can go far towards increasing one's tolerance and expanding one's knowledge beyond the borders of one's home country" (p. 13). Tolerance for those of different cultures will help people to enhance their nonethnocentric world view. Harrell(1986) has positive feelings about the cross-cultural experience:

It is a privilege for young people to have the opportunity to know people from different language backgrounds and realize their unique contributions. This exposure often results in maturity and freedom of thought, as well as the keener appreciation of individual worth. World travel is valuable in helping the person to break out of his ethnocentric framework and form non-prejudiced and empathetic judgements (p. 200).

Kelly (1973) states that if it is positively reinforced, usually attitudinal changes of the returnees are seen in the form of international and world-mindedness. 
Some scholars indicate that cross-cultural experience affects chilaren's future careers:

If children are in junior or senior high school when they live overseas, their impressions may influence later study and career choices. Some students take more interest in foreign language study. Others study political science, international law, international business, economics, anthropology, or diplomacy partly because of interests developed out of their overseas exposure (Guither and Thompson, 1986 , p. 215 ).

This statement shows how young people develop broader perspectives when they live abroad.

As described in the foregoing, it is not undeniable that there are also some negative aspects which cause the returnees to suffer from problems in the process of reentry. A significant period of overseas sojourn develops deviance from the home culture. Brisin (1981) points out that people who participate in extensive cross-cultural interaction tend to become deviant from the viewpoint of their nonsojourning peers.

Returnees to the home culture sometimes do not readily fit back into their former groups. They had had experiences which are difficult to share and, ideally, have increased their level of tolerance and their ability to see many sides of complex issues. . . Group members undoubtedly perceive the returnee's frustration, interpret it as rejection, and consequently keep their distance ( $p .125)$.

This kind of deviance from the norms of the home culture puts the returnee into the marginal situation. According to Adler (1985), a marginal man is a new kind of person who is neither totally a part of nor totally apart from his culture; he lives, instead, on the boundary (p. 412). There are both positive and negative aspects of marginality. According 
to Stonequist's (1935) definition, marginality is "a process of abstraction, a core of psychological traits which are the inner correlates of the dual pattern of social conflict and identification" (p. 10). Ehrlick (1973) regards marginality or deviance as an advantage, stating that marginal persons manifest a more favorable attitude toward ethnic targets than do the more socially integrated, which implies that a marginal man has less prejudice toward ethnic groups (p. 165). Everyone needs to feel that he/she belongs to some place. The negative characteristics of marginality make it hard to satisfy this feeling.

The problematic feature of reentry is also determined by how people in the home culture analyze and judge their own behavior and the returnee's behavior. A major research area to be examined in this concern is called "attribution." Brislin (1981) defines the term "attribution" by saying that "attribution refers to judgments made about the behavior of others as well as to judgment about one's own behavior. The basic assumption is that people actively seek out explanations for the behavior they observe" ( $p .91$ ). He states that there are two kinds of attribution: trait attribution and situational attribution.

When an individual observes another person behave in some way, there is a strong tendency to attribute the behavior to a trait. Situational factors are downplayed. When an individual engages in the same behavior, on the other hand, an attribution to situational factors is much more likely (p.93).

This attribution theory can be combined with the in-group/ out-group bias. Based on Taylor and Jaggi's research 
findings, Brislin (1981) summarizes this concept as follows:

$$
\text { TABLE I }
$$

PEOPLE'S PERCEPTIONS

\begin{tabular}{l|l|l}
\hline \hline Groups & Desirable Behavior & Undesirable Behavior \\
\hline In-Group & Positive traits & $\begin{array}{c}\text { Pressures of situa- } \\
\text { tion }\end{array}$ \\
Out-Group & $\begin{array}{c}\text { Pressures of } \\
\text { situation }\end{array}$ & Negative traits \\
\hline
\end{tabular}

In cross-cultural situations this attribution theory tends to be focused on encounters with people from different cultures. However, it is also applied to the returnee's case, especially in regard to how people in the home country perceive undesirable behavior shown by the returnees. Brislin, (1981) explains this tendency as follows:

They realize they have changed but cannot explain how and why. Further, their friends sense a change and are likely to make trait attributions ("irritable," "mixed-up") rather than situational attribution based on the sojourner's recent experiences. Because of their disorientation and the reactions of others, returning sojourners are often rather unpleasant, feisty, and lacking in social graces (p. 131 ).

While home country people tend to make a trait attribution, the returnee is more likely to make a situational attribution. For example, the Japanese returnee from America may greet a guest by shaking hands rather than bowing. In this case, people in Japan tend to attribute their judgment of that behavior to the returnee's personality. However, for 
the returnee this kind of behavior is simply a learned behavior through experience in the American culture. Since deviance from the home society is critically observed by home country people, the psychological dilemma suffered by the returnee will also be serious.

In summary, Part I has described how reentry shock (reverse culture shock) is a significant dimension of crosscultural transition, and has different aspects than culture shock which is experienced in the process of adjustment to the host culture. It is pointed out that reentry shock is generally reinforced by the following facts: (1) changes in the home culture, and within the returnees; (2) the returnee's unawareness of the potential problems; (3) expectations of people in the home culture; and (4) the indifference of people in the home culture.

Cross-cultural experiences include both positive and negative dimensions. Foreign language acquisition helps a person to develop a totally new outlook on the social world, and because of this, a bilingual person is less likely to hold an ethnocentric world view. However, it is also true that an ability to speak two languages could affect an individual's self-concept, which could cause a bilingual person to lose his/her own stable self-concept. Moreover, although overseas experience helps both children and adults to develop a tolerance for other people and enhance international mindedness, it is also likely to put a returnee into a marginal position which is reinforced by the different 
perspectives of the people in his/her home culture. This aspect was explained by attribution theory.

\section{PART II: U.S. CULTURAL INFLUENCE ON JAPANESE RETURNEE CHILDREN}

An extended overseas experience has a significant influence on the returnees' cultural aspects. Since the focus of this study is Japanese children who returned to Japan after living in the United States, dealing with the dimensions specifically between America and Japan through comparison and contrast is vitally important for the purpose of this research. In this section, U.S. cultural influence on Japanese returnee children will be discussed by focusing on the following cultural dimensions: communication styles, cultural assumptions (values), thought patterns, and role behavior.

\section{COMMUNICATION STYLES}

This section will focus on the dimension of selfdisclosure, and the prominence of verbal and/or nonverbal communication styles in the U.S. and Japan mainly based on the research conducted by Barniund (1975).

\section{Self-Disclosure and Criticism}

In conducting a survey of cultural differences between Japan and the U.S., Barnlund (1975) supported a hypothesis that the degree of self-disclosure in interpersonal 
encounters was different in each culture. He found that "the public self as distinguished from the private self constitutes a smaller area of the total self among Japanese and a larger area among Americans" (p. 69). It is easy to imagine what will happen if people who manifest these different communication styles interact with each other.

If a person feels greatly frustrated in communicating with another ferson, it will probably be the occasion when they are in a conflict situation. Barnlund and Nomura (1983) also investigated the patterns of interpersonal criticism in the U.S. and Japan. "Criticism" is defined by them as "the expression of dissatisfaction concerning the personal qualities or behavior of another person that is offered in face-to-face dyadic encounters" (p. 2). The results of this survey indicated that both cultures demonstrated preference for expressing dissatisfaction in a direct way. However, the Japanese scored high in all of the passive-withdrawing forms of criticism, such as, "to criticize humorously," "not to show dissatisfaction," and "to criticize ambiguously." On the other hand, Americans consistently preferred to use active-aggressive forms, such as, "to criticize angrily," "to give sarcastic remarks," or "through constructive suggestions" ( $p \cdot 9)$. The results of this survey showed a close consistency with that of the "patterns of defense" of American and Japanese cultures. That is, that both Americans and Japanese react to defend themselves in the face of anxiety 
or threat in interpersonal encounters, but in a different manner.

\section{Silence}

Cne of the interesting results of the above surveys is that Japanese people tend to use "silence" as one communication pattern in both criticism and defense. Not only in the conflict situation, but on any kind of occasion silence is considered to be one of the major communication styles in the Japanese culture. According to Ishii and Bruneau (1988), the western rhetorical tradition uncritically places great value on explicit verbal expressions or speaking out, and people in the Western cultures have generally negative attitudes toward silence and ambiguity. On the other hand, many of the oriental cultures emphasize the importance of silence, viewing silence as a positive aspect in interpersonal communication.

From cross-cultural survey results, Ishii and Klopf found that the average person in the U.S. spends about twice the time in conversation ( 6 hours, 43 minutes) per day as does the Japanese ( 3 hours, 31 minutes) (Ishii, 1985). Japanese traditional proverbs often clearly reflect this tendency. Katayama, investigating 504 Japanese proverbs on the values of language, states that $25 \%$ of them had positive values, $63 \%$ had negative values, and $12 \%$ were neutral. Inagaki's investigation of Japanese attitudes toward speaking showed that $82 \%$ of the subjects agreed with the 
proverb "Kuchiwa Wazawai no moto" ("Out of the mouth comes all evil"). In terms of business situations Ishikawa's survey concludes that men should or need to be silent to be successful in life, which contrasted with the results of Rader and Wunsch's research for American attitudes toward speech that ability to communicate orally is very important in the business classroom (Ishii and Bruneau, 1988).

Reviewing the results of the aforementioned studies,

Ishii and Bruneau (1988) state:

Not only in business but in everyday social life people in the United States like to ask questions and force others to talk to fill interpersonal silences. Because silence is not valued and therefore not tolerated socially in the U.S. society... , one function of speech is to avoid silence, generally, as well as to fill silences during the transference of messages. Contrary to the U.S. practice, in Japanese society silence and silences are generally considered to be positively meaningful; they are socio-culturally accepted to a much higher degree (p. 313 ).

Kato, cited by Barnlund (1975), states that "in Japan speech is not silver or copper or brass--but scrap" (p. 89). Intuitive communication, through means other than words, is respected. Articulate persons are seen as foolish, or even dangerous, and eloquence can result in disqualifying a person for positions of authority. In contrast, in the American culture articulating ideas and feelings is highly valued. A deep commitment to discussion is the primary mode of inquiry, of learning, of negotiation, and of decision making, which is a vitally important aspect in the U.S. social system ( $p p .89-90)$. 
This has implications for intercultural communication. Since the quantity of speech and silences is interpreted differently in the U.S. and Japan, and if people do not know when, where, and how to keep silent, a serious misunderstanding will occur. This could affect the returnee children since it is quite possible that their communication styles, either verbally or nonverbally, will be Americanized during an extended sojourn abroad.

\section{CULTURAL ASSUMPTIONS (VALUES)}

Stewart (1972) states that "members of different cultures possess various ideas of reality since their assumptions about both the world and experience differ" (p. 10). Porter and Samovar (1985) state that Asian and Western cultures represent a maximum difference in regard to the sociocultural aspects (pp. 22-23). This is reinforced by condon and Yousef (1975) in their modified version of Kluckhorn's Value orientation System. Most of the values held in Japan and the U.S fall on opposite sides of the scale. In the following section some aspects of values in each culture will be discussed in relation to communication.

\section{Equality vs. Status Difference}

Naotsuka and Sakamoto (1982) state that in order to behave politely in a different culture, a person needs to exhibit a "fictitious performance" which is against the feeling of an individual in one's own culture. The 
egalitarian American value is expressed as "You and I are equals" (p. 5). U.S. social relationships are typically horizontal; therefore, there is no special politeness distinction in communication style between people in the U.S. culture. On the other hand, Japanese people are very sensitive to status difference in interpersonal relationships. The vertical principles of rank and hierarchy dominate all relationships in Japanese society. Under the consciousness of a hierarchical rank order, conversation is likely to be monopolized by the speaker in a higher status, and it is unconsciously demanded that the 1 istener should show an agreeable attitude toward every statement made by his/her superior.

Nakane (1984) states that the Japanese concept of status difference is closely connected with the concept of strong group membership, another dimension of the Japanese cultural assumption.

In particular, a junior takes every care to avoid any open confrontation with his superior. Such attempts lead to the point that a flatly negative form is rarely employed in conversations: one would prefer to be silent rather than utter words such as "no" or "I disagree." The avoidance of such open and bold negative expression is rooted in the fear that it might disrupt the harmony and order of the group, that it might hurt the feelings of a superior, that, in extreme circumstances, it could involve the risk of being cast out from the group as an undesirable member (pp. 36-37).

This statement illustrates how one's own cultural assumption directly affects the way we communicate with people. 
The young Japanese is not free of this kind of vertical system, either. School is an important social group for children where they are expected to be engaged in vertical relationships. According to Nelson's (1988) definition, "superiority in vertical roles is obtained only by reference to relationships in given situations" (p. 25). Therefore, a teacher/student relationship could be an example of a vertical relationship, which is relative and situational. Also, at school there is a vertical relationship not only between teachers and students, but also among the students themselves. For example, distinct senior/junior ranking among students is often seen in sports clubs, and junior students are expected to use appropriate honorifics for their senior members.

One's age is another cultural assumption which influences the communication styles in one's own culture, and this is directly related to the above described cultural dimension. Condon and Yousef (1975) set forth possible value orientations that a culture might have toward age: valuing youth, middle age, or old age. They selected value of youth as the choice of Americans in general. However, this is not applicable in the Japanese culture. As the Japanese saying "Kameno ko yori toshi no ko" ("Wisdom grows with age") goes, old people are expected to be respected, and in Japanese culture they are automatically considered to be experienced people. For example, this idea is reflected in the seniority system in the working situation, and the use of keigo (an honorific expression of the Japanese language) for those 
people. Since there is a direct correlation between superior and senior persons, in communication younger members are tacitly expected to be reticent in the presence of seniors. Naotsuka (1984) introduces one Japanese teacher's beginning statement at the seminar for the Japanese teachers of English: "Please excuse me for my poor English. Since I think I am the oldest participant here, I'd like to make a comment on this seminar" ( $p, 168$ ). This example implies that priority of conversation is expected to be given to aged people in Japanese society.

\section{Individualism vs. Interdependence}

Individualism and interdependence also present value differences between the American and Japanese cultures. Americans highly value individualism. They have a strong consciousness that it depends entirely on an individual's effort whether he or she spends one's life happily or not. Moreover, as the English capital "I" suggests, each person tries to exhibit him/herself as an independent individual. Asking such questions as "Who am I?" or "What am I?" is a common pastime of Americans. In other words, for Americans, seeking one's own identify in life is indispensable. This value of individualism is clearly reflected in their conduct. In interpersonal communication it is important for them to clearly state and support their own positions. As Stewart (1972) states, "this means facing the facts, meeting the problem head on, putting the cards on the table" (p. 48). 
On the other hand, the Japanese value interdependence and strong group membership. Unlike individualism, in the view of interdependence "self" always includes consciousness of one's presence in the group to which they belong. In the Japanese language "self" is translated as jibun. As Doi (1973) points out, the expression of jibun ga aru (to have a self) or jibun ga nai (to have no self) is peculiar to Japan (p. 132). Doi goes on to say that "an individual is said to have a jibun when he can maintain an independent self that is never negated by membership of the group" (p. 134). Tai (1986) summarizes Kimura's ideas, which are concerned with the tendency of the Japanese to say "we, Japanese" in their conversation with foreigners, by stating that "the Japanese have a collective identity as the Japanese, which transcends the level of individual identities" (p. 46). Doi and Tai's statements show that for the Japanese "self" exists only in the presence of the group they belong to, and they cannot perceive "self" without taking into account their relationship with other members of the group.

This different view of "self" leads to different conversational styles in the U.S. and Japan. For example, with reference to the American style, Stewart (1972) states that "since achievement has to be visible and measurable, Americans become very sensitive to praise or blame. . more so than perhaps any other people except the Japanese" (p. 37). Therefore, in conversation Americans tend to be preoccupied with the "win-lose" situation. In discussing or dealing with 
a conflict situation they are likely to defend themselves and try to defeat the other participants rather than leaving a thing to take its own course by not revealing their feelings and/or opinions, which is what the Japanese would do. The reason why this concept does not destroy relationships in American culture is that challenging the other person's opinion does not mean to deny his/her personal worth. This willingness to stand up for one's ideas reinforces that the individual self is valued.

As pointed out by Stewart (1972), the Japanese are also sensitive to praise or blame from the other person; however, they react differently since the vision they have of "themselves" is totally different. For example, as described in the previous section, the Japanese form of criticism and pattern of defense in interpersonal communication is totally different from the American style. As one of the reasons for this difference, Barnlund and Nomura (1983) introduce Benedict's idea that,

- . with their emphasis upon sanction of shame, the Japanese tend to be vulnerable to other's slurs, rejections, and accusations, and criticism of one's acts or one's competence automatically becomes criticism of one's self (pp. 2-3).

Haglund (1984) also states:

In Japan, even when venturing an opinion or expressing a personal feeling, one is gambling; if what is communicated appears ludicrous or inappropriate to others, there is cause for the speaker to suffer the dreaded loss of face (p. 72).

The Japanese value of interdependence demands that people be carefully concerned with the human relationship. Since 
losing face and/or making the other person lose face is a dreadful thing which leads to experiencing shame, people try not to express personal opinions and/or feelings in public situations.

Self-respect is a word which implies different values between the U.S. and Japanese cultures. From the American point of view, self-respect means to "consciously conform to a worthy standard of conduct--not truckling to another, not lying, not giving false testimony" (Benedict, 1946, p. 219). In interpersonal communication it means to be honest with one's own feelings and to confront the situation tactfully and directly. On the other hand, in the Japanese language "self-respect" is translated as jicho, which means to be careful about personal relationship in the group. Benedict (1946) points out that in Japan "those who do respect themselves are the good men who 'know shame' (haji) and endlessly circumspect in the interpersonal relation" (p. 293). This Japanese attitude would be regarded as being like a sacrifice of one's "self" in the American culture. It is essential to note that this difference stems from the conceptualization of the word "self," which is peculiar to each culture, and it supports the different cultural assumptions represented by individualism and interdependence.

\section{THOUGHT PATTERNS}

Changes in thought patterns could also affect the readjustment of the Japanese children who returned from 
America. This section will discuss what kind of American mode of thinking the children tend to acquire, and how such a changed thought pattern affects their communication styles. Condon (1984) surveyed the communication habits in the U.S. and Japan. Among his lists which mostly showed dichotomy, the polarity expressed as "verbal vs. nonverbal" and "direct vs. indirect" are the important aspects in regard to the different dimension of thought patterns between the U.S. and Japanese cultures. Moreover, as Porter and Samovar (1985) point out, "culture's thought patterns affect the way individuals in that culture communicate, which in turn will affect the way each person responds to individuals from another culture" (p. 28).

\section{Organization}

First, it is essential to clarify the current general organizational patterns of speech and writing in the U.S. and Japan since they reflect the thought patterns in each culture. An American speaker usually presents his first "point" (or generalization), and thus adds reason or others for proof. The second "point" (or generalization) may then be followed by reasoning or evidence (Condon and Yousef, 1975). In this pattern the speaker uses "topic sentence" style. He begins his speech with either conclusion or generalization, and after that he presents abstract or general statements with proof and details. The feeling is that if the speech consists of only abstract or general statements, 
the contents tend to be vague, and as a result the listeners cannot clearly understand the speaker's intention. The second American pattern of organization is to use an inductive reasoning process. Facts lead to the general principles of "points." This is felt to be the effective technique to attract an audience's attention (Mitarai, 1981; Barker, 1987). On the other hand, a Japanese speaker uses a quite different pattern of organization. He/she may offer abstractions or generalizations, followed by other abstractions or generalizations. The problem is that since this pattern of organization is so different from the American pattern, the American listeners tend to conclude that Japanese speech is ambiguous and illogical. However, as Condon and Yousef (1975) point out, in Japan if the speaker is accepted by the audience as authority, there is no need for him to give specific proofs, and also if not everybody understands what he is talking about maybe so much the better--it makes him even more respected (p. 242). In Japan this kind of obscurity is considered to show the high quality of the speaker; listeners can fill in the blanks of the speech by themselves.

Cultural differences of thought patterns between the U.S. and Japan are also evident in the organizational patterns of writing. Ishii (1985) introduces Kaplan's analysis of paragraphs written by American and oriental students (p. 99). His conclusion was that the American thought pattern takes a linear form, while the oriental thought pattern is more like a gyre. 
He states that the distinction between those two rhetorical patterns may be partially explained by Hall's (1976) discussion of "high" and "low" contexts (p. 100). The Japanese "stepping stone" pattern is an example of high context communication since in this context most of the information is either in the physical context or internalized in the communicating persons. In high context cultures information is integrated from already internalized situations, and from nonverbal cues that provide implicit meaningful messages that will not be obtained by verbal expression. On the other hand, the American "bridge" pattern indicates a low context communication in a sense that most of the information should be elaborated, clearly communicated by the specific verbal utterances. The above characteristics of high context cultures leads to preference of nonverbal communication.

\section{Logic vs. Intuition}

In connection with Eastern and Western world views, Kim (1985) states that while the Western view of the universe is characteristicaly dualistic, materialistic, and lifeless, the Eastern view is profoundly holistic, dynamic, and spiritual (p. 410). This different view of the world also leads people in the East and the west to a different approach to knowledge. Kim (1985) states:

- . while the East has tended to emphasize the direct experience of oneness via intuitive concepts and contemplation, the West has viewed the faculty of the intellect as the primary instrument 
of world mastery. While thinking in the East tends to conclude in more or less vague, imprecise statements with existential flexibility, western thinking emphasizes clear and distinct ideas by means of categorization and the linear, analytic, logic of syllogism ( $p .403$ ).

In this kind of approach the Eastern way of communication tends to pursue intuition which is conveyed through an implicit nonverbal communication mode rather than logical reasoning through an explicit, direct, verbal style, which is the major Western communication mode. These different approaches toward knowledge have molded the current American and Japanese thought patterns expressed as "direct, verbal," and "indirect (ambiguous) nonverbal," respectively.

The above different modes of thinking between the U.S. and Japan directly affect the way people talk in each culture. For example, the Western concept of dualism leads to a logical reasoning expressed as "everything is $A$ or notA," and this supports an American's preference for giving an explicit answer, "yes," or "no." In the Japanese culture it often happens that "yes" does not always mean agreement, but rather it indicates that "I can understand what you say." Americans usually complain about this ambiguous Japanese attitude, but the Japanese are so sensitive to interpersonal relationships that they try to reduce the disappointment rendered to the other person by giving an indirect answer. Generally, the English "no" is translated as lie in Japanese, however, it is hardly used in real conversation in Japan. There is a tacit agreement in the 
Japanese culture which indicates that one is not expected to say "no." Ueda (1974) states that there are 16 different ways to express one's negative ideas by not saying "no" in Japanese. For example, the most typical pattern is called "yes-but" style.

In this case one seems to accept the request but then expresses doubts whether he can fulfill the request. When one is unexpectediy asked to do something or when one is in an inferior position .... he may not be able to decide immediately. In such a case he may say "yes," not as agreeing but more as an injection without an strict meaning. Therefore, he will add "but" (demo) to express the real state of his mind, which is that he hesitates or fears to accept the request. And in most cases, even if the requesting person forces his demand, the final answer will be negative. In other words, "yes, but - . " is commonly recognized as meaning "no" (p. 188).

This attitude tends to give an American the impression that Japanese people are insincere. It is essential to note that there are no equivalent Iinguistic expressions for the Western dualistic sense of "yes" and "no" in the Japanese culture. The Japanese are expected to read between the Iines in communicating with the other person. If they fail to do so, they will be labeled as Sasshi no warui hito (a person who is bad at reading one's mind), which is a severe criticism for Japanese people.

The point is that the intention to give a logical and clear answer by such things as saying "no," is likely to be regarded as assertive, which is not a desirable personal trait in the Japanese culture. This is one of the important points that the Japanese returnee children from America must bear in mind. 
ROLE BEHAVIOR

The cultural dimensions which were discussed in the foregoing (communication styles, cultural assumptions, and thought patterns) are all interrelated with one another and with the use of language. They are also likely to be reflected into another cultural dimension: role behavior.

Andersen (1985) states that the "entire educational system, together with all the rules and procedures for proper classroom interaction reflect a cultural dictate rather than a universal mandate" (p. 161). She also points out that "classroom interaction rituals and patterns vary extensively from culture to culture" (p. 162).

Concerning the factor which influences Japanese returnee children, it is significant to focus on the difference in classroom behaviors in the U.S. and Japan. Ulrich (1986) conducted research on normative teacher and student role behaviors in American high schools, and she compared her findings with Barna's (1986) study whose focus was the Japanese high school and college students. In this research Ulrich found that there were several differences between the U.S. and Japanese classroom conduct. For example, teachers and students in the U.S. classroom have an open communicative relationship where the students are encouraged to freely participate in classroom discussion. This is unlikely to be seen in the Japanese classroom situation. In Japanese schools (except for universities), once a week 
there is a period of the class called "homeroom." In this class one important topic is chosen and discussed among the students. However, usually there are only a few students who volunteer to give an opinion. On this occasion the teacher is expected to be involved as an observer and/or facilitator; however, many times this class ends up listening to the teacher's lecture about the issue. Moreover, in the usual classroom situation, students are not expected to give their opinion freely, and they have to raise their hand, saying "Hai," a word similar to "yes," in order to get permission from their teacher to speak. These different behaviors between the U.S. and Japanese classroom reflect their communication styles which are expressed as assertive and nonassertive, respectively.

These different classroom role behaviors are a reflection of the values of each culture. Ulrich (1986) states as follows :

Primarily, the U.S. classroom role behaviors reflect the U.S. values of individualism, equality, and informality. In general, teachers and students have an open communicative relationship and students are encouraged to give their opinion and interact in classroom discussions. The Japanese classroom role behaviors, on the other hand, reflect the Japanese values of groupism, hierarchical relationship, and formality. The relationship between the teacher and student is far more formal and ritualized than in the U.S. Students are not expected to interact in the classroom, but rather to remain quiet and speak only when called upon. The results proved interesting and heightened one's awareness that classroom role behaviors stem from basic cultural values (p. 2 ).

Unlike the U.S. classroom, in the Japanese classroom challenging the teacher's opinion through open communication 
is regarded as a challenge to their authority, which consequently hinders the harmony of the entire classroom situation.

With reference to the returnee children, their changed behavior is shown not only in the classroom but also in other situations. White (1988) states:

Some young children were puzzled when adults objected to their "overseas style." When asked at his school's opening ceremonies to make the traditional formal greeting to teachers and classmates, a first-grade returnee responded by swaggering up to the microphone in the manner of a U.S. television master of ceremonies. In Japanese sprinkled with English he told a shaggy dog story of his experience with bears in Yellowstone Park, until a teacher took the microphone away. He had not known what was expected of him and was surprised at the teasing he later suffered (pp. 66-67).

Moreover, returnee children are likely to have forgotten some of the nonverbal behavior which is important to the Japanese culture. Kitashiro (1984), a Japanese wife who returned to Japan after her husband's overseas assignment, recalls her daughter's feelings about the Japanese ritual of bowing:

"You are doing it again, Mom. Why do you bow when you can't see the other person on the phone?" For me it was quite a natural behavior which I could do almost unconsciously. However, for my daughter, who lived in America for eight years, it looked strange. My daughter was in the seventh grade when she returned to Japan. When it came to dinner time, she used to bring out a topic of Japanese bowing, and complain at a repeated traditional ritual at the morning meeting, and the classroom at school. It was hard for her to understand why the Japanese bow frequently (p. 56).

Yanagihara (1983), who Iived in New York from senior high school for 7 years, is an English teacher in high 
school in Tokyo. She states her reverse culture shock as follows :

When I started this job, I sometimes wondered if my assertiveness might have hurt my colleagues' feelings. It is because they did not show any facial expression on their face, nor gave any response to my opinion. I also felt irritated at their roundabout response which implied that they did not disagree, but it did not imply agreement, either (p. 37).

Yanagihara (1983) also says that since the students' facial expression was also inscrutable, she could not understand what was in their minds. Her attitude is "they are very passive, and never assert themselves" ( $p .37)$.

It seems to be a general case that the returnees' deviant behavior from the norms of their home culture often surprise their peer group and/or teachers at school. However, the above case is an opposite in a sense that the teacher, who was a returnee, was surprised at her colleagues' and students' behavior. The point is that until she encountered the situation, she could not notice the difference between herself and the people in the home culture. This tendency supports Condon and Yousef's (1975) idea which reads that much of our behavior is outside of our own awareness. As far as people living in their own country, this fact may not cause any serious problem. However, it is difficult for the returnees to be aware of their own change during their sojourn abroad. In Yanagihara's case, although she went to America at the age of 16 , she still had odd feelings upon reentry about the behavior of the home culture people. The 
effect is even stronger on young children who were not fully acculturated as Japanese before they left their own country.

Part II has dealt with the potential U.S. cultural influences on the Japanese returnee children. The aspect of self-disclosure and criticism, and the aspect of silence in the U.S. and Japan were discussed. Compared to the Americans the Japanese are much less likely to be exposed to verbal self-disclosure. This tendency becomes prominent in conflict situations, and it takes the form of silence, which is a significant aspect of Japanese nonverbal communication.

Communication styles in the U.S. and Japan also reflect the cultural assumptions in each culture. Two main concepts expressed as "equality vs. status difference" and "individualism vs. interdependence" were described. Unlike the American concept of equality, strong concern for harmony in interpersonal relationships in the group encourages the Japanese to be sensitive to the status difference. The different values of American individualism and Japanese interdependence were also discussed in relation to the different conceptualization of "self" in each culture.

Thought patterns are another aspect which could affect the readjustment of the Japanese returnee children. While the Americans follow the "bridge" pattern in both writing and speaking, the Japanese pattern is expressed as "stepping stone" or "gyre." The reflection of these different thought patterns are viewed in a "direct, explicit" U.S. communication style, and an "indirect, ambiguous" Japanese communication style. 
In the last section, based on Ulrich's (1986) research, the different classroom behavior in the U.S. and Japan was discussed. Overall, the U.S. classroom behavior represents the values of individualism, equality, and informality while the Japanese classroom behavior reflects the values of groupism, hierarchical relationships, and formality. An important point to remember is that since much of our behavior is outside of our awareness, it is difficult for the returnees to become aware of their own change, which occurred during their sojourn abroad.

\section{CONCLUSION}

In Part I, as background information for the present study, several aspects of reentry shock which were distinct from culture shock were described, focusing on (1) changes in the home culture and within the returnees, (2) the returnees' unawareness of the potential problems, (3) the expectations of people in the home culture, and (4) the indifference of people in the home culture. Cross-cultural experience tends to hold both positive and negative dimensions, and these were discussed in regard to language and other cultural aspects.

Part II discussed potential U.S. cultural influence on Japanese returnee children through comparison and contrast of the following cultural dimensions between the U.S. and Japan: (1) communication styles, (2) cultural assumptions (values), (3) thought patterns, and (4) role behavior. 


\section{CHAPTER III}

\section{LITERATURE REVIEW: THE ISSUES OF JAPANESE}

\section{RETURNEE CHILDREN}

\section{PROBLEMS FACING THE JAPANESE RETURNEE CHILDREN}

As discussed in the previous chapter, it is likely that children would acquire new ways of thinking and new behavioral patterns through their cross-cultural experiences. This could be positive in their overall development. However, Piet-Peion (1986) points out that "it is still impossible to say whether the overseas experience will be a positive or negative one for our children" (p. 28). In considering Japanese children's reentry, it is essential to be aware that their overseas experiences tend to cause serious problems when they return to their home country. A Japanese children's game chant says "Iki wa yoi, yoi, Kaeri wa kowai," which means that "Leaving is good, but it's frightening to return" (White, $1988, \mathrm{p} .1$ ).

After reviewing a survey of overseas managers of Japanese firms, LaBrack (1983b) states that "the number one anxiety of these men was the education and future of their children, even greater anxiety than over their own personal reintegrations upon returning to their Japan-based companies" (p. 85). Further evidence of the problem is that the issue 
of Japanese returnee children has begun to draw media attention not only in Japan, but also overseas. For example, The Oregonian introduces a case of one Japanese businessman who is working in the Portland-Vancouver metropolitan area:

He worries about how his son will react to being a Japanese in a sea of American youngsters. And he worries even more about the future when he must return home with his family. In Japan, he says, his son may be considered an "outsider" because he has been abroad and because he may be behind in the competition to enter better high schools and, ultimately the better universities which in Japanese society are a key to obtaining the best jobs (Ota, 1985, p. 2).

As pointed out by LaBrack (1983b), every category of the Japanese returnees, such as grade school returnees, high school exchange students, and businessmen and their wives has similar types of adjustment difficulties because all of them face the same social milieu after their return (p. 78). However, it is important to note that there are specific problems which the Japanese returnee children will face.

Kobayashi (1981) conducted an extensive piece of research on 655 Japanese children. He concluded that, in general, children took a longer time to readjust to their home country than to their host country. Moreover, he found that the longer they stayed in the foreign countries, the longer time the children took in order to readjust to the home country after their return (p. 229).

Farkas and Kono (1987) investigated 72 Japanese returnee children who were students at elementary, middle, or high schools in the Kobe-Hanshin area (pp. 202-207). The foreign countries of their sojourn included various places in 
the world, and the average period of their sojourn abroad was 3.4 years. The results showed that more than $50 \%$ of the returnee children had some problems after returning to Japan, which the investigators called "reverse culture shock." They also found that $55.3 \%$ of the children who answered that they did not want to come back to Japan were those who returned from North America and other English-speaking countries. This was consistent with the result that the children who felt that there were more unpleasant things than pleasant things after returning were ones who came back from the English-speaking countries. In connection with the difficulties they experienced, $45.5 \%$ of the children answered that "I was called gaijin by my classmates," "I was bullied," "The teacher didn't help me when I was bullied." In addition, $12.5 \%$ of them had Japanese language problems, and $5.6 \%$ listed strictness of study at Japanese schools. Only $21.6 \%$ of the children felt that they had no problems. In regard to the things that surprised them after returning to Japan, the children from every country mentioned smallness of the land, and the large number of cars and people, especially the number of the students in one class at school. They were also surprised at the uniformity of the Japanese school system, such as the school uniform, a lot of homework, attending school in a group, and strict teachers and school regulations. Reviewing the above findings, Farkas and Kono (1987) stated the following: 
This result shows that in order to readjust to the Japanese society the returnee children are forced to experience a more hard time than they had expected. Moreover, this indicates that in Japan, when an outsider tries to enter the restricted group named "school," a great deal of rejection reaction occurs to the school side (p. 206).

These researchers also reported that $71.4 \%$ of the children felt that they did not want to use their foreign experiences in the future.

Kobayashi (1981) states:

- . one of the most fundamental problems of the education of children overseas is that most of the overseas experience acquired by the children is negatively evaluated at Japanese schools. This is related to the Japanese school system whose main purpose appears to be to prepare for successful entrance examinations. Without taking into consideration of this point, it is very difficult to internationalize Japanese schools in a way that the returnee children can make use of their overseas experiences (pp. 207-208).

Hasebe (1985) presents the results of a survey conducted by the Ministry of Education in 1982 on the anxieties about returning to Japan which were held by the Japanese families overseas. A large percentage of the families overseas were worried whether the children could keep up with the study after they went back to Japanese school. However, it is interesting to know that there was some discrepancy of feelings between the parents and the children overseas. For example, the parents listed as their second concern whether or not the children could make friends at school while the children themselves ranked it as the sixth. Anxieties which the Japanese family overseas had are described in Appendix $A$. Their third concern was if their children could readjust to the climate and Iife environments in Japan. Their fourth 
and fifth concern was if the children could enter the Japanese high school or university, and if they could speak and write Japanese well, respectively. On the other hand, the children listed these as the seventh, fourth, and eighth concern, respectively. Moreover, it was found that $26.2 \%$ of the children overseas felt that there would be no problems after returning to Japan.

It is noticeable that there is a discrepancy between the concern of the children overseas and the problems which were actually faced by the returnee children. Another part of the research found that what the returnee children thought to be their number one problem was the short length of vacation at Japanese school (Appendix B). The second problem was that they could not speak Japanese as well as they wanted to. The rest of the problems listed by the returnee children were as follows. The third problem they faced was that it was difficult to keep company with friends. The fourth problem was that school regulations were too strict and the fifth was that they felt embarrassed with the Japanese custom and manner. An interesting point is that the potential problem of being behind in their study, which was listed as the number one concern by both parents and children overseas, was 1 isted as the eighth problem in the national survey conducted of the returnee children.

A problem of great concern to parents who were assigned overseas was their children's readjustment to the Japanese educational system, which consequently means to compete 
successfully in the rigorous university entrance examination ordeal. Considering this fact, the Ministry of Education has established a number of special programs and schools for these children. The following shows how much effort the Japanese government is making to help the children integrate into the Japanese school system.

The Ministry of Education of Japan runs 82 full-time and 120 supplementary schools in 56 and 48 foreign countries, respectively, to provide Japanese children living abroad with the same education that is given to the children in Japan at a cost that has increased from 1.5 billion yen in 1974 to over 16.5 billion yen in 1982 . As of $1987,39.9 \%$ of overseas children attended full time Mombusho (Ministry of Education) schools, $40.3 \%$ attended supplementary education schools one to two days a week, and only $19.8 \%$ were enrolled on a full-time basis in local foreign schools. Moreover, the Ministry of Education itself provides the teachers, texts, and guidance materials for its overseas schools. The educational service for these children also continues after they return to Japan (Ministry of Education, 1988).

According to the research done by Enloe and Lewin (1987), within Japan the Foundation of Japanese Overseas Education runs three elementary and three middle schools which have special remedial classes for the returnee students. There is a total of 43 elementary, 43 middle, and 61 high schools that enroll those students in regular classes. They also provide special classes and tutoring to students who are 
weak in various areas. Moreover, in recent years, three high schools have been established mainly to help returnee children prepare for the college entrance examination, and 56 colleges and universities give special consideration to returnee applicants (p. 226).

Referring to the survey by the Ministry of Education which was introduced previously, it was found that the problem of being behind their counterparts in Japan drew little attention from the returnee children. This result appears to owe much to the above described efforts by the Ministry of Education. This and the other discrepant opinions given by the families overseas and the children who had already returned indicate that Japanese families in foreign countries do not anticipate the potential problems their children will face after returning to Japan.

\section{SCHOOL PHOBIA}

In this section problems faced by the Japanese returnee children will be discussed in more detail beginning with what has been labeled "school phobia."

Kitagawa (1982) defines "school phobia children" as whose who cannot go to school psychologically in spite of the fact that they are healthy and have no economic problems in attending school. According to Kitagawa (1982), school phobia began to draw public attention in the mid-1950's in Japan. At that time, school phobia was considered to be a result of the parent's overprotection of the first child, which 
consequently led to spoiling the child. However, as the number of children who, because of their father's job, went abroad, stayed there, and came back is increasing, an aspect of school phobia has changed. School phobia is not limited to the first child any more, but it is a negative result of the overseas experience which is mainly caused by the ijime (school bully) in the children's peer group in Japan.

In considering the problems of the returnee children, it is important to consider the deep-rooted cause of school phobia. As discussed in chapter II, the returnees have acquired new behaviors and traits through their overseas experience. However, because of the homogeneous characteristic of the nation of Japan such changes are likely to be negatively evaluated, and as a result, children tend to be caught in a painful situation. Impoco (1988) said:

Overseas stints are - . daunting. Returnees must fight to fit back into their homogeneous society. This "homecoming problem" takes a toll, especially on children harassed by peers for losing their Japaneseness $(p .34)$.

Domoto (1987) states:

of course it is natural for people raised in a different cultural environment to embrace different concepts and mental associations; what is odd is that in Japan this is a source of friction and discrimination against those who vary from the norm (p. 35 ).

White (1988), who did research on the problems which were faced by the Japanese families as a result of their international sojourn, states as follows:

Fitting into a society in which an outside experience is at best irrelevant and at worst stigmatizing 
is most difficult for returning children. Children are under strong pressure from the community to be "normal." The experiences of the children returning to Japanese schools reflect the confusion and anxiety surrounding the introduction of diversity into a conservative and homogeneous system ( $p .65$ ).

The situation described above is likely to be inflicted by the children's peer group in the classroom. White (1988) reiterates that family, school, and workplace are important social groups in Japanese society, and points out a difficulty in integrating into the home society after an overseas sojourn.

The person who has lived and worked or studied outside Japan may indeed have acquired some dysfunctional "foreign" ways or forgotten Japanese habits and knowledge crucial to his or her integration in a group that demands a very precise and exacting socialization (p. 13).

It is difficult for the Japanese returnees to reestablish their relationship with their primary groups. In the case of returnee children, reintegration means to become a part of an already established school clique. LaBrack (1983a) states:

The returnee child is often unequipped with the social or attitudinal skills demanded for quick assimilation into an existing school group. They may find themselves isolated and even ostracized by fellow students, called henna nihonjin ("strange Japanese") or yosomono ("outsider"). Even if they have attended one of the Japanese schools established abroad to provide instruction in the Japanese language and traditional curriculum subjects, the returnees' ability to read the intricate Japanese script, or even to speak Japanese, may not be at the level of his peer group ( $p .32$ ).

Because of the strong membership within the society, Japanese people are expected to behave the same. This is exemplified by the difficulties faced by Japanese-Americans 
general notion that people who look Japanese are expected to communicate and behave in exactly the same way as other Japanese do. As pointed out by Brislin (1981), children in particular are quick to notice any difference in people. If the returnee children fail to behave in the same manner as their peer group in Japan, they will be regarded as deviant, and ostracized.

Interestingly, experiences abroad need not mean any loss of Japaneseness. Some children realize this.

As some of the younger school children assert, "when we come back from living in a foreign land, we are not han japa (half Japanese) as some would say. We are Japanese plus. We have Japanese culture and more" (LaBrack, 1983a, p. 37).

However, this kind of wishful thinking cannot be realized since receiving an education in a foreign country is not necessarily regarded as positive in the Japanese society. Minoura (1981b) implies that Japan is a society of deduction, while America is a society of addition. She introduces one returnee student's comment as follows:

In Japan people are likely to give a negative evaluation, saying "you couldn't do it," or "you didn't do it." However, in America the situation is totally opposite to Japan. Americans gave me a positive evaluation after adding everything that I could do ( $p .45)$.

The above described tendency is likely to be viewed in the education system. It seems obvious that the children who have received education in America will have contradictory feelings after returning to the Japanese educational system. The purpose of the readjustment classes and schools is to relieve the problems which returnee children will face 
after coming home. However, those remedial courses give a double message to the returnees.

- . on the one hand, they encourage rapid assimilation of Japanese skilis and habits, while on the other hand, they seem to convey to returnee children that they are already impossibly different, that conformity is not possible (White, 1988, p. 66).

Domoto (1987) also states:

The Japanese students they find themselves among are bent on what they call "stripping off America" or "stripping off the foreign country"--in other words forcing the returnee to abandon the characteristic traits or behavior that Japanese students regard as American or foreign ( $p .35$ ).

Children make a great effort to return to a "normal" student in the classroom. White (1988) introduces some examples of the efforts made by these children.

Children who at first insisted on retaining some signals of their overseas stay--such as eating peanut butter sandwiches for lunch or wearing foreign lace-up sneakers instead of elasticized Japanese ones--quickly adopted Japanese habits in response to teasing from other children, or pressure from their parents. One boy wore an American printed sweat shirt to school until he was teased out of it by classmates who kept calling him an Eskimo, even though similar sweat shirts were being sold all over Tokyo at the time (p. 66).

As discussed in a previous part of this paper, people in the home country do not show their interest in the returnee's overseas experiences. In a homogeneous country like Japan, talking about their own sojourning abroad is likely to be regarded as "showing off." Some children try to reassimilate to their peer group through rejecting their foreign experiences.

"The group leader finally said I could join the group if I promised not to talk about Europe.... 
After this experience, I decided never to talk about it, and whenever I talked I asked myself whether I was being conspicuous or not. Gradually I began to hate my European experience. If only I had not gone there!. - I would not have experienced this pain. . . By rejecting my overseas experience, I started to assimilate to Japan" (White, 1988, p. 67).

Moreover, in order to make themselves more comfortable in this situation, some returnees try to make their own clique with other children who have lived abroad, or those who look different for other reasons. For example:

A returnee girl who attends a regular school in Tokyo has developed a close friendship with a girl who was raised in Osaka, whom others teased for her "strange foreign accent"--a dialect common to the osaka region. The returnee said that she felt very protective of the Osaka girl because others had teased her in the same way. The both of them were called gaijin by their classmates (White, 1988, p. 67).

As discussed in the foregoing, Japanese children's school phobia, which was a consequence of the parents' overprotection of the first child 30 years ago, has become a negative result of the overseas experience of the returnee children.

\section{THE JAPANESE EDUCATIONAL SYSTEM}

As Domoto (1987) states, it is probably true that any failure to adapt to the Japanese school situation is due more to the exclusionist nature of the Japanese students in general than to the inflexibility of the returnees (p. 35). It is important to notice that this tendency is intensified by the Japanese educational system which places a great emphasis on uniformity and predictability. 
Education in Japan, as in many modern societies, has three important functions; to create an educated populace, to provide credentials needed in the occupational system, and to train children in the norms and behavior of the culture. In Japan's tightly ordered and homogeneous society, it is the educational system itself well organized and uniform, that explicitly encourages a predictability, if not a monolithic uniformity in each generation socialized (White, 1988, p. 45).

It is this return to uniformity that will make their actions predictable so that the returnee children must learn quickly in order to readjust to the Japanese society.

The main goal of Japanese education is to teach the indispensable values of the Japanese culture, that is, harmony and cohesion. White (1988) says, "Harmony is manifested in the uniformity of educational experience, in minimizing differences between children, and in the positive value placed on cooperation" (p. 46). In contrast, the researcher of this study had an opportunity to observe the fifth grade children of an elementary school in Portland, and found that in the same class the children were doing different things depending on the progress of their study. Some were studying arithmetic, and others were working on hand craft. However, in the Japanese school this kind of thing is very unlikely to happen. White (1988) states:

That on a given day all third graders in Japan are working at the same level in arithmetic, that teachers expect children to follow regular and predictable routines of classroom behavior, and that the two-yearly sports day follows a single sequence of events throughout Japan are evidence of the uniformity encouraged by centralized planning and administration (p. 46 ). 
It is very difficult for the returnee children, who were exposed to a flexible school system in a foreign country, to adjust to the conservative Japanese educational system, and experiences which the returnees acquired during the overseas sojourn tend to be discouraged. White (1988) states:

For the returning child who has studied overseas, even for a period as short as a year, the Japanese style of school life and world often requires a major adjustment. Moreover, preparation for the crucial examination demands a type and intensity of commitment that are rarely seen elsewhere. Work done in other educational systems is not considered useful or relevant to Japanese schools or organizations. The Japanese educational system is a welldefended, conservative institution ( $p .10)$.

Under these circumstances the main job of the Japanese school teachers is to keep classroom uniformity and because of this, any difference shown by the returnees is likely to be regarded as a burden in the class.

PARTICULARISM OF THE JAPANESE CULTURE

LaBrack (1983b) points out that,

- . the immediate task confronting researchers is to separate to whatever extent possible the culturespecific manifestations of the Japanese reentry experience from the more general process of readjustment (p. 86 ).

Although children are likely to suffer from the most serious problems after coming home, there are specific common characteristics of Japanese culture which seem to make it difficult for the returnees in general to assimilate to their home society. Four of these characteristics will be discussed 
here: the insularity of the Japanese culture which has been historically maintained since the Edo era; the concept of Japanese group membership; ethnocentrism of the Japanese culture; and, the Japanese notion of internationalization.

Insularity of the Japanese Culture

Haglund (1984), pointing out Japan as an island-nation (shimaguni), states that the tradition of isolation in Japan is both culturally and geographically abetted.

During the Tokugawa Era (1603-1867), every effort was made to seal her culture from the rest of the world, from the divergent influences which would occur through cross-fertilization of ideas.... Japan has not known significant conflict of interest, due to her high degree of homogeneity, ethnically and culturally (p. 62).

Moreover, Japan has a long history of not only isolating foreign people who try to come into the nation, but also rejecting Japanese who left the islands. LaBrack (1983b) states as follows:

In a country in which insularity is not only a natural consequence of an island environment but enforced by 1 aw from the 17 th century until 1857 , it is not surprising that "outsider" in any form might be looked upon with suspicion. However, these returnees are all racially . . Japanese, communicate in Japanese, and have no major physical characteristics which set them apart from the general population. It is clear that what is at issue here is not simply a matter of "recognition" of small differences in behavior but a much more inclusive set of attitudes and perceptions towards Japanese who have 1 ived and worked abroad (pp. 7879).

This Japanese attitude toward the outside world (including people), which has been maintained through a long history, 
makes it hard for the returnees to be accepted by their society.

The Japanese Concept of

Group Membership

Although group membership in the Japanese culture was described previously in this paper in connection with the current problems faced by the returnee children, this concept will be discussed in more detail here, being related to the idea of boundary.

The Japanese characteristic of insularity tends to intensify the distinction between "insiders" and "outsiders." For Japanese going abroad this means to cross not only a geographical border, but also a special boundary. White

\section{(1988) states:}

To do so [to cross a social boundary] is to violate the often unspoken rules that define membership. Group membership in general may have primarily political or contractual dimensions . . . it may be marked, as in some ethnic groups, by common rituals and sentiments; or it may be measured by active participation and constant interaction with other members. Each type of membership has a different checklist or qualification by which the boundary is defined (p. 105).

In making a comparison between the problems faced by the American returnees and Japanese counterparts, LaBrack (1981) says:

In the case of the American returnees, they can find new friends, and a new group even if they cannot return to their old group. However, in the case of the Japanese returnees, if they are rejected to reenter their old group, it is not easy for them to make new friends, nor find a new group they can belong to ( $p p .35-36$ ). 
It is essential to note that this strong group membership is a core of the Japanese social structure. Ie, the Japanese word which means "family system," is a social group based on an established frame of residence and often of management organization. The formation of social groups on the basis of fixed frames is characteristic of Japanese social structure. Pointing out that the principles of the Japanese social group structure are clearly portrayed in the household structure, Nakane (1984) states that "the concept of this traditional household institution, $\underline{i e}$, still persists in the various group identities which are termed uchi, colloquial form of ie" (p. 7). According to Nakane, the institution to which an individual belongs is regarded as the extension of his/her household, and an individual has an absolute loyalty toward this group. Uchi means an institution as a whole, or section to which an individual belongs. Usually, an individual belongs to a certain informal group, and this is a primary group, which is of the most intimate concern in one's social life. The bases for the formation of such a group may be seen in congenial friendships, and long and stable associations through work and common backgrounds, such as graduates of the same school (p. 125).

Even though family members are relaxed and open with each other, seen from the outside the uchi is intensely private. White (1988) states that the family has secrets and its own language that are very seldom shared with outsiders. 
The term mizuirazu (water doesn't enter or watertight) is used to describe this tight family exclusivity and privacy. Kazoku mizuirazu ga ichiban ii means "the close family circle is the best." BY extension, any context a person calls uchi (home) is a world in which one can be excused and in which one can depend on others. These relaxed relationships cannot function if an outsider is present ( $p .146)$.

An important point is that this concept of boundary, from the outside, is not only applicable to the relationship between the family and people in the outside world within Japan, but also to the one between Japan and other foreign countries. White (1988) supports this statement by saying that Japan is macro-uchi (p. 121). In other words, Japan itself makes one big family whose function depends on maintaining privacy from the outside world. In this kind of society, returnees who acquired any kind of difference through overseas experience can be threats. White (1988) states :

Returnees - . may be marked as different, or as having been away too long to be trusted, and may be subtly isolated or directly confronted by the results of their "apostasy." While returnees are not absolutely abandoned by most uchis, they may nonetheless find themselves with permanently flawed identities or isolated within the group as functional but problematic or marginal members (p. 2).

White introduces a term "insider-outsider" (uchi no gaijin), which describes the situation of the Japanese returnees. It means "any kind of person who is different and who must yet be acknowledged as Japanese" ( $p .27)$. 
Ethnocentrism of the

Japanese Culture

Tai (1986) introduces Sumner's definition of ethnocentrism as follows:

Ethnocentrism is the technical name for this view of things in which one's own group is the center of everything, and all others are scaled and rated with reference to it. . . Each group nourishes its own pride and vanity, boasts itself superior, exalts its own divinities, and looks with contempt on outsiders. Each group thinks its own folkways the only right ones, and if it observes that other groups have other folkways, these excite its scorn. Opprobrious epithets are derived from these differences (p. 20).

Concerning the idea of ethnocentrism with reference to the Japanese culture there is one contradiction which has to be clarified. Bennett (1986) presented a phenomenological developmental model on intercultural sensitivity. This model describes a continuum of increasing sensitivity and accepting of difference, moving from "ethnocentrism" to "ethnorelativism." In other words, the more people are sensitive to and accepting of difference among people, the closer they can move to the concept of "ethnorelativism," which increases people's understanding in intercultural communication (pp. 2728).

Because of its closed national characteristics, which have been maintained since the Edo Era (early 17 th century through the mid-19th century), Japanese people are likely to recognize cultural differences sensitively through assuming basic human differences (Tai, 1986, p. 41). Therefore, it appears that theoretically Japanese people are located closer to the concept of "ethnorelativism." However, 
the catch is that although the Japanese tend to see differences between themselves and foreign people, they are likely to expect similarities among the Japanese.

An important point is that this latter case is applicable to the returnee children, and this complex characteristic of the Japanese culture can be explained through the first and second ethnocentric stages of Bennett's model, namely the denial and defense stage. First of all, since they consider that every Japanese has the same kind of beliefs, attitudes, behavioral norms, and value orientations in spite of his/her different experiences overseas, people in Japan do not allow for the possibility of differences in the returnees. However, while they are interacting with the returnees, they begin to realize that differences do exist between themselves, which leads them to the first stage of ethnocentrism. As pointed out by Bennett (1986), "in the denial state, the threat was amorphous and the strategy was to simply ignore it, hoping, perhaps, that it would go away" (p. 36). However, when the situation proceeds to the second stage of ethnocentrism, that is, defense, people recognize specific cultural differences and begin to create specific defenses against them. In the returnee's case, this "cultural difference" could be modified into "differences acquired through overseas experiences."

In the case of the Japanese returnees these two stages are exemplified by their teacher and peer group. For example, the teacher has no idea that the difference exists 
between the returnee child and other children in the class at first. In the meantime, he/she beings to notice the different classroom behavior shown by the returnee child, but tends to simply ignore it, hoping that it is just temporary. Then, when he/she realizes that the returnee has different cultural aspects from other Japanese children, the teacher begins to regard the existence of the returnee as threatening to normal classroom conduct. In order to prevent these differences from breaking harmony and conformity in the class, the teacher begins to defend his/her class by taming and criticizing that child. Children are generally more sensitive to differences. If the returnee child tries to join the peer group, other children will keep a defensive attitude at first, and then give him/her permission to join their group on the condition that the returnee child forgets his/her foreign experiences.

The Japanese Concept of

Internationalization

Meiji restoration in the late 19 th century put an end to a national isolation policy which lasted for over 200 years. Moreover, it is said that in order to catch up with the Western industrialized nations, one-third of the Meiji educational budget was devoted to sending students and scholars abroad at that time (White, 1988, p. 15). Japan's imperialism, which was intensified from the end of World War I through the end of World War II, made the nation close the windows on the world again, geographically and culturally. 
However, Japan's postwar economic recovery awakened once again Japan's strong motivation to catch up with and surpass the other industrialized nations. With the help of the upbeat international mood of the 1964 Tokyo 01ympics a period of economic growth implanted the notion of the necessity of becoming internationalized.

However, an important point is that although Japan made a drastic change in its economic aspect, its social structure has retained pre-modern elements. Nakane (1984) observes that the fabric of Japanese society thus appears to be torn in two. The retaining of "feudal" or "pre-modern" elements while adapting a Western industrialized stance seems peculiar to Japan in the sense that these two are regarded as contradictory to modernization by Westerners. She notes that "the traditional is one aspect of the same social body which also has 'modern' features" (Preface). She emphasizes that it is the persistence of the modes of personal social relations which is the basic value orientation inherent in the Japanese society. This dual aspect within the Japanese society appears to disturb any effort to originate true international consciousness within its people. LaBrack (1983a) states:

- . Japan's internationalization efforts are often counterbalanced by a conservative social structure, and that returnees of any variety will face certain deeply ingrained prejudices (p. 37).

Naturally, Japan's economic and industrial advancement cannot be discussed without referring to the people involved, such as businessmen, their wives, and their children. However, 
the fact is that contrary to Japan's yearning for internationalization, their international experiences are likely to be negatively evaluated. This results in such things as "international dropouts" among returnees. This term is usually used for younger people who have chosen to work either in foreign established firms or universities, or in nontraditional arts and media (White, 1988, p. 101). "International dropouts" leave the Japanese business arena because they are impatient with the Japanese hierarchical system in Japanese offices, and with the slow pace of career promotion. Although returnees who are not young and who return to the same company after the overseas assignment may not "drop out," they have a hard time in readjusting to their old company. Because of a tightly organized vertical personal relationship, if they are away from their group for a number of years, it will be very difficult for them to return to the mainstream of their own organization. This indicates that in spite of their contribution to Japan's internationalization, the businessmen's return to Japan is often fraught with difficulty. Returnee children also suffer, perhaps more severely, from the same double standard of Japan toward internationalization.

The Ministry of Education established Rinkyoshin (the Ad Hoc Educational Council) in 1984 in order to investigate future reforms and improvements in Japan's educational system. One of the important principles of this council 
is internationalization of Japanese education. The second report of the council held in April, 1986 says:

It is necessary for Japan, as a nation in the world, to look at itself from a world-wide viewpoint, and contribute to the world not only in the field of economy, but also in the educational and cultural fields for the sake of peace and prosperity of human beings (Ministry of Education, p. 122).

In connection with returnee children, the principle of the council states that efforts should be made so that returnees are actively welcomed into schools and that their overseas experiences are positively evaluated as their precious property. It also states that it is important for children overseas to enroll in local schools, which will consequently produce international Japanese ( $p .123)$. This may be the theoretical goal but considering the problems faced by the returnee children, "there remain many problems that must be solved before students who have been educated at local schools abroad can be ensured of making a smooth reentry into Japanese society upon their return" (Domoto, 1987, p. 37).

Previously in this paper, the author discussed special schools which were established by the Ministry of Education for the children overseas and returnee children. The main purpose of those schools was to help children who have been exposed to foreign education for a certain period of time to readjust to the Japanese school system. However, in spite of the principle of international education, the fact is that emphasis is placed upon stripping of foreign flavor from the returnee children, and helping them to return to being $100 \%$ pure Japanese. 
The Foundation for the Education of Children Overseas represents the most conservative position of the Ministry of Education. White (1988) reports that the task of the foundation is to "cure the overseas disease" of the children and to recommend schools that range from a normal Japanese school to intensive "therapeutic" private schools (pp. 51-52). For example, one teacher at a special high school in Tokyo who was interviewed by White (1988) states, "They come there to think, not to memorize, but in a year they are tamed" (p. 61). Befu, cited by Enloe and Lewin (1987), states that internationalization in Japan more frequently than not leads to a reassertion of nationalism.

Instead of freeing Japanese from local attachment (to Japan) and prejudices against foreigners in Japan or against locals abroad, Japanese experience with foreigners at home and in foreign countries seems to renew their attachment to their fatherland and even awaken their prejudices against locals or foreigners (such as Southeast Asians) to whom their sense of prejudice in the past was at best merely dormant. Instead of leading directly by the shortest and surest road to the cosmopolitan world, internationalization, at least for Japan, leads to the opposite world, as if each internationalization process is a U-turn, returning to renewed nationalism (p. 246).

Although it may appear that the Ministry of Education keeps a rigid and conservative standpoint concerning international education, it is also true that general confusion and ambiguity about the meaning of an international educational experience exists within the ministry itself (White, 1988). This confusion and ambiguity blurs the teacher's position toward the returnee children, which consequently 
hinders those children's smooth reentry into the Japanese culture.

THE SIGNIFICANCE OF PREPARATION AND THE PARENTAL ROLE IN CHILDREN'S REENTRY

\section{Significance of Preparation}

As discussed previously, while culture shock is an expected phenomenon of overseas sojourn, reentry shock is often an unexpected experience. If people have expectation of the same kind of interacting as before, the landing, when reality hits, can be quite jarring (Wallack and Metcalf, 1981, p. 14). Because of this, several scholars point out that preparation is essential to reduce the reentry crisis faced by the returnees.

Piet-Pelon (1986), a Foreign Service spouse who is an international population/family-planning consultant, states that the entire overseas experience should be, in a sense, a preparation for reentry (p. 30). Irish (1986) presents ten important rules for reentry which overseas Foreign Service employees must keep in mind when they leave the diplomatic profession. Guither and Thompson (1986) provide a pragmatic discussion of reentry by stating:

Making plans for return should begin before you leave the U.S. if your overseas assignment is for one to two years. If you are on a longer assignment, some plans will begin from six to twelve months before you depart from your overseas post (p. 208).

Reentry shock is even more painful and stressful than culture shock. Brislin and Van Buren (1986) introduce the 
theoretical concept of Janis who wrote about preparation for stressful events as follows:

- . worrying about potentially stressful events is helpful. Such work can force the person to learn as much as possible about the event, to prepare for its negative efforts so as not to be surprised by them, and to envisage what he might do if any of the negative effects indeed occur ( $p .221$ ).

Brislin and Van Buren conducted Reentry/Transition workshops at the East-West Center in Hawai based on the principles expressed by Janis (Brislin, 1974). They emphasize that through regarding reentry shock as an expected phenomenon and preparing for it, people can reduce the shock which will be experienced upon reentry.

\section{Parental Role}

Concerning the parental role in cross-cultural transition Eakin (1979) states:

The role of the parents in the adjustment is clear. Children whose parents are supportive and positive about the move will be able to make the transition more easily. Continuity and support are very important for children, and it is up to the family, especially one with a mobile life style, to provide that (p. 22 ).

Harrell(1986), pointing out that "the home is the vital key to a positive experience for our young people" (p. 201), states that many parents do not prepare their children because they themselves do not expect reentry shock. Concerning U.S. adolescents returning to the home country, Eakin (1979) states:

This is a good time, then, to reiterate and discuss the family's value system in order that the adolescents have a clear idea of where parents stand 
and what they expect, and the parents have an awareness about the feelings of their teenagers (p. 22 ).

This statement indicates the importance of parents' preparation for their children's reentry through discussion.

Maintenance of Japanese Language Ability. What should parents do to prepare their Japanese children overseas for their return home? Usually the importance of helping the children to maintain their Japanese language ability is emphasized. As an important parental role for future Japanese returnee children, Domoto (1987) warns that "an emphasis on English at the expense of Japanese damages the child's identity as a Japanese and causes many problems in later life" (p. 37). After reviewing a survey conducted by the New York Japanese School, she recognized that linguistic problems arise among students even with less than two full years of residence abroad.

In their efforts to study English intensively to adapt to their new surroundings, they forget the Japanese they learned in their elementary schools in Japan or, at the least, come to use it clumsily. This tendency is particularly strong when parents enthusiastically encourage English mastery at home. As a result of this linguistic confusion, the children become unreceptive to intellectual stimuli in either language and have increased difficulty in mastering the basics of learning or advancing in conceptual and social reasoning (p. 36).

Suzuki (1979) states that being proficient in a foreign language can bring about a serious problem in Japanese society. This problem is concerned with the ambiguity of one's own cultural belongingness, which indicates a so-called "identity crisis" (pp. 22-23). He points out that in the 
mid-1960's many parents abroad encouraged their children to study a foreign language during their overseas sojourn, thinking that they would regain their Japanese language ability soon after they returned to Japan. However, Iinguists believe that if the children are exposed to the foreign environments before the linguistic sense of their native language is established, their foreign experience will result in a negative effect. In other words, rather than becoming a Japanese who maintains Japaneseness and at the same time is also skillful in a foreign language, they are likely to become a strange Japanese who does not have any aspect of Japaneseness. When these kinds of young Japanese return to Japan, they tend to suffer from serious identity shock sooner or later. Adding to the fact that they are lacking in the knowledge of Japanese language and culture, they are possessed by the feelings that they are an outsider in Japan. Suzuki's main point is that in order to prevent this kind of problem from occurring to the returnee children, the parents should encourage their children to use only the Japanese language at home. For through interacting with their parents in their own language children will acquire the thought pattern and values which are peculiar to the Japanese culture. Kikoku Shijo Kyoiku Manyuaru (Parent's Manual for Educating Children Overseas) (Hasebe, 1985) supports this idea, stating that the basic structure of our thought pattern and principle is acquired through our own language (pp. 64-65). Through the subtle function which each language holds, our 
personality and national characteristics are formed. This follows the principle of the Sapir-Whorf hypothesis (Hoijer, 1985). Following the extreme view of this theory of linguistic determinism, this could mean that if a Japanese child is raised only through a foreign language, possibly his/her mental structure and behavior will be formed like a native speaker of that language. It is up to the parents of the children who are living in a foreign country to counteract the foreign language influence; an influence which could result in a serious barrier to their children's involvement in social activities as a Japanese in the future. Even if the children are proficient in speaking foreign languages, familiar with foreign cultures, and have grown up in the foreign environments, they will never be thought of as a foreigner in Japan. However, to be a Japanese means to have a thorough knowledge of Japanese, to have a clear understanding of the country, and to have a sense of being Japanese. It is important to prevent the children from becoming "foreigners" in their own country without the privileges of being different that are extended to other foreigners. It is essential at least to help them keep their Japanese language ability. Kikoku Shijo Kyoiku Manyuaru emphasizes that it is the parents who should play an active role in this matter, and that no one except the parents will be able to accomplish this task.

In summary, language has much to do with the personality formation of the children, which consequently results in 
the formation of their own cultural identity. The literature tends to focus on the parental role of the preparation for the children's reentry only from the viewpoint of the language, and it does not state the importance of communication between parents and children about the other potential problems which the children may face after returning to Japan.

Motivation to Retain Identity. Minoura (1981a) did extensive research on the process of personality formation of the Japanese children who stayed in America for an extended time. He states that although overseas sojourn is generally considered to be karizumai (temporary residence) by the parents, it is difficult for children, prior to the stage of the personality formation, to think of it in the same way (p. 20). Enloe and Lewin (1987), report Minoura's findings that the desire to retain a sense of Japanese identity remains strong for parents and it probably contributes to the relative ease of their own readjustment to Japan.

While parents participate and integrate into the foreign culture to a greater or lesser degree, for most there is no fundamental confusion generated around issues of identity--they perceive themselves clearly as Japanese citizens living for a temporary period of time outside their homeland who have been given an opportunity to experience life in another country (p. 240).

The situation is totally different for children who are still at an age when their identity has not yet been stabilized. Minoura (1981a) states that for children under 14 or 15 years of age every place becomes their honzumai (true residence) (p. 21). She laments that most of the parents are not aware that their children go through this different stage 
than theirs while they are living abroad. The children's personality is formed through absorbing the way they see people interacting with each other, and the behavior and thought patterns peculiar to the foreign culture to which they belong, however temporarily. This unawareness of the difference of their acculturation prevents parents from recognizing potential problems which their children will face after returning to Japan. In order to do a successful reentry, "parents need to be aware of what kind of experiences their children had during their sojourn abroad, and need to make a great effort to build a bridge with the parent-child relationship" (Minoura, 1981a, p. 21). As Wallack and Metcalf (1982) point out, "family members need to have the opportunity to spend quality time with each other, time when sharing and real communication take place" (p. 22). Here they suggest that parents spend some special time with each of their children each week. Preparation through active communication plays an important role in building this bridge.

\section{CONCLUSION}

While an overseas experience has positive aspects for the children, it is clear that it tends to cause serious problems upon Japanese children's reentry to their own culture. Difficulty in readjustment to the Japanese school system characterizes this problem. The returnee's psychological problem is reinforced by the school bully (ijime) 
and their teachers' inflexible attitudes toward them. Not only the conservative educational system, but also the particularism of Japanese culture (insularity of the culture, concept of group membership, ethnocentrism, and the Japanese concept of internationalization) is the major cause which makes it difficult for the returnee children to readjust to the school system.

The last section of this chapter has presented the central idea of the present research. The literature has demonstrated that the entire overseas experience should include a preparation for reentry. If they have prepared for potential problems, the impact they experience upon reentry can be reduced. The parent's active role is vitally important for successful reentry of their children. Some significant points which the Japanese parents must keep in mind were also discussed here.

In the present study deviance from one's own culture is regarded as a negative effect of cross-cultural experience for Japanese returnee children. However, it does not mean that this researcher encourages Japanese parents to strip off every aspect their children acquired through sojourn in America. It is essential to understand that because of the unique Japanese cultural characteristics, in the Japanese returnee's case, it is advantageous to look at, and prepare for the potential problems which may be incurred by overseas sojourn. The following is a list of potential problems experienced by Japanese returnee children: 
Language issue:

1. Because of Japan's particularism, returnee children's high English proficiency could become a serious barrier to their readjustment to the schools in Japan.

2. Because of Japan's particularism, returnee children's reduced Japanese ability, due to intensive use of English, could become a serious barrier to their readjustment to the schools in Japan.

3. Returnee children's reduced Japanese ability could cause an "identity crisis" for the returnee children.

Issues other than language:

4. Losing "Japaneseness" could become a serious barrier to the Japanese returnee children's readjustment to the schools in Japan.

a. Changes in terms of values, ways of thinking, behavioral patterns, and communication styles could occur to the person who has sojourned in a foreign country. The Japanese children who have lived out of Japan, especially in the U.S., could be much influenced in terms of these intercultural aspects.

b. Because of Japan's particularism, even subtle differences which occurred in the returnee children could become a serious barrier to their adjustment to the schools in Japan partly because of the reaction of their peers and their teachers being against it (see Appendix $C$ ). 
CHAPTER IV

METHODS

PURPOSE OF THE STUDY

The purpose of the present study is to discover whether Japanese parents visiting the U.S. for extended periods anticipate and are preparing themselves and/or their children to cope with the possibility of psychological and communicative problems which the returnee children may encounter in Japan.

\section{RESEARCH QUESTIONS}

The research questions in the present study are as follows :

1. Are the Japanese parents who are temporarily staying in the U.S. with their children anticipating the possibility of psychological and communicative problems their children may face as returnees?

2. To what extent do the Japanese parents discuss these potential problems with each other and/or with their children?

3. Are the Japanese parents doing anything to prepare themselves and/or their children to cope with the potential problems which their children may face 
RESEARCH METHOD

A descriptive method is employed in this research. The overall purpose of the descriptive method is to describe events, beliefs, attitudes, values, intentions, preferences, or behaviors. The main task of descriptive researchers is to systematically and objectively describe what is happening, how people feel about what is happening, or what people would like to have happen (Tucker, Weaver, and Berryman-Fink, 1981, p. 90).

The subjects used in this study are Japanese nationals who are temporarily living in the United States. Considering the fact that the Japanese in general are not accustomed to being subjects in a survey research (Barna, 1988), and that language and cultural differences are limitations in any cross-cultural research, it would be difficult to obtain the defined conditions which are needed for an experimental method.

Face-to-face interviews were not used as a data collection technique for two reasons. First, White (1988), who conducted interviews of the Japanese returnee families, states that "particularly in Japan, where these [insider and outsider] categories have great weight, an outsider is at a paradoxical advantage" (p. 128). Although white did not give the reason for this apparent contradiction, two things can be considered as possible reasons. One is the general adverse Japanese attitude toward criticism of people and/or country 
within Japan. As stated in the literature review, since they value a harmonious relationship in the group, any criticism in Japan is actively discouraged. Therefore, in an interview it is likely that the subjects would not disclose their feelings. The other reason is that when Japanese people have a foreigner as a guest, especially if he/she is a westerner, they try to meet his/her needs as much as they can in order not to disappoint that person. In considering these facts, this researcher's presence as a Japanese could have been a hinderance during the interview phase of this study.

Second, White (1988) states that when she interviewed a Japanese husband and wife together, the wife deferred to the husband. In the Japanese culture, it is quite usual for the wife to restrain from giving her own opinion in public when she is with her husband. The present researcher might encounter the same situation in conducting an interview. Since it is the mothers who are mainly responsible for the raising of the chilaren, her views are important to this research. The Japanese husband would probably not want to use his time to cooperate with this kind of survey, yet he might be present under interview conditions. Because of these factors, mailing a questionnaire to mothers was chosen as the best method for the study.

Questions used for this study were a combination of open and closed-ended questions depending on the type of information that was elicited from the subjects. Three types of closed-ended questions were used: a 5-point Likert scale, 
discrete yes or no questions, and multiple choice questions. The data was tabulated by percentage. For the open-ended questions content analysis was used, suggesting themes which emerged from those questions. The results of a content analysis typically represent the frequency with which responses are placed into each theme associated with the chosen nominal scale (Smith, 1988, p. 267). In this research each response given by the subjects to each open-ended question was clustered into content themes. The content themes were analyzed as to their consistency with the returnee children's problems discussed in the Iiterature (Appendix $C$ ). Themes were established by the researcher according to the problems expressed by the returnee children and parents (Appendix D).

In order to establish interrater reliability Japanese graduate students in the Speech Communication Department at Portland State University acted as coders. Each coder individually clustered specific responses from each of the subjects open-ended questions into established themes. During the process of coding responses, no communication between the coders took place. The interrater reliability coefficient for clusters within the themes was strong $(+0.83)$. Content analysis was made of the themes (except for question $6 \mathrm{~b}$, which was asked to elicit information for separate data analysis) obtained from all the subjects. Demographic analysis was also done according to the following categories: 1. Sex of the subjects' children (male vs. female). These subjects will be referred to as MC's Vs. FC's hereafter. 
2. Age (children at the ages of 9-15 vs. children younger and older). These subjects will be referred to as 915 's vs. N9-15's ("not belonging to 9-15").

3. Subjects' specific feelings being assigned to the U.S. prior to leaving Japan (positive vs. negative). These subjects will be referred to as Pta's ("positive toward assignment") vs. Nta's ("negative toward assignment").

4. Subjects having lived previously in the U.S. because of their husbands overseas assignment vs. subjects without any previous experience in the U.S. These subjects will be referred to as Pa's ("previous U.S. assignment") vs. Npa's ("no previous U.S. assignment").

5. Subjects who overtly prepared for living in the U.S. vs. those who did not do any preparation. These subjects will be referred to as Pfa's ("preparation for assignment") vs. Npfa's ("no preparation for assignment").

When the researcher indicates category of demographic information, not subjects themselves, the "'s" attached after each abbreviation will be left out. Several items were omitted because of too few or no subject responses. For example, only 2 subject-families will be returning to Japan within the next 6 months. Therefore, question 5 of the questionnaire was omitted from separate data analysis.

\section{OPERATIONAL DEFINITIONS}

There are two specific terms which need to be defined in this study. 
1. Reentry. As described in the beginning of Chapter II, some scholars define this term as "readjustment of the sojourners into their own home culture" or the "readapting of the individual to the home environment after an extended stay in another culture." It is interesting to note that those commonly accepted definitions in the field of intercultural communication are based on the value of individualism since they imply that it is the individual goal of each person to readjust to his/her own home environments. However, White (1988), focusing on the value of group membership in the Japanese culture, defines reentry as "establishment of relationships to the satisfaction of those at home" (p. 106). For the purpose of this research, based on White's definition, the term "reentry" will be defined as "the process of reestablishment of relationship upon return to Japan to the satisfaction and expectation of those at home, particularly the teachers and other students at school which the Japanese returnee children will enter after their return."

2. Returnees. Through an interview with the principal at the Portland Japanese School, the researcher learned that a Japanese businessman who is assigned overseas would usually leave his children with his wife in Japan if his assignment is less than a year. Taking this into consideration, in the present study returnees are defined as those children who have been living in the U.S. with their parents for at least a year and are planning to return to Japan. 
POPULATION

The population in this study is made up of Japanese parents, specifically the mothers, in the Portland-Vancouver metropolitan area. The subjects of the questionnaire were selected from the Portland Japanese School, one of the Saturday Schools where Japanese children living with their parents abroad study Japanese language and mathematics. The target subjects of this study were Japanese families who are expecting to return to Japan in the future. Usually these families send their children to the Japanese school to help them keep up with their studies. Therefore, it was considered that the researcher would be able to collect appropriate subjects easily at this school. Since these families are trying to prevent their children from falling behind in their studies and facing readjustment problems to the Japanese educational system, they are more likely to be concerned with other reentry issues than those families who do not send their children to this school.

There were 158 students enrolled at the school. Among them there were 6 students who are children of intercultural marriages. These were eliminated from this study. If more than 2 children from a family attend this school, they were counted as 1 family. After these adjustments there were 91 Japanese families eligible for the present study. Before the questionnaires were mailed to all 91 mothers, an application for review of the research project was submitted 
to the Human Subjects Research Review Committee at Portland State University. The study met the requirement and was subsequently approved (Appendix E).

\section{QUESTIONNAIRE DEVELOPMENT}

The questionnaire (Appendix F) was designed in an attempt to provide answers to the three survey research questions as stated at the beginning of this chapter. In order to develop the questions it was first necessary to do an extensive review of the literature to discover the accepted theoretical concepts and research findings that were identified as potential problems for Japanese returnee children (see Appendix C).

The sequencing of the questions was carefully considered so that the subjects could respond to the questionnaire easily and willingly. For example, the questions were arranged from the general to the specific. Also, in order not to control the subject's thinking pattern, the potential problems discussed in the literature review were approached indirectly in this questionnaire. The origin of the questions will be briefly discussed in the following sections. Headings used in these sections were not shown in an actual questionnaire.

Demographic Information

The following 5 questions were asked in order to screen out inappropriate subjects and/or to provide demographic information for data analysis. 
Question 1 asked the length of sojourn of the subject's family. As defined for this study, "returnees" means the Japanese future returnee children who have lived with their parents in the U.S. for more than a year. The main reason for asking this question was to eliminate inappropriate subjects who did not fit in this definition.

Question 2 asked the children's age and sex in order to be able to investigate whether differences existed in the results depending on age and/or sex. Separate analysis for the chiloren's age stems from Minoura's (1987) statement that if the children spent their life at the age of $9-15$ in America, they tend to be psychologically assimilated to the meanings which exist behind the American mode of interpersonal relationship and/or behavior (p. 168).

Question 3 asked if parents (either or both) spent their childhood in foreign countries. Here childhood was defined as up to high school age. Any subject who answered "yes" was also asked to give information about the place, length of sojourn, and his/her age at that time. This question was asked in order to determine whether there were any differences in the results between the parent(s) who had overseas experience in childhood and those parents without experience.

Question 4 asked about the previous overseas assignment of the subject's family. The purpose in asking this question was to investigate the existence of differences in results between the families with a previous overseas assignment and 
those without previous experience. A subject whose family had a previous overseas experience was also asked about the language which her children used at school at that time (if they were school age).

Question 5 asked whether the subject's family would expect to return to Japan within the next 6 months. As described in the Iiterature review, Guither and Thompson (1986) suggest that parents begin to prepare for their family's reentry at least 6 to 12 months in advance of returning home. If the subject's family is planning to return within the next 6 months, it is very important for them to have begun their preparation.

Questions 6 and 7 asked how the subject felt when she heard about the present overseas assignment from her husband and its reason, and if she did anything in Japan to prepare for the present sojourn in the U.S. The purpose of these questions was to see if either positive or negative attitudes toward the sojourn and/or the parents' preparation for living abroad affected their reentry preparation for their children.

\section{Questions to Elicit Responses} to Research Question One in Regard to Language

Research question 1 asks, "Are the Japanese parents who are temporarily staying in the U.S. with their children anticipating the possibility of psychological and communicative problems their children may face as returnees?" It has been determined that because of Japan's conservatism represented 
by uniformity and predictability, returnee children's English proficiency tends to be regarded as a disturbing element in the classroom situation, and it is likely to cause friction between returnees themselves and their teachers and/or other children (Enloe and Lewin, 1987; White, 1988). The following 2 questions were designed to discover how many subjects were anticipating these problems. Question 8 asked how the subject judged her children's English proficiency, and question 9 asked what advantages and/or disadvantages the subject believed her children would have after they returned to Japan because of their advanced English ability. Question 9 was an open-ended question with both advantages and disadvantages being asked in order to prevent giving any bias to the respondents.

The importance of maintaining Japanese language ability was emphasized in the literature review. One reason is that poor Japanese language ability can cause friction between the returnee children and their teachers and/or other children at school. In order to see the mother's anticipation of this issue, question 10a asked, "How important do you think it is for your children to maintain and/or improve their Japanese language ability in preparation for return to Japan?" In question $10 \mathrm{~b}$ the subject was asked to explain the reason why she thought this way. 
Questions to Elicit Responses

to Research Question One in

Regard to Issues other

than Lanquage

As specified in the literature, there are potential problems for their children's reentry to Japan, other than the language issue, which parents need to anticipate.

Question 18 asked, "How important do you think it is for your children to maintain their 'Japaneseness'?" The literature emphasizes the importance of this factor. "Japaneseness" means to behave exactly the same as other Japanese do. The literature states that with the loss of Japaneseness, they are regarded as an outsider, and ostracized by their peer group (LaBrack, 1983, Impoco, 1988).

As another important reentry issue, the literature states that the changes in connection with values, ways of thinking, and behavioral patterns happen to the people who have sojourned abroad for an extended period of time (Kagitcibasi, 1978; Austin, 1986; Brislin, 1981). In the case of the Japanese returnee children, even a little difference can be taken seriously (White, 1988) and result in ostracism and bullying at school. These differences could cause difficulties in both the relationship between the returnees and their teachers and/or peer group. The following 3 questions were designed to discover whether the mother was anticipating these issues.

Question 19 asked, "Are you aware of any changes in your children since they arrived in the U.S. in regard to 
their values, ways of thinking, and behavioral patterns?" Question 20 asked the subjects who answered "yes" to question 19, "Do you believe that these changes are or will be strong or serious enough to make your children appear different from those Japanese children who have never lived outside of Japan?" Question 21 asked the subjects who answered "yes" to question 20, "Do you expect these differences to cause any difficulties for your children's reentry to Japan?"

\section{Questions to Elicit Responses}

\section{to Research Question Two in}

Regard to Language

Research question 2 asks, "To what extent do the Japanese parents discuss these potential problems with each other and/or with their children?"

Questions 12 and 13 asked about the subject's communication with her husband and children concerning the language issues described from questions 9 to 11 . This stems from Kaigai Shijo Kyoiku Manyuaru (Parents' Manual for Educating Children Overseas) (Hasebe, 1985) which states that it is the parents who should play an active role in helping their children to maintain their Japanese language ability, and no one except the parents will be able to accomplish this task. This parental role should be reflected through communication between the spouse and/or children. Question 12 asked, "Have you ever discussed such language issues as those mentioned in questions 9 to 11 with your husband?" Question 13 asked, "Have you ever discussed these same language issues with your children?" 
For additional information, question 14 asked the respondent who seldom or never discussed the issues with her husband and/or children why she did not have a discussion with her family members.

\section{Questions to Elicit Responses} to Research Question Two in Regard to Issues other than Language

Question 22 asked, "Have you ever discussed such issues as those mentioned in questions 18 to 21 with your husband?" Question 23 asked, "Have you ever discussed these same issues with your children?"

As stated by Wallack and Metcalf (1982), family members need to provide an opportunity for verbal communication. Kaigai Shijo Kyoiku Manyuaru (Parents' Manual for Educating Children Overseas) stresses the importance of the parental role in maintaining their children's Japanese language ability. It will also be important for parents to show their anticipation of the other issues by discussion. Questions 22 and 23 were asked to determine whether the subjects' behavior met these goals.

Questions to Elicit Responses to

Research Question Three in

Regard to Children's

Reentry Issue in

Genera1

Research question 3 asks, "Are the Japanese parents doing anything to prepare themselves and/or their children to cope vith the potential problems which their children may 
Question 11 regarded maintaining their Japanese language ability. It asks what language the subjects' children usually spoke in their home in the U.S. and the reason for using that language in the home. As the literature says, in order to prevent the returnee children from experiencing "identity crises," the parents should encourage their children to use only Japanese at home (Suzuki, 1979; Domoto, 1987). Encouragement of constant use of the Japanese language is considered to be one of the preparations which can be done by the parents. There were several options given in this closed-ended question, but the main focus was to see how many mothers would choose item 3 which stated encouragement of Japanese language use at home. Also, item 7 was relevant to this same issue.

The literature emphasizes that preparation is important for people's reentry. Those who anticipate the potential problems will not always anticipate the necessity of preparation. Question 15 was asked to see if the mothers anticipated the necessity of preparation for their children's reentry besides just helping them keep up with their studies. This question was a preliminary question which led to the major question, 16, which asked the subjects to choose those items which described their own and/or their children's preparation for the children's reentry to Japan. 


\section{General Information}

Questions 24 and 25 were open-ended questions to elicit additional pertinent information for research questions 1 , 2 , and 3 .

\section{TRANSLATION}

Since this thesis is written in English, the questionnaire was also constructed in English first, and then translated into Japanese. In order to minimize the risk of mistakes, the following procedures were used. (1) The researcher, as the first transiator, translated the document into Japanese. (2) The researcher then asked another person (the second translator) to translate the same English document into Japanese. The second translator did not see the Japanese translation done by the researcher in this process. (3) The researcher then checked to see whether her transiation corresponded to that produced by the second translator. The researcher asked an instructor in the Department of Foreign Languages at Oregon State University to cooperate with this research by doing the second translation. No significant discrepancy was found between the original and second translation.

\section{PILOT STUDY}

The questionnaire underwent one revision before the actual survey was conducted. It was distributed as a pilot study to 2 Japanese mothers whose families had been in the 
U.S. for more than a year (Appendix G). The feedback was helpful, and these was a major revision made concerning questions $12,13,22$, and 23 . These questions asked the subject how often she had discussed the reentry issues with her husband and/or children. In the original questionnaire, the subject was asked to choose an appropriate answer from a 5-point Likert scale: 5 (more than once a week), 4 (once a week), 3 (once a month), 2 (seldom), and 1 (never). In the pilot study 1 respondent said that since the Japanese in general did not try to have an opportunity for discussion, it would be easier for them to choose an answer from "often," "not often," or "sometimes" rather than the above 5 types. However, the words suggested by this respondent are inappropriate in research because of the ambiguity. After taking this into consideration, the scale was revised into 5 (once a week), 4 (once a month), 3 (once every three months), 2 (seldom), and 1 (never) (see Appendix F).

\section{MAILING}

A cover letter was carefully constructed in order to promote the subject's cooperation (Appendix $H$ ). In the letter subjects were informed of: (1) the identification of the person conducting the research; (2) the significance of the present research; (3) the significance of the subjects' cooperation; and (4) the assurance of anonymity and confidentiality. It was also written in the cover letter that a 
copy of the thesis would be donated to the Portland Japanese School. In Japan, people need to have a mediator of high status before asking for someone's cooperation directly. Therefore, in the present study an authority's recommendation was considered to have a positive effect on the cooperation of the Japanese. Recommendation papers from the researcher's academic and thesis adviser (Appendix I), and a chairman of the Board of Education at the Portland Japanese School (Appendix J) were therefore enclosed with the questionnaire. A self-addressed, stamped return envelope was also enclosed with each questionnaire.

Of the 91 questionnaires in the first mailing, 40 were returned. As Bailey (1982) states, "there seems to be consensus that the response rate can be greatly improved through follow-ups, and nearly all mailed studies now use follow-ups as standard operating procedure" (p. 170). In the present study a follow-up letter was sent after 3 weeks (Appendix $K$ ), and 17 more questionnaires were returned. As a result, the response rate increased from $44.0 \%$ to $62.6 \%$. Tucker, Weaver, and Berryman-Fink (1981) present the guidelines, proposed by Lin as follows: $50 \%$ or higher is adequate, $60 \%$ or higher is good, $75 \%$ or higher is very good (p. 16). Through the subjects' demographic information it was found that 16 families had been in the U.S. for less than a year, and they were eliminated from the present study. Finally, 41 questionnaires were appropriate for this study. 
CHAPTER V

RESULTS AND INTERPRETATIONS

The purpose of the present study was to discover whether Japanese parents in the U.S. anticipate and are preparing themselves and/or their children to cope with the possibility of psychological and communicative problems which their children may encounter as returnees in Japan. This chapter will be devoted to reporting the results of the questionnaire based on the procedure described in Chapter IV, together with the interpretations of the data. For ease in reading, the results will appear in the same order as on the questionnaire.

Questions 1 through 5 provided demographic information to be used to select appropriate subjects and to provide information for separate data analysis. In question $6 a$ the subject was asked, "How did you feel when you heard about this present overseas assignment from your husband?" In this question 14 out of the 38 (36.8\%) who responded chose either 5 (very pleased) or 4 (somewhat pleased), 12 subjects (31.6\%) chose 3 (neutral), and 12 subjects (31.6\%) chose either 2 (not pleased) or 1 (very displeased). Thus, almost the same number of the subjects had either positive, neutral, or negative feelings about the present U.S. assignment prior to leaving Japan. 
Question $6 \mathrm{~b}$ elicited the reason for these feelings. The following themes emerged from the 28 subjects who responded to this part of question 6 : curiosity about overseas living, benefit for the family, and anxiety (see Appendix D). The overall interrater reliability coefficient for the cluster with the themes was strong $(+0.83)$.

of the 28 respondents, $12(42.9 \%)$ had positive feelings about the present U.S. assignment because of their curiosity about living abroad. Four subjects considered that living in the U.S. would be beneficial for their family. Among the total 28 subjects, $19(67.9 \%)$ had some anxiety about the present U.S. sojourn prior to leaving Japan. Eleven subjects (57.9\%) reported anxiety about speaking the English language, safety in the host country, leaving their familiar place in Japan, and quitting their own job. Eight subjects (42.1\%) expressed anxiety about their children's education. For example, one mother reported, "I was so worried about my first son who had to remain in Japan because of preparation for his entrance examination." Although they reported their anxiety about their adjustment and/or readjustment to the educational system of either the U.S. or Japan, no subjects reported concern for their children's reentry in terms of the issues other than educational systems.

Question 7 asked, "Did you do anything in Japan to prepare for living in the U.S.?" It was found that 33 subject $(80.1 \%)$ made some preparation for living in the U.S., while 8 subjects $(19.5 \%)$ did not do any preparation prior to 
leaving Japan. Twenty-one subjects $(63.6 \%)$ attended orientation programs for living overseas sponsored by their spouses' company and/or other organizations. Nineteen subjects (57.6\%) read a book(s) about the U.S. Fifteen subjects (45.5\%) talked with their acquaintances who had an experience of overseas assignment in the U.S. Five subjects gave other answers. Three of them reported that their children or the subjects themselves studied English conversation, and 2 subjects reported that they talked with their husbands who had studied in a U.S. college and/or their acquaintances who had lived overseas other than in the U.S. The remainder of the questionnaire is directly related to the research questions as follows.

RESEARCH QUESTION ONE

Are the Japanese parents who are temporarily staying in the U.S. With their children anticipating the possibilty of psychological and communicative problems their children may face as returnees?

Question 8 on the questionnaire provided information in regard to the issue of language: "How would you judge your children's English proficiency?" As shown in Table II, $50 \%$ of the subjects considered that their children had advanced English proficiency. This means that at least half of the children could be victims of school bullying after they return to Japan. Since $56 \%$ of the subjects were found to have been in the U.S. for less than 3 years, it is likely 
that many more children will become proficient in English before they leave America.

TABLE II

CHILDREN'S ENGLISH PROFICIENCY

\begin{tabular}{lcc}
\hline \hline Ordinal Scale & No. of & Responses \\
\hline 5 - Very Good & 9 & 22.5 \\
4 - Good & 11 & 27.5 \\
3 - Fair & 14 & 35.0 \\
2 - Poor & 5 & 12.5 \\
1 - Very Poor & $\frac{1}{40}$ & $\frac{2.5}{100.0}$ \\
\hline
\end{tabular}

Question 9 asked, "Obviously your children will have better English speaking ability than those Japanese children who have never left Japan. What advantages and/or disadvantages do you believe your children will have after they return to Japan because of this English ability?"

Three themes regarding advantage and 4 themes regarding disadvantage emerged from the subjects' responses. They are as follows: advantages--social necessity and/or desirability of knowing the English language, academic reasons, and cultural enrichment; disadvantages--reduced Japanese language ability, difficulty of maintaining good social relationships with people at school and/or in the community, academic reasons, and more limited occupations (see Appendix D). 
of the 18 subjects, $11(61.1 \%)$ considered that children's advanced English proficiency was advantageous because of social necessity and/or desirability of knowing English if employment is sought in an international occupation. One subject reported, "It is advantageous because good English ability is indispensable in the present international society." Another subject said, "Having advanced English proficiency helps Japan to be internationalized." This theme is not pertinent to the present research, but it describes Japan's great interest in the notion of "internationalization" which was discussed in the literature review. As a subject commented, "In the present Japanese society English ability is considered to be indispensable in order to be engaged in an international occupation."

of the 18 subjects, $9(50 \%)$ considered that their children's advanced English proficiency was advantageous because of academic reasons. One subject reported, "If my children can maintain their English ability, it will be advantageous for their entrance examination." Another subject reported, "My children will not have a harder time in studying English at school than those children who have never been abroad." This theme is not related to the focus of the present study; however, it is consistent with Enloe and Lewin's (1987) statement that the problems which have received much attention concerning the issue of the returnee children is how to readjust to the Japanese educational system by successfully 
competing in the rigorous entrance examination ordeal (pp. 224-225).

Two subjects $(11.1 \%)$ considered that having an advanced English proficiency was advantageous because of cultural enrichment. It indirectly supports the positive aspect of cross-cultural experience discussed in the literature review. One subject reported, "Through foreign language acquisition children will be able to understand the culture and a different way of thinking in the country of that language." The other subject reported, "Foreign language acquisition enabled my children to acquire not only the language itself, but also an American culture in a broader sense. They could learn to cope with the problems by themselves."

of 24 subjects, $11(45.8 \%)$ considered that their children's reduced Japanese language ability was a disadvantage for the children's reentry to Japan. This theme is directly related to the Japanese returnee children's potential problems discussed in the literature. One subject who has a previous overseas experience reported, "My children's Japanese ability is getting inferior day by day. They will have a much harder time than before when they return to Japan." Another subject reported, "I am worried if my children can speak Japanese as well as the other children at their age in Japan do."

of 24 subjects, $11(45.8 \%)$ considered that because of their children's advanced English proficiency, they may have difficulty in maintaining good social relationships 
with people at school and/or in the community. This is a theme which is directly pertinent to the focus of the present study. One subject reported, "I am worried if my children would be bullied because of the different English pronunciation from that of the other children in Japan." Another subject reported, "If my child can speak English better than her English teacher at school, the class will become boring to her, and the teacher will also regard my child as a burden in the class. I think that such unbalance is one of the causes of school bully."

of the 24 subjects, $4(16.7 \%)$ considered that their children's advanced English proficiency was disadvantageous because of academic reasons. One subject reported, "Since my children learned natural English in America, not English for entrance examination, I am worried if they are lacking in an ability to understand English grammar in Japanese." This theme is not relevant to the focus of this study, however, this is one example to show how much the mothers in this study are concerned with the children's reentry issue from an academic point of view.

of the 24 subjects, $1(4.2 \%)$ considered that her children's advanced English proficiency would result in more limited occupations. This theme is indirectly relevant to the focus of this study. In other words, returnees' advanced English ability makes it difficult for them to be engaged in a variety of jobs in the future. 
In this question 3 themes which were related to the Japanese returnee children's potential problems discussed in the Iiterature emerged, and those were: (1) reduced Japanese language ability; (2) difficulty of maintaining good social relationships with people at school and/or in the community; and (3) more limited occupations.

A demographic breakdown of question 9 is reported as follows. As shown in Table III, MC's, 9-15's, Nta's, Npa's, and Npfa's anticipated the present issue more than the counterpart in each category. There was only a slight difference in terms of the children's sex. 
TABLE III

PERCENTAGE OF SUBJECTS WHO REPORTED THEMES

REGARDING JAPANESE RETURNEE CHILDREN'S POTENTIAL PROBLEMS IN QUESTION 9

Category

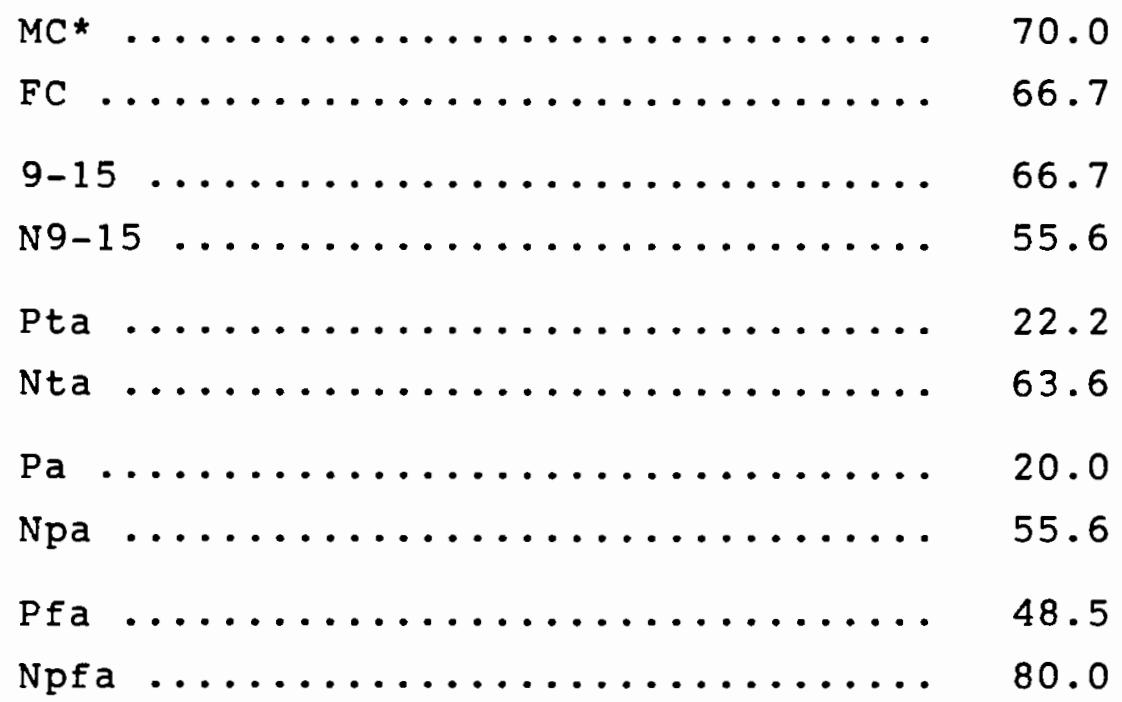

$\star M C=$ subjects with only male children; $F C=$ subjects with only female children; $9-15$ = subjects with children in the $9-15$ age category; $\mathrm{N} 9-15$ = subjects with children not in the 9-15 age category; Pta = subjects who had positive feelings about the present U.S. sojourn; Nta = subjects who had negative feelings about the present U.S. sojourn; $\mathrm{Pa}=$ subjects who had a previous U.S. assignment; $\mathrm{Npa}=$ subjects who had no previous U.S. assignment; Pfa = subjects who prepared for the present U.S. sojourn; Npfa = subjects who did not prepare for the present U.S. sojourn.

Question loa asked, "How important do you think it is for your children to maintain and/or improve their Japanese language ability in preparation for return to Japan?"

Table IV indicates that $92.7 \%$ of the subjects anticipated the importance of their children's maintaining and/or improving their Japanese language ability for their reentry. The mean of parents' awareness in this issue was 4.4 . 
TABLE IV

SUBJECTS' ANTICIPATION OF THE IMPORTANCE OF THE JAPANESE LANGUAGE FOR THEIR CHILDREN

\begin{tabular}{lcc}
\hline \hline ordinal Scale & No. of Responses & $\%$ \\
\hline 5 - Very Important & 21 & 51.2 \\
4 - Important & 17 & 41.5 \\
3 - Neutral & 2 & 4.9 \\
2 - Not So Important & 1 & 2.4 \\
1 - Not Important at A11 & $\frac{0}{41}$ & $\frac{0.0}{100.0}$ \\
\hline
\end{tabular}

As shown in Table V, MC's, 9-15's, Pta's, Npa's, and Npfa's showed more anticipation of the present issue than the counterpart in each category. There was a smaller difference in terms of the category which described the subjects' feelings about the present U.S. living situation. 
TABLE V

RESULTS OF THE DEMOGRAPHIC DATA ANALYSIS IN QUESTION $10 \mathrm{a}$

\begin{tabular}{|c|c|c|c|c|}
\hline \multirow[t]{3}{*}{ Scale } & $\begin{array}{c}\text { No. of } \\
\text { Responses }\end{array}$ & $\%$ & $\begin{array}{l}\text { No. of } \\
\text { Responses }\end{array}$ & $\%$ \\
\hline & \multicolumn{2}{|c|}{$M C *$} & \multicolumn{2}{|c|}{ FC } \\
\hline & \multicolumn{2}{|c|}{$($ Mean $=4.57)$} & \multicolumn{2}{|c|}{$($ Mean $=4.17)$} \\
\hline 5 & 9 & 64.3 & 5 & 41.7 \\
\hline 4 & 4 & 28.6 & 5 & 41.7 \\
\hline 3 & 1 & 7.1 & 1 & 8.3 \\
\hline 2 & 0 & 0.0 & 1 & 8.3 \\
\hline 1 & 0 & 0.0 & 0 & 0.0 \\
\hline \multirow[t]{2}{*}{ TOTAL } & 14 & 100.0 & 12 & 100.0 \\
\hline & \multicolumn{2}{|c|}{$\begin{array}{c}9-15 \\
(\text { Mean }=4\end{array}$} & \multicolumn{2}{|c|}{$\begin{array}{c}\text { NQ-15 } \\
(\text { Mean }=4.07)\end{array}$} \\
\hline 5 & 14 & 51.9 & 7 & 50.0 \\
\hline 4 & 12 & 44.4 & 5 & 35.7 \\
\hline 3 & 1 & 3.7 & 1 & 7.1 \\
\hline 2 & 0 & 0.0 & 1 & 7.1 \\
\hline 1 & 0 & 0.0 & 0 & 0.0 \\
\hline \multirow[t]{2}{*}{ TOTAL } & 27 & 100.0 & 14 & 99.9 \\
\hline & \multicolumn{2}{|c|}{ Pta } & \multicolumn{2}{|c|}{ Nta } \\
\hline 5 & 8 & 57.1 & 8 & 66.7 \\
\hline 4 & 6 & 42.9 & 3 & 25.0 \\
\hline 3 & 0 & 0.0 & 0 & 0.0 \\
\hline 2 & 0 & 0.0 & 1 & 8.3 \\
\hline 1 & 0 & 0.0 & 0 & 0.0 \\
\hline TOTAL & 14 & 100.0 & 12 & 100.0 \\
\hline
\end{tabular}


TABLE V

RESULTS OF THE DEMOGRAPHIC DATA ANALYSIS

IN QUESTION $10 \mathrm{a}$

(continued)

\begin{tabular}{|c|c|c|c|c|}
\hline Scale & $\begin{array}{l}\text { No. of } \\
\text { Responses }\end{array}$ & $\%$ & $\begin{array}{c}\text { No. of } \\
\text { Responses }\end{array}$ & $\%$ \\
\hline & \multicolumn{2}{|c|}{$\left.\begin{array}{c}\mathrm{Pa} \\
(\text { Mean }\end{array}=3.80\right)$} & \multicolumn{2}{|c|}{$($ Mean $\stackrel{\text { Npa }}{=} 4.50)$} \\
\hline 5 & 1 & 20.0 & 20 & 55.6 \\
\hline 4 & 2 & 40.0 & 15 & 41.7 \\
\hline 3 & 2 & 40.0 & 0 & 0.0 \\
\hline 2 & 0 & 0.0 & 1 & 2.8 \\
\hline 1 & 0 & 0.0 & 0 & 0.0 \\
\hline TOTAL & 5 & 100.0 & 36 & 100.0 \\
\hline \multicolumn{3}{|c|}{$($ Mean $=4.25)$} & \multicolumn{2}{|c|}{$\begin{array}{c}\text { Npfa } \\
(\text { Mean }=4.45)\end{array}$} \\
\hline 5 & 3 & 37.5 & 18 & 54.5 \\
\hline 4 & 4 & 50.0 & 13 & 39.4 \\
\hline 3 & 1 & 12.5 & 1 & 3.0 \\
\hline 2 & 0 & 0.0 & 1 & 3.0 \\
\hline 1 & 0 & 0.0 & 0 & 0.0 \\
\hline TOTAL & 8 & 100.0 & 33 & 99.9 \\
\hline
\end{tabular}

p. 115 .

*For explanation of symbols in table, see Table III,

Question $10 \mathrm{~b}$ asked, "Please explain why you think this way." The following 3 items emerged from the subjects' responses: academic reasons, maintaining good social relationships with people at school and/or in the community, and Japanese national characteristics (see Appendix D). 
of 24 subjects, $12(50 \%)$ considered that maintaining and/or improving children's Japanese language ability was very important because of academics. This shows the mothers' concern for the childrens' readjustment to the Japanese educational system. One subject reported, "Japanese language ability is indispensable to keep up with their study at school." Another subject reported, "Improving children's Japanese language ability is important in order to keep up their English ability since people who have abundant Japanese vocabulary will be able to speak better English."

only 2 out of 24 subjects ( $8.3 \%$ ) considered that the present issue was very important in regard to the maintenance of good social relationships with people at school and/or in the community. This theme is directly pertinent to the present study. One of the two subjects said, "The children's Japanese language ability is important to keep company with other children in Japan."

of 24 subjects, $16(66.7 \%)$ considered that the present issue was very important because of Japanese national characteristics. This theme is also included on the 1 ist of the Japanese returnee children's potential problems. Two subthemes were included in this theme. One is related to the correspondence of the language with ethnic identity. Most of the subjects whose responses belonged to this sub-theme reported, "Japanese language is important for my children because they are Japanese." The other sub-theme is related to the necessity of communicating with people in Japan. The 
subjects reported this by stating either "My children will return to Japan in the future," or "Everyone in Japan speaks only Japanese in communicating with each other." The above content of the present theme describes the particularism discussed in the literature. People who look Japanese are expected to communicate and behave in exactly the same way as other Japanese do. One subject clearly pointed out this issue by stating: "Japanese language is very important since in the homogeneous country like Japan, even subtle differences cannot be accepted. The situation could be worse in the case of the Japanese and/or Oriental people because of their appearance."

The result of the demographic data analysis is shown in Table VI. The data indicates that FC's, 9-15's, Pta's, Pa's, and Npfa's showed more anticipation of the present issue than their counterparts in each category. However, there were only slight differences in terms of the children's sex and age. 
TABLE VI

PERCENTAGE OF SUBJECTS WHO REPORTED THEMES REGARDING JAPANESE RETURNEE CHILDREN'S POTENTIAL PROBLEMS IN QUESTION $10 \mathrm{~b}$

Category

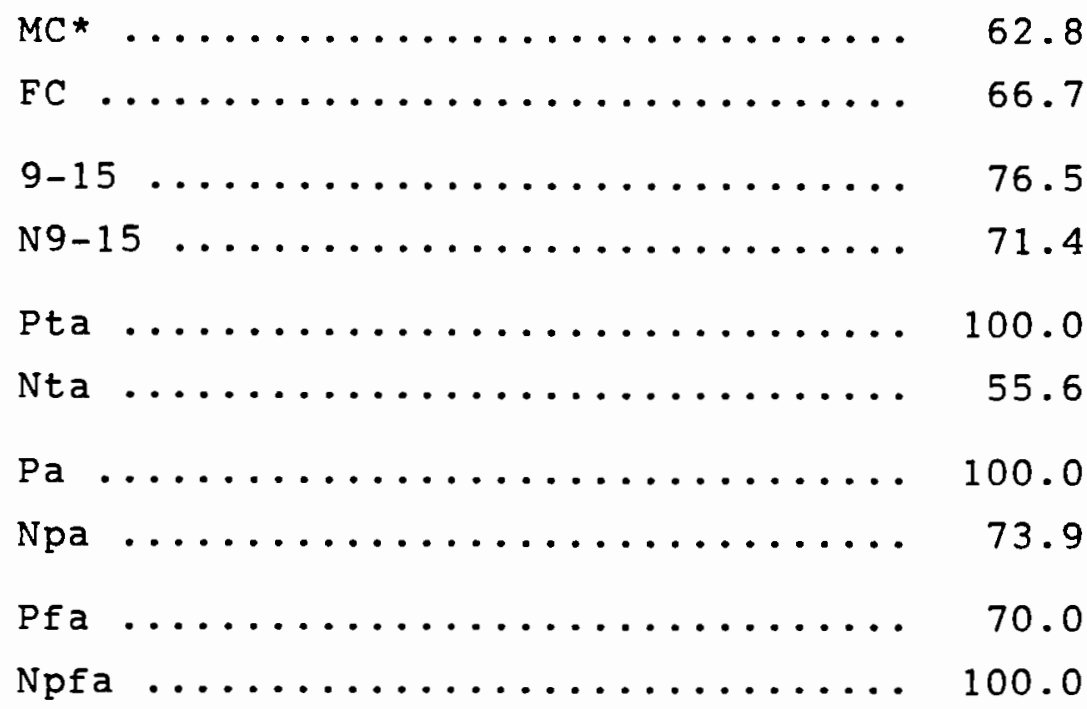
p. 115 .

*For explanation of symbols in table, see Table III,

Additionally, 2 mothers who showed neutral judgment concerning the importance of their children's Japanese language ability in question $10 a$ reported as follows: "If my children are still at the age of elementary school at the time of reentry, there would be no differences in their Japanese ability in comparison with the other children in Japan"; and, "After they return to Japan, the children's language ability will be naturally improved." Also, a subject who considered that the present issue was not so important reported, "Since my children are old enough to have a stable thought pattern, I'm not worried about this issue." 
All these reports indicate that these parents do not anticipate their children's potential reentry problems.

The questions below provided information in regard to issues other than language concerning research question 1 . Question 18 asked: "How important do you think it is for your children to maintain their 'Japaneseness'?"

As shown in Table VII, $57.9 \%$ of the subjects anticipated the importance of the children's "Japaneseness" in preparation for their reentry. However, it was found that only $18.4 \%$ of the subjects considered their children's "Japaneseness" was very important. The mean of the total subjects was 3.66 .

\section{TABLE VII}

SUBJECTS' ANTICIPATION OF THE IMPORTANCE OF "JAPANESENESS" FOR THEIR CHILDREN

\begin{tabular}{lcc}
\hline \hline Ordinal Scale & No. of Responses & $\%$ \\
\hline 5 - Very Important & 7 & 18.4 \\
4 - Important & 15 & 39.5 \\
3 - Neutral & 13 & 34.2 \\
2 - Not So Important & 2 & 5.3 \\
1 - Not Important at All & 0 & 2.6 \\
Total & 38 & 100.0 \\
\hline
\end{tabular}

Table VIII indicates that FC's, 9-15's, Nta's, Npa's, and Pfa's showed more anticipation of the present issue than their counterparts in each category. However, there were 
only slight differences in terms of the subject's previous U.S. experience and preparation for the present living situation in the U.S. (see Table VIII, pp. 124-125).

Question 19 asked, "Are you aware of any changes in your children since they arrived in the U.S. in regard to their values, ways of thinking, and behavioral patterns?" of 39 subjects, $31(79.5 \%)$ responded "yes" to this question. The results of the demographic data analysis will be shown as follows.

Table IX indicates that MC's, 9-15's, Pta's, Npa's, and Pfa's showed more awareness of the present issue. There was only a small difference in terms of children's sex (see Table IX, p. 126).

Question 20 asked, "If you checked 'yes' to question 19, do you believe that these changes are or will be strong or serious enough to make your children appear different from those Japanese children who have never lived outside of Japan?" In this question $100 \%$ of the subjects chose "yes," clearly indicating the mothers' anticipation that their children will appear different to their welcoming countrymen.

Question 21 asked, "If you checked 'yes' to question 20 do you expect these differences to cause any difficulties for your children's reentry to Japan?" of 30 subjects, 23 (76.7\%) answered "yes" to this question.

As shown in Table X (p. 126) FC's, N9-15's, Nta's, Npa's, and Pfa's showed more awareness of the present issue. 
TABLE VIII

RESULTS OF THE DEMOGRAPHIC DATA ANALYSIS IN QUESTION 18

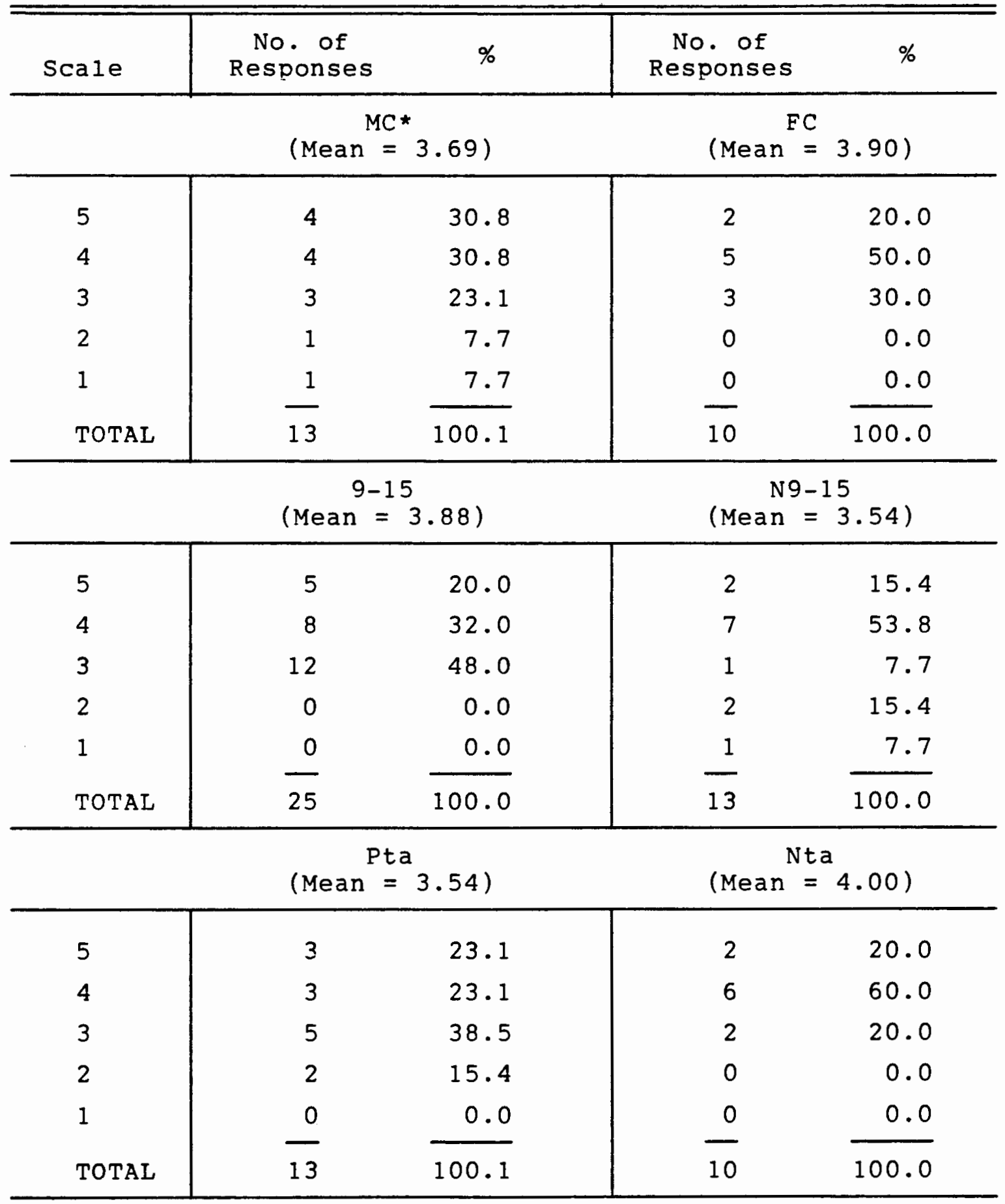


TABLE VIII

RESULTS OF THE DEMOGRAPHIC DATA ANALYSIS

IN QUESTION 18

(continued)

\begin{tabular}{|c|c|c|c|c|}
\hline Scale & $\begin{array}{c}\text { No. of } \\
\text { Responses }\end{array}$ & $\%$ & $\begin{array}{c}\text { No. of } \\
\text { Responses }\end{array}$ & $\%$ \\
\hline & \multicolumn{2}{|c|}{$\mathrm{Pa}$} & (Mean $^{\mathrm{N}}$ & $3.67)$ \\
\hline 5 & 1 & 20.0 & 6 & 18.2 \\
\hline 4 & 1 & 20.0 & 14 & 42.4 \\
\hline 3 & 3 & 60.0 & 10 & 30.3 \\
\hline 2 & 0 & 0.0 & 2 & 6.1 \\
\hline 1 & 0 & 0.0 & 1 & 3.0 \\
\hline \multirow[t]{2}{*}{ TOTAL } & 5 & 100.0 & 33 & 100.0 \\
\hline & \multicolumn{2}{|c|}{$\begin{array}{c}\text { Pfa } \\
(\text { Mean }=3.40)\end{array}$} & \multicolumn{2}{|c|}{ Npfa } \\
\hline 5 & 6 & 20.0 & 1 & 12.5 \\
\hline 4 & 13 & 43.3 & 2 & 25.0 \\
\hline 3 & 9 & 30.0 & 4 & 50.0 \\
\hline 2 & 1 & 3.3 & 1 & 12.5 \\
\hline 1 & 1 & 3.3 & 0 & 0.0 \\
\hline TOTAL & 30 & 99.9 & 8 & 100.0 \\
\hline
\end{tabular}

p. 115 .

*For explanation of symbols in table, see Table III, 


\section{TABLE IX}

PERCENTAGE OF SUBJECTS WHO ANSWERED "YES" TO QUESTION 19

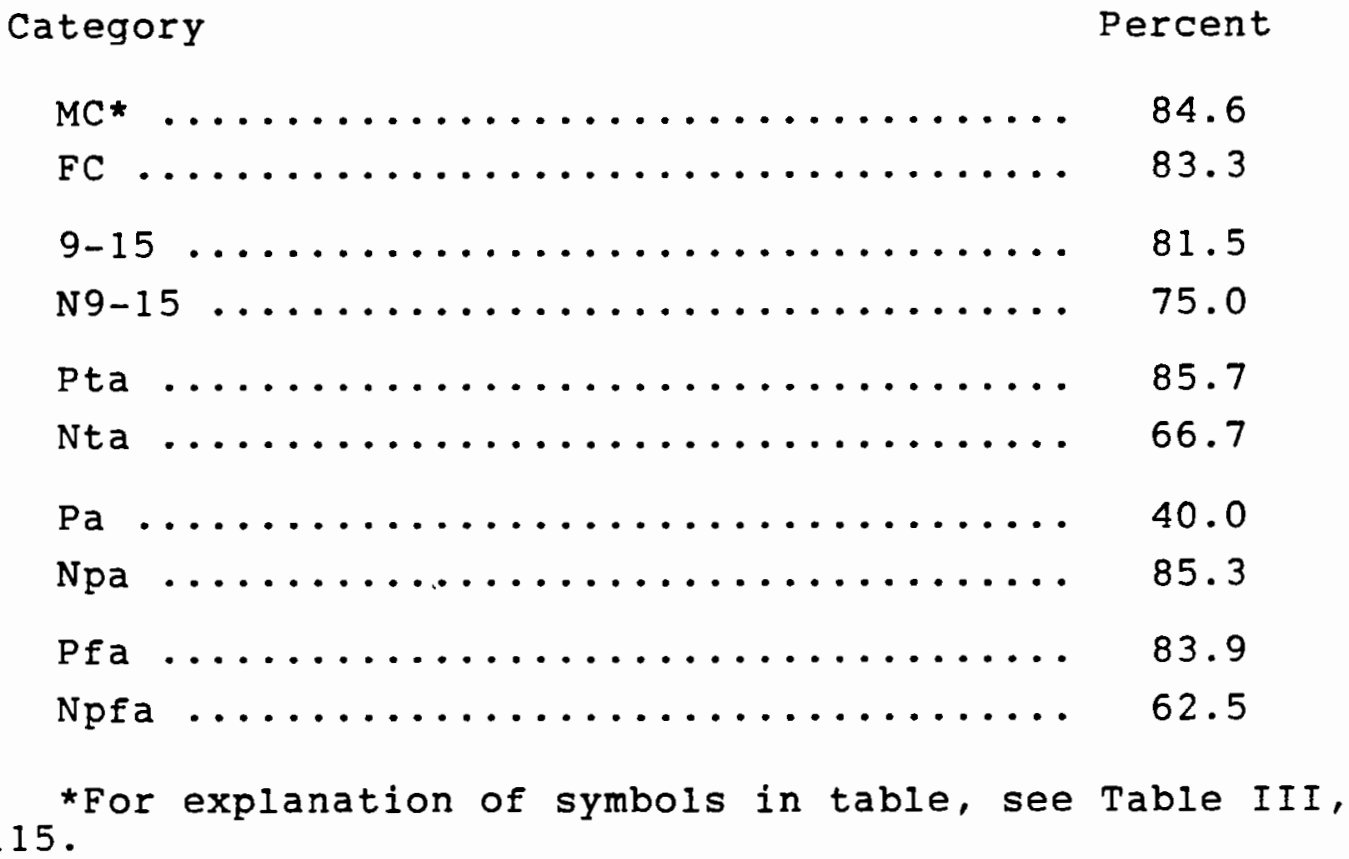

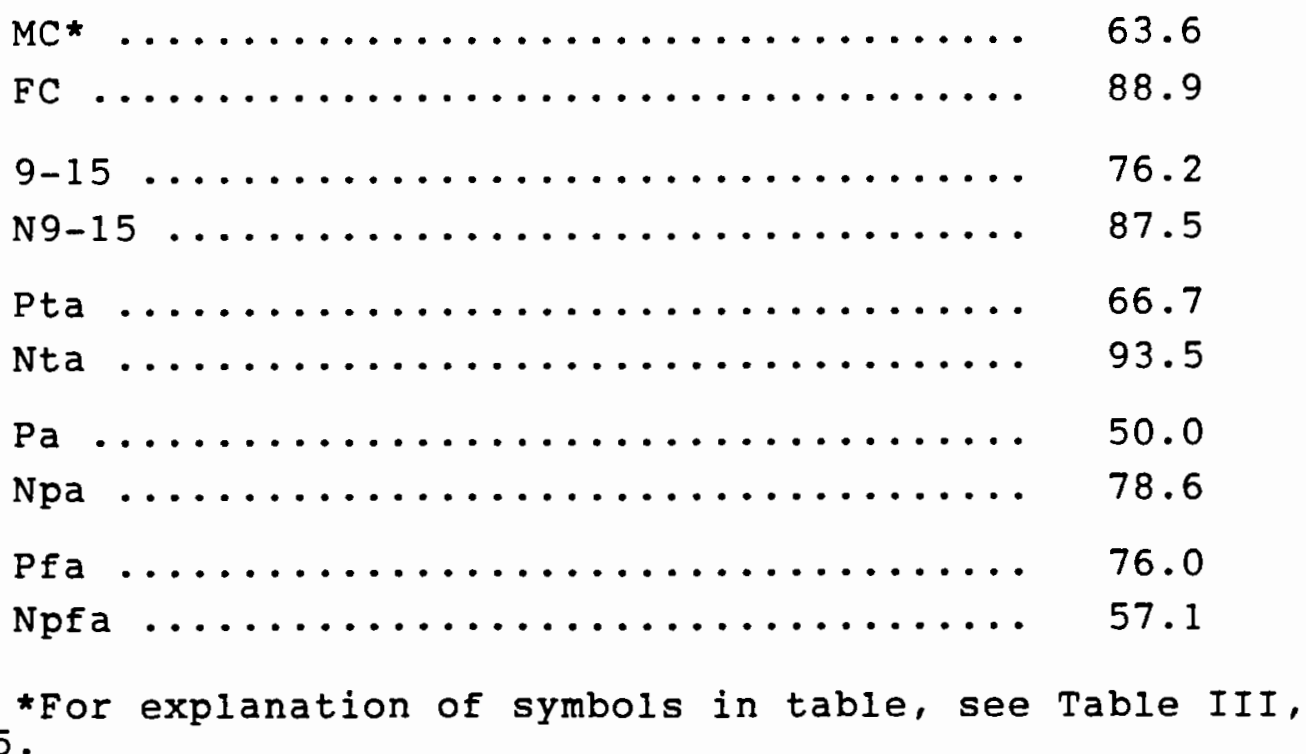

TABLE X

PERCENTAGE OF SUBJECTS WHO ANSWERED "YES" TO QUESTION 21

\section{Category}

Percent

63.6 p. 115 . 
The following questions provided information in regard to research question 1 in general. Question 17 asked, "Please describe the types of problems that concern you." The following 5 themes emerged in the answers to this question: concern for readjusting to the Japanese ways of life, academic concerns, concern for maintaining good social relationships with people at school and/or in the community, concern for Japanese national characteristics, concern for maintaining Japanese language ability, and social necessity and/or the desirability of knowing the English language (see Appendix D).

Out of 25 subjects, $4(16 \%)$ showed concern for the children's readjustment to the Japanese ways of Iife. This theme is directly related to the Japanese returnee children's potential problems. One mother whose family had been in the U.S. for more than 15 years reported, "I'm concerned about whether my children can smoothly readjust to the Japanese school life because of the different values and ways of thinking between Japan and the U.S." The other subject reported, "I'm concerned about whether my children can smoothly readjust to the Japanese society."

Out of 25 subjects, $11(44 \%)$ reported concern for the children's readjustment to the Japanese educational system. This is not a theme pertinent to the present research, however, this theme does indicate the mothers' tendency to consider the children's reentry issue from an academic point of view. For example, one subject reported, "I'm concerned. 
about whether my child can smoothly pass the university entrance examination."

Only $9(36 \%)$ out of 25 subjects reported concern for the children's maintaining good social relationships with people at school and/or in the community. This is a theme which is directly related to the Japanese returnee children's potential problems. One mother reported, "I consider that teachers and other students at school in Japan cannot easily accept the differences which are shown by my children."

Out of 25 subjects, $3(12 \%)$ reported concern for Japanese national characteristics in connection with the children's reentry. This theme is also directly related to the focus of this study. One subject reported, "I'm concerned about the fact that my child has to readjust to the tightly ordered Japanese educational system." Another subject reported, "I'm worried about if my children's flexible attitude acquired in the U.S. may be suppressed in the Japanese society."

Out of 25 subjects, $2(8 \%)$ reported concern for the social necessity and/or desirability of knowing the English language. One of them stated, "I'm concerned whether my children can maintain their English ability after returning to Japan." This theme was not included as a Japanese returnee child's potential problem. Finally, 1 subject (4\%) reported her concern for her children's Japanese language ability which was dealt with in question 10. 
A demographic data analysis of question 17 is shown in Table XI. The data indicates that MC's, N9-15's, Pta's, Npa's, and Npfa's exhibited more anticipation of children's reentry issues that are the focus of the present study. Concerning children's sex and preparation for the present living situation in the U.S., there were only slight differences.

TABLE XI

PERCENTAGE OF SUBJECTS WHO REPORTED THEMES REGARDING JAPANESE RETURNEE CHILDREN'S POTENTIAL PROBLEMS IN QUESTION 17

Category

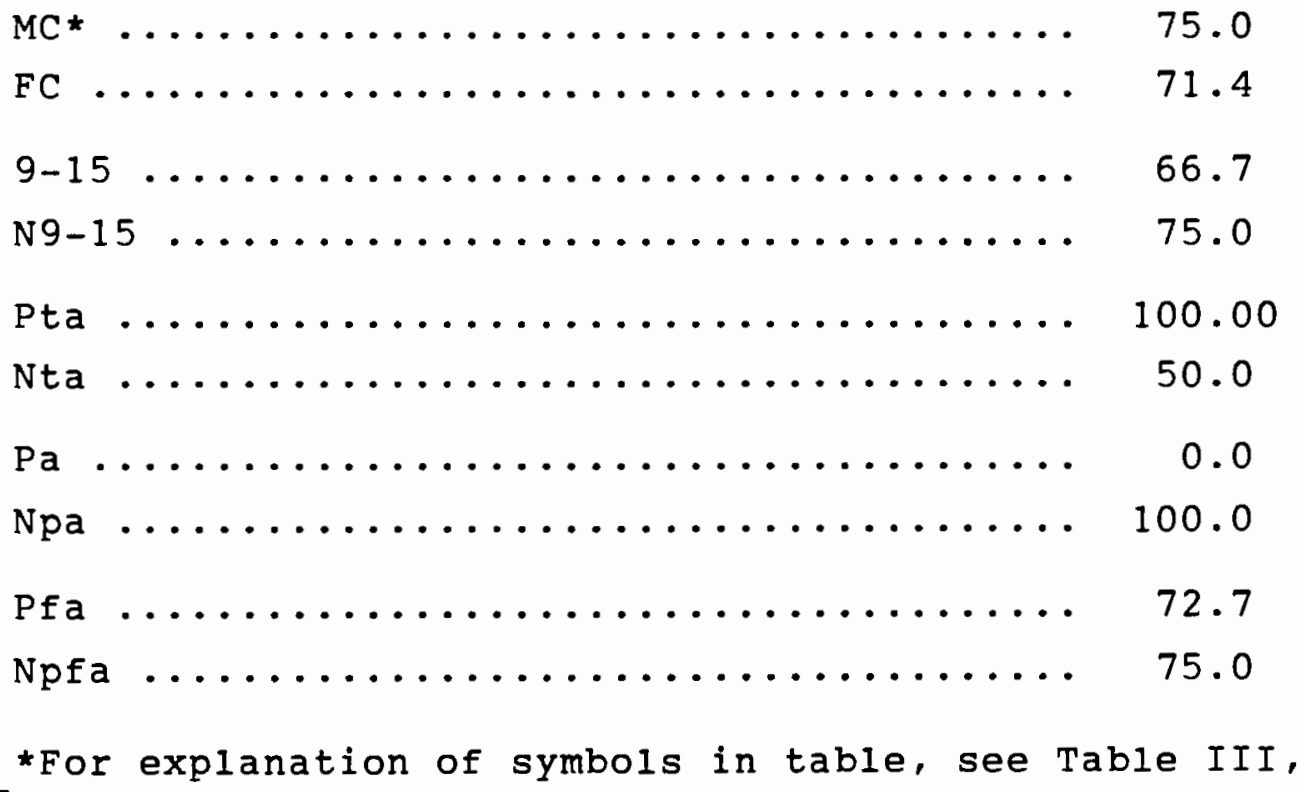

*For explanation of symbols in table, see Table III, p. 115 .

$$
\text { RESEARCH QUESTION TWO }
$$

To what extent do the Japanese parents discuss these potential problems with each other and/or their children? 
The questions below provided information in regard to the language aspect.

Question 12 asked, "Have you ever discussed such language issues as those mentioned in question 9 through question 11 with your husband?" From the results obtained, it was found that the mean of the frequency of discussion with the subjects' husbands in regard to the language issue was 2.73 (see Table XII).

The result of the demographic data analysis is shown in Table XIII. As can be seen, the frequency of discussion with the husbands was higher in the MC's, N9-15's, Pta's, Npa's, and Pfa's in comparison with the counterparts in each category. The difference was bigger in terms of the sex of the children, age, and existence of previous U.S. assignments (see Table XIII, pp. 131-132).

\section{TABLE XII}

SUBJECTS' COMMUNICATION WITH THEIR HUSBANDS IN REGARD TO THE LANGUAGE ISSUE CONCERNING CHILDREN'S REENTRY

\begin{tabular}{lcc}
\hline \hline Ordinal Scale & No. of Responses & $\%$ \\
\hline 5 - Once a Week & 1 & 2.7 \\
4 - Once a Month & 10 & 27.0 \\
3 - Once Every Three Months & 6 & 16.2 \\
2 - Seldom & 18 & 48.6 \\
1 - Never & $\frac{2}{37}$ & $\frac{5.4}{99.9}$ \\
\hline
\end{tabular}


TABLE XIII

RESULTS OF THE DEMOGRAPHIC DATA ANALYSIS IN QUESTION 12

\begin{tabular}{|c|c|c|c|c|}
\hline Scale & $\begin{array}{c}\text { No. } \\
\text { Respo }\end{array}$ & $\%$ & $\begin{array}{c}\text { No. of } \\
\text { Responses }\end{array}$ & $\%$ \\
\hline & \multicolumn{2}{|c|}{$M C^{*}$} & \multicolumn{2}{|c|}{ FC } \\
\hline & \multicolumn{2}{|c|}{$($ Mean $=3.20)$} & \multicolumn{2}{|c|}{$($ Mean $=2.18)$} \\
\hline 5 & 1 & 10.0 & 0 & 0.0 \\
\hline 4 & 4 & 40.0 & 1 & 9.1 \\
\hline 3 & 1 & 10.0 & 2 & 18.2 \\
\hline 2 & 4 & 40.0 & 6 & 54.5 \\
\hline 1 & 0 & 0.0 & 2 & 18.2 \\
\hline \multirow[t]{2}{*}{ TOTAL } & 10 & 100.0 & 11 & 100.0 \\
\hline & \multicolumn{2}{|c|}{$9-15$} & \multicolumn{2}{|c|}{$($ Mean $=3.33)$} \\
\hline 5 & 0 & 0.0 & 1 & 8.3 \\
\hline 4 & 5 & 20.0 & 5 & 41.7 \\
\hline 3 & 3 & 12.0 & 3 & 25.0 \\
\hline 2 & 15 & 60.0 & 3 & 25.0 \\
\hline 1 & 2 & 8.0 & 0 & 0.0 \\
\hline \multirow[t]{2}{*}{ TOTAL } & 25 & 100.0 & 12 & 100.0 \\
\hline & \multicolumn{2}{|c|}{ Pta } & \multicolumn{2}{|c|}{ Nta } \\
\hline 5 & 0 & 0.0 & 1 & 10.0 \\
\hline 4 & 5 & 41.7 & 1 & 10.0 \\
\hline 3 & 3 & 25.0 & 2 & 20.0 \\
\hline 2 & 4 & 33.3 & 5 & 50.0 \\
\hline 1 & 0 & 0.0 & 1 & 10.0 \\
\hline TOTAL & 12 & 100.0 & 10 & 100.0 \\
\hline
\end{tabular}


TABLE XIII

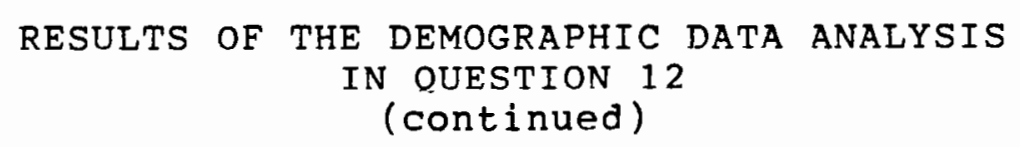

\begin{tabular}{|c|c|c|c|c|}
\hline Scale & $\begin{array}{c}\text { No. of } \\
\text { Responses }\end{array}$ & $\%$ & $\begin{array}{c}\text { No. of } \\
\text { Responses }\end{array}$ & $\%$ \\
\hline & \multicolumn{2}{|c|}{$\left(\right.$ Mean $^{\mathrm{Pa}}=$} & \multicolumn{2}{|c|}{$($ Mean $\stackrel{\text { Npa }}{=} 2.82)$} \\
\hline 5 & 0 & 0.0 & 1 & 3.0 \\
\hline 4 & 0 & 0.0 & 10 & 30.3 \\
\hline 3 & 0 & 0.0 & 6 & 18.2 \\
\hline 2 & 4 & 100.0 & 14 & 42.4 \\
\hline 1 & 0 & 0.0 & 2 & 6.1 \\
\hline \multirow[t]{2}{*}{ TOTAL } & 4 & 100.0 & 33 & 100.0 \\
\hline & \multicolumn{2}{|c|}{$\begin{array}{c}\text { Pfa } \\
(\text { Mean }=2.80)\end{array}$} & \multicolumn{2}{|c|}{$\begin{array}{c}\text { Npfa } \\
(\text { Mean }=2.43)\end{array}$} \\
\hline 5 & 1 & 3.3 & 0 & 0.0 \\
\hline 4 & 9 & 30.0 & 1 & 14.3 \\
\hline 3 & 5 & 16.7 & 1 & 14.3 \\
\hline 2 & 13 & 43.3 & 5 & 71.4 \\
\hline 1 & 2 & 6.7 & 0 & 0.0 \\
\hline TOTAL & 30 & 100.0 & 7 & 100.0 \\
\hline
\end{tabular}
p. 115 .

*For explanation of symbols in table, see Table III,

Question 13 asked, "Have you ever discussed these same language issues with your children?"

Table XIV shows that mothers' communication behavior with their children is almost similar to that between husband and wife. The mean of the total subjects was 2.81 . This mean of frequency with the subjects' chiloren was a little higher than that with their husbands. 
SUBJECTS' COMMUNICATION WITH THEIR CHILDREN IN REGARD TO THE LANGUAGE ISSUE CONCERNING CHILDREN'S REENTRY

\begin{tabular}{lcc}
\hline \hline Ordinal Scale & No. of Responses & $\%$ \\
\hline 5 - Once a Week & 2 & 5.4 \\
4 - Once a Month & 11 & 29.7 \\
3 - Once Every Three Months & 5 & 13.5 \\
2 - Seldom & 16 & 43.2 \\
1 - Never & $\frac{3}{37}$ & $\frac{8.1}{99}$ \\
\hline
\end{tabular}

Table XV indicates that MC's, N9-15's, Pta's, Npa's, and Npfa's discuss the language issue with their children more often than their counterparts in each category. However, there was only a slight difference in terms of preparation for the present living situation in the U.S. See Table XV, pp. $134-135$. 
TABLE XV

RESULTS OF THE DEMOGRAPHIC DATA ANALYSIS IN QUESTION 13

\begin{tabular}{|c|c|c|c|c|}
\hline Scale & $\begin{array}{l}\text { No. of } \\
\text { Responses }\end{array}$ & $\%$ & $\begin{array}{l}\text { No. of } \\
\text { Responses }\end{array}$ & $\%$ \\
\hline & \multicolumn{2}{|c|}{$M C^{*}$} & \multicolumn{2}{|c|}{ FC } \\
\hline 5 & 1 & 8.3 & 0 & 0.0 \\
\hline 4 & 6 & 50.0 & 2 & 18.2 \\
\hline 3 & 1 & 8.3 & 2 & 18.2 \\
\hline 2 & 4 & 33.3 & 5 & 45.5 \\
\hline 1 & 0 & 0.0 & 2 & 18.2 \\
\hline \multirow[t]{2}{*}{ TOTAL } & 12 & 99.9 & 11 & 100.1 \\
\hline & \multicolumn{2}{|c|}{$\begin{array}{c}9-15 \\
(\text { Mean }=2.38)\end{array}$} & \multicolumn{2}{|c|}{$\begin{array}{c}\text { N9-15 } \\
(\text { Mean }=3.08)\end{array}$} \\
\hline 5 & 2 & 8.3 & 0 & 0.0 \\
\hline 4 & 4 & 16.7 & 7 & 53.8 \\
\hline 3 & 5 & 20.8 & 0 & 0.0 \\
\hline 2 & 11 & 45.8 & 6 & 46.2 \\
\hline 1 & 2 & 8.3 & 0 & 0.0 \\
\hline \multirow[t]{2}{*}{ TOTAL } & 24 & 99.9 & 13 & 100.0 \\
\hline & \multicolumn{2}{|c|}{$\begin{array}{c}\text { Pta } \\
(\text { Mean }=3.25)\end{array}$} & \multicolumn{2}{|c|}{$($ Mean $\stackrel{N t a}{=} 2.73)$} \\
\hline 5 & 0 & 0.0 & 0 & 0.0 \\
\hline 4 & 7 & 58.3 & 4 & 36.4 \\
\hline 3 & 1 & 8.3 & 1 & 9.1 \\
\hline 2 & 4 & 33.3 & 5 & 45.5 \\
\hline 1 & 0 & 0.0 & 1 & 9.1 \\
\hline TOTAL & 12 & 99.9 & 11 & 100.1 \\
\hline
\end{tabular}


TABLE XV

RESULTS OF THE DEMOGRAPHIC DATA ANALYSIS

IN QUESTION 13

(continued)

\begin{tabular}{|c|c|c|c|c|}
\hline Scale & $\begin{array}{c}\text { No. } \\
\text { Respor }\end{array}$ & $\%$ & $\begin{array}{c}\text { No. of } \\
\text { Responses }\end{array}$ & $\%$ \\
\hline & \multicolumn{2}{|c|}{$\mathrm{Pa}$} & \multicolumn{2}{|c|}{$\mathrm{Npa}$} \\
\hline 5 & 0 & 0.0 & 2 & 6.1 \\
\hline 4 & 1 & 25.0 & 10 & 30.3 \\
\hline 3 & 0 & 0.0 & 5 & 15.2 \\
\hline 2 & 3 & 75.0 & 14 & 42.4 \\
\hline 1 & 0 & 0.0 & 2 & 6.1 \\
\hline \multirow[t]{2}{*}{ TOTAT } & 4 & 100.0 & 33 & 100.1 \\
\hline & \multicolumn{2}{|c|}{ Pfa } & \multicolumn{2}{|c|}{ Npfa } \\
\hline 5 & 2 & 6.7 & 0 & 0.0 \\
\hline 4 & 8 & 26.7 & 3 & 42.9 \\
\hline 3 & 5 & 16.7 & 0 & 0.0 \\
\hline 2 & 13 & 43.3 & 4 & 57.1 \\
\hline 1 & 2 & 6.7 & 0 & 0.0 \\
\hline TOTAL & 30 & 100.1 & 7 & 100.0 \\
\hline
\end{tabular}
p. 115 .

* For explanation of symbols in table, see Table III,

Question 14 asked, "If you do not discuss language issues with your husband and/or children, please check appropriate number(s) below." Nine subjects who chose either "seldom" or "never" in question 12 and/or 13 responded. of the 9 subjects, 2 chose (1): "It never occurred to me to do so." One subject chose (2): "I do not think that it is 
important." One subject chose (3): "Discussion would not accomplish anything." Two subjects chose (4): "Since they are busy in working and/or study, we do not have enough time for discussion." Three subjects reported different answers. One mother reported, "Even if we do not discuss, I know that all of our family have the same opinion." This response appears to indicate Japanese tendency to value intuition rather than verbal expresssion within the in-group situation. Another mother reported, "Since my family has to stay in the U.S. for a few more years, I'm not thinking about the children's reentry issue seriously right now." The other subject reported, "My husband considers that it is good for our children to speak English at home, but I cannot give in especially in this matter." These three reports clearly indicate the mothers' unawareness of the importance of discussion that is mentioned in the literature. In the last parent's case, although it was found that her children spoke only Japanese at home (through the response to question 11a), her comment showed that her husband did not anticipate the importance of the Japanese language for the children at all. It appears that the subject herself anticipates the importance of the Japanese language for her children, however, since her husband has an opposite opinion concerning this issue, it seems that further discussion cannot be realized between this couple.

The questions below provided information in regard to the issues other than language concerning research question 2 . 
Question 22 asked, "Have you ever discussed such issues as those mentioned in questions 18 to 21 with your husband?"

Table XVI shows that there were fewer subjects who seldom or never discuss other reentry issues with their husbands than in the case of the language issue. However, the mean of the total subjects was 2.74 .

TABLE XVI

SUBJECTS' COMMUNICATION WITH THEIR HUSBANDS IN REGARD TO CHILDREN'S REENTRY

\begin{tabular}{lcc}
\hline \hline ordinal Scale & No. of Responses & $\%$ \\
\hline 5 - Once a Week & 1 & 2.9 \\
4 - Once a Month & 6 & 17.6 \\
3 - Once Every Three Months & 11 & 32.4 \\
2 - Seldom & 15 & 44.1 \\
1 - Never & $\frac{1}{34}$ & $\frac{2.9}{99.9}$ \\
\hline
\end{tabular}

Table XVII indicates that MC's, N9-15's, Pta's, Npa's, and Pfa's discuss the issues with their husbands more often than their counterparts. There was only a sight difference in terms of those who did preparation for the present living in the U.S. and those who did not do any preparation. A bigger difference of frequency of discussion was found in terms of MC vs. FC, and Pta vs. Nta. See Table XVII, pp. $138-139$. 
TABLE XVIT

RESULTS OF THE DEMOGRAPHIC DATA ANALYSIS

IN QUESTION 22

\begin{tabular}{|c|c|c|c|c|}
\hline Scale & $\begin{array}{l}\text { No. } \\
\text { Respol }\end{array}$ & $\%$ & $\begin{array}{c}\text { No. of } \\
\text { Responses }\end{array}$ & $\%$ \\
\hline & \multicolumn{2}{|c|}{$\left(\right.$ Mean $\left.{ }^{M C}=2.92\right)$} & \multicolumn{2}{|c|}{$($ Mean $\stackrel{F C}{=} 2.10)$} \\
\hline 5 & 1 & 8.3 & 0 & 0.0 \\
\hline 4 & 3 & 25.0 & 0 & 0.0 \\
\hline 3 & 2 & 16.7 & 2 & 20.0 \\
\hline 2 & 6 & 50.0 & 7 & 70.0 \\
\hline 1 & 0 & 0.0 & 1 & 10.0 \\
\hline \multirow[t]{2}{*}{ TOTAL } & 12 & 100.0 & 10 & 100.0 \\
\hline & \multicolumn{2}{|c|}{$\begin{array}{c}9-15 \\
(\text { Mean }=2.59)\end{array}$} & \multicolumn{2}{|c|}{$\begin{array}{c}\text { N9-15 } \\
(\text { Mean }=3.00)\end{array}$} \\
\hline 5 & 0 & 0.0 & 1 & 8.3 \\
\hline 4 & 4 & 18.2 & 2 & 16.7 \\
\hline 3 & 6 & 27.3 & 5 & 41.7 \\
\hline 2 & 11 & 50.0 & 4 & 33.3 \\
\hline 1 & 1 & 4.5 & 0 & 0.0 \\
\hline \multirow[t]{2}{*}{ TOTAL } & 22 & 100.0 & 12 & 100.0 \\
\hline & \multicolumn{2}{|c|}{$\left(\right.$ Mean $\left.{ }^{\text {Pta }}=3.36\right)$} & \multicolumn{2}{|c|}{$($ Mean $=2.60)$} \\
\hline 5 & 0 & 0.0 & 1 & 10.0 \\
\hline 4 & 5 & 45.5 & 0 & 0.0 \\
\hline 3 & 5 & 45.5 & 4 & 40.0 \\
\hline 2 & 1 & 9.1 & 4 & 40.0 \\
\hline 1 & 0 & 0.0 & 1 & 10.0 \\
\hline TOTAL & 11 & 100.1 & 10 & 100.0 \\
\hline
\end{tabular}


TABLE XVII

RESULTS OF THE DEMOGRAPHIC DATA ANALYSIS

IN QUESTION 22

(continued)

\begin{tabular}{|c|c|c|c|c|}
\hline Scale & $\begin{array}{l}\text { No. of } \\
\text { Responses }\end{array}$ & $\%$ & $\begin{array}{l}\text { No. of } \\
\text { Responses }\end{array}$ & $\%$ \\
\hline & (Mean & $\mathrm{Pa}$ & (Mean & $2.77)$ \\
\hline 5 & 0 & 0.0 & 1 & 3.3 \\
\hline 4 & 1 & 25.0 & 5 & 16.7 \\
\hline 3 & 0 & 0.0 & 11 & 36.7 \\
\hline 2 & 3 & 75.0 & 12 & 40.0 \\
\hline 1 & 0 & 0.0 & 1 & 3.3 \\
\hline \multirow[t]{2}{*}{ TOTAL } & 4 & 100.0 & 30 & 100.0 \\
\hline & \multicolumn{2}{|c|}{ Pfa } & \multicolumn{2}{|c|}{$\begin{array}{c}\text { Npfa } \\
(\text { Mean }=2.67)\end{array}$} \\
\hline 5 & 1 & 3.6 & 0 & 0.0 \\
\hline 4 & 5 & 17.9 & 1 & 16.7 \\
\hline 3 & 9 & 32.1 & 2 & 33.3 \\
\hline 2 & 12 & 42.9 & 3 & 50.0 \\
\hline 1 & 1 & 3.6 & 0 & 0.0 \\
\hline TOTAL & 28 & 100.1 & 6 & 100.0 \\
\hline
\end{tabular}
p. 115 .

*For explanation of symbols in table, see Table III,

Question 23 asked, "Have you ever discussed these same issues with your children?"

As seen in Table XVIII, $62.8 \%$ of the subjects seldom or never discuss the reentry issues with their children. The mean of the total subjects in this question was 2.49 . Also, the mean of frequency of discussion with the subjects' 
children was lower than that with their husbands. This contradicts the results of the discussion in regard to the issue of language which showed that the subjects discussed with their children more often than with their husbands.

\section{TABLE XVIII}

SUBJECTS' COMMUNICATION WITH THEIR CHILDREN

IN REGARD TO CHILDREN'S REENTRY

\begin{tabular}{lcc}
\hline \hline Ordinal Scale & No. of Responses & $\%$ \\
\hline 5 - Once a Week & 1 & 2.9 \\
4 - Once a Month & 6 & 17.1 \\
3 - Once Every Three Months & 6 & 17.1 \\
2 - Seldom & 18 & 51.4 \\
1 - Never & $\frac{4}{35}$ & $\frac{11.4}{99.9}$ \\
\hline
\end{tabular}

Table XIX indicates that MC's, 9-15's, Pta's, Npa's, and Pfa's discuss the reentry issue with their children more often than their counterparts in each category. Also, there was only a slight difference in terms of children's age, and the difference of frequency of discussion in terms of the subjects' feelings about the present U.S. assignment was bigger than those of the other demographic categories. See Table XIX, pp. 141-142. 
TABLE XIX

RESULTS OF THE DEMOGRAPHIC DATA ANALYSIS

IN QUESTION 23

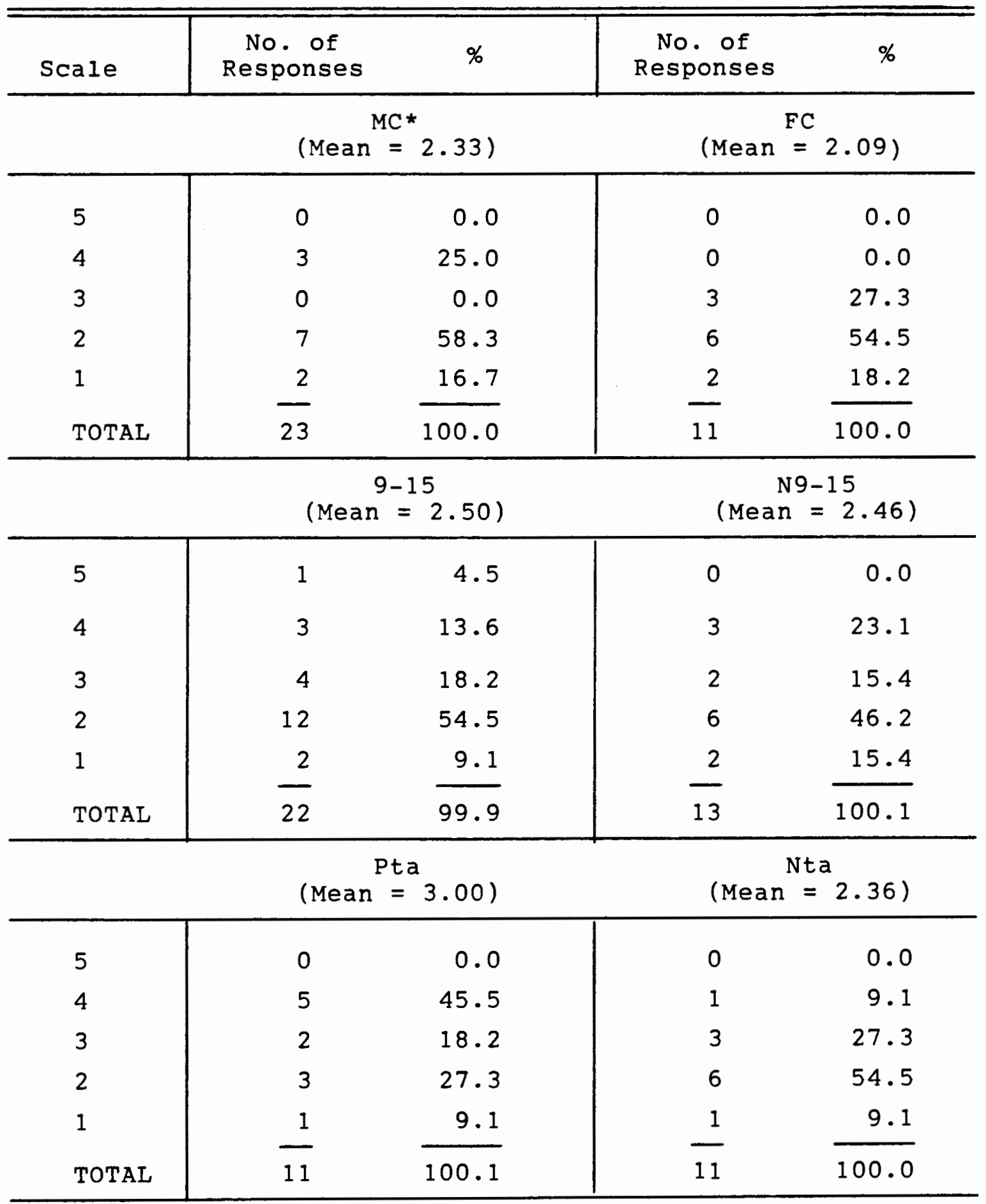


TABLE XIX

RESULTS OF THE DEMOGRAPHIC DATA ANALYSIS

IN QUESTION 23

(continued)

\begin{tabular}{|c|c|c|c|c|}
\hline Scale & $\begin{array}{l}\text { No. of } \\
\text { Responses }\end{array}$ & $\%$ & $\begin{array}{c}\text { No. of } \\
\text { Responses }\end{array}$ & $\%$ \\
\hline & \multicolumn{2}{|c|}{$\mathrm{Pa}$} & (Mean & $2.52)$ \\
\hline 5 & 0 & 0.0 & 1 & 3.2 \\
\hline 4 & 1 & 16.7 & 5 & 16.1 \\
\hline 3 & 0 & 0.0 & 6 & 19.4 \\
\hline 2 & 4 & 66.7 & 16 & 51.6 \\
\hline 1 & 1 & 16.7 & 3 & 9.7 \\
\hline \multirow[t]{2}{*}{ TOTAL } & 6 & 100.1 & 31 & 100.0 \\
\hline & \multicolumn{2}{|c|}{$($ Mean $=2.55)$} & \multicolumn{2}{|c|}{$\begin{array}{c}\text { Npfa } \\
(\text { Mean }=2.17)\end{array}$} \\
\hline 5 & 1 & 3.4 & 0 & 0.0 \\
\hline 4 & 5 & 17.2 & 1 & 16.7 \\
\hline 3 & 5 & 17.2 & 1 & 16.7 \\
\hline 2 & 16 & 55.2 & 2 & 33.3 \\
\hline 1 & 2 & 6.9 & 2 & 33.3 \\
\hline TOTAL & 29 & 99.9 & 6 & 100.0 \\
\hline
\end{tabular}

p. 115 .

*For explanation of symbols in table, see Table III,

$$
\text { RESEARCH QUESTION THREE }
$$

Are the Japanese parents doing anything to prepare

themselves and/or their children to cope with the

potential problems which their children may face as

returnees? 
The question below provided information to answer this research question.

Question 11 a asked, "What language do your children usually speak in your home in the U.S.?"

As seen in Table $\mathrm{XX}$, a large number of the children ( $85.4 \%)$ were preparing for their reentry by using only Japanese in their home in the U.S.

TABLE XX

LANGUAGE USED BY THE SUBJECTS' CHILDREN AT HOME IN THE U.S.

\begin{tabular}{lcc}
\hline \hline Language & No. of Responses & $\%$ \\
\hline Japanese & 35 & 85.4 \\
English & 0 & 0.0 \\
Both & $\frac{6}{41}$ & $\frac{14.6}{100.0}$ \\
\hline
\end{tabular}

Table XXI indicates that more children of FC's, 9-15's, Nta's, Npa's. and Pfa's speak only Japanese at home than their counterparts. 
TABLE XXI

PERCENTAGE OF SUBJECTS WHOSE CHILDREN SPEAK ONLY JAPANESE AT HOME IN THE U.S.

Category

Percent

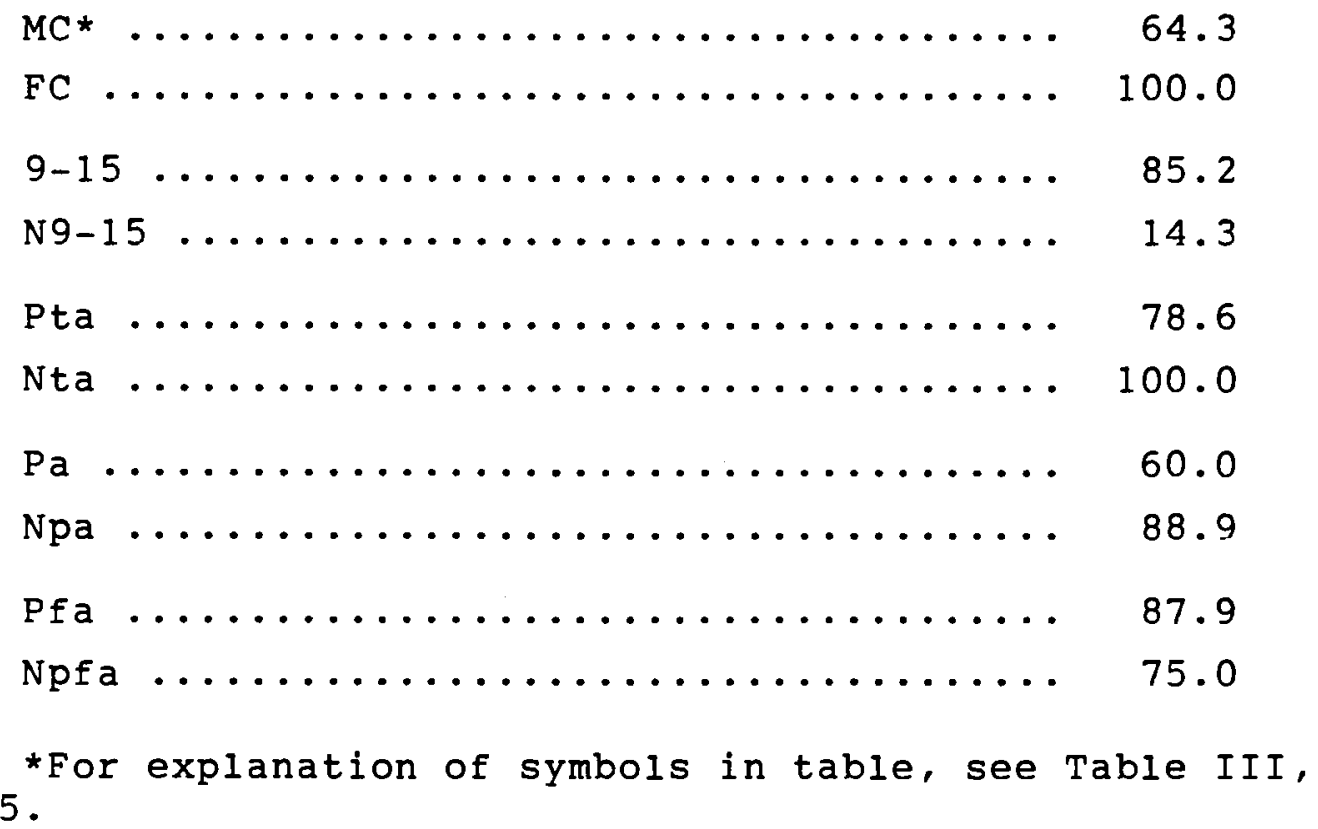
p. 115 .

Question $11 \mathrm{~b}$ asked, "Why do you think they use this language at home?" Among the total number of 41 subjects, $25(61.0 \%)$ including the subjects whose children spoke both languages at home, chose the item (1): "They are used to speaking Japanese more than English." Eighteen subjects (43.9\%) chose (3): "I encourage them to use Japanese." Four subjects $(9.8 \%)$ chose (4): "They are used to speaking English more than Japanese." Eleven subjects ( $26.8 \%$ ) chose (5): "Most of their playmates use English." Ten subjects (24.4\%) chose (7): "Other." Among 8 of these 10 subjects whose children used only Japanese at home, 5 subjects reported: "Since their parents speak only Japanese at home, the children also speak Japanese." One subject reported 
"My children use only Japanese at home in preparation for returning to Japan." Another subject reported, "My children speak only Japanese in order not to forget it." Since the last 2 subjects did not check the item (3), "I encourage them to use Japanese," it can be speculated that their children are preparing for their reentry voluntarily by speaking only Japanese. Moreover, another subject reported, "As my children sometimes mix English and Japanese in speaking, they speak Japanese at home." Since the same subject was found to encourage her children to speak Japanese at home, it is evident that she does this in order to prevent them from experiencing linguistic confusion.

In this question it was found that $43.9 \%$ of the subjects, including 4 subjects whose children spoke both Japanese and English at home, encouraged their children to speak Japanese at home, which meant that less than half of the subjects in the present study encouraged their children. The results of the demographic data analysis are shown in Table XXII. As can be seen, more MC's, 9-15's, Pta's, Npa's, and Pfa's encourage their children to speak Japanese at home than their counterparts in each category. The difference in terms of children's age was smaller than the other demographic categories. Moreover, in terms of the children's sex the results in this question were consistent with those of question $10 \mathrm{a}$ which asked about the importance of the Japanese language for their children. However, it contradicted the results of question $11 \mathrm{a}$ which asked the language 
spoken by their children. This shows that although parents with only male children encourage the children to speak Japanese, more than those with only female children, some male children use both languages regardless of their parents' encouragement.

\section{TABLE XXII}

PERCENTAGE OF SUBJECTS WHO ENCOURAGE CHILDREN TO SPEAK JAPANESE AT HOME IN THE U.S.

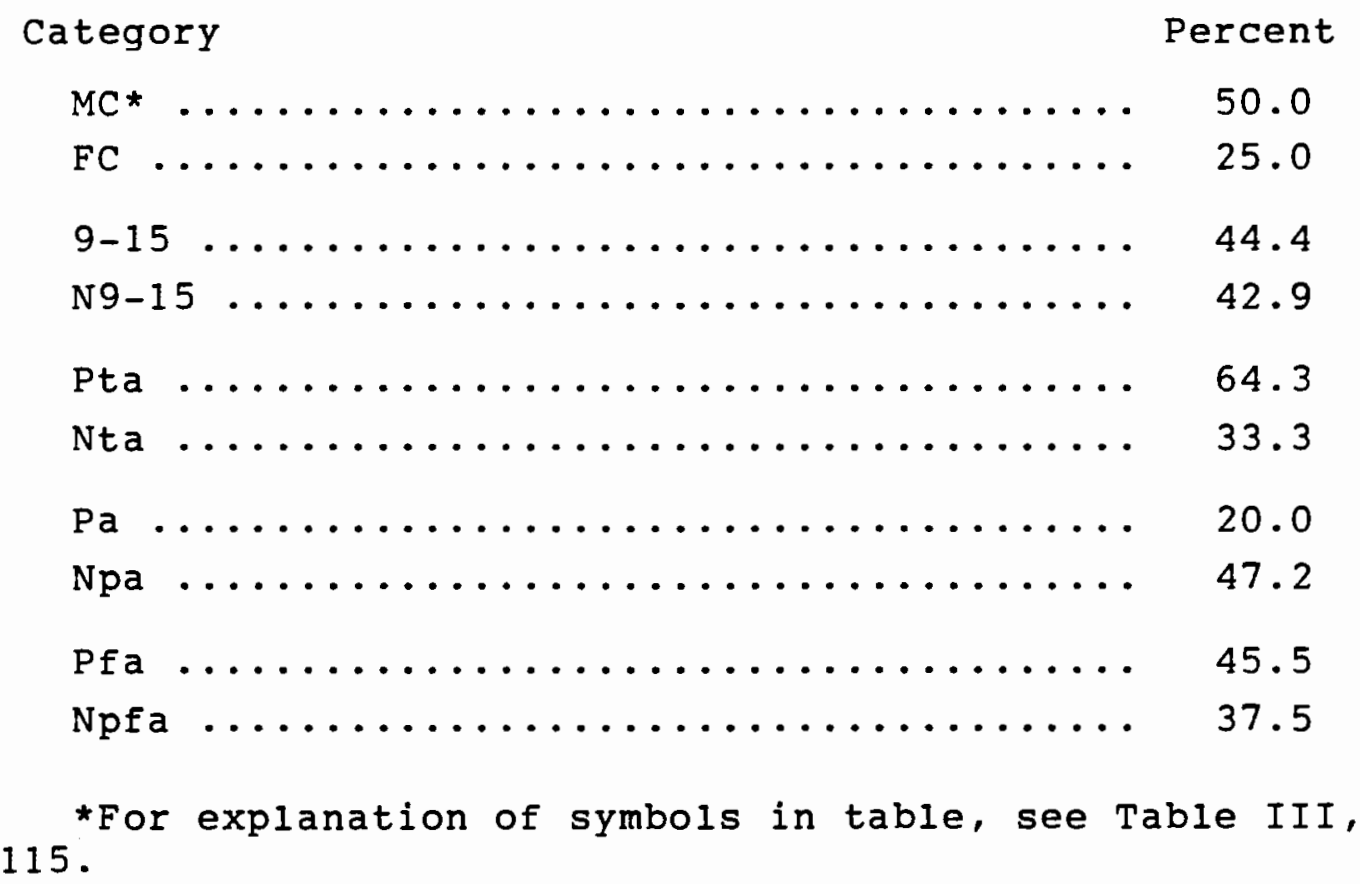

Question 15 asked, "Do you feel parents need to prepare themselves and/or their children for their children's return to Japan besides helping them keep up with their studies?" of the subjects responding, $75 \%$ of them said "yes" to this question. The results of the demographic data analysis are shown in Table XXIII. The results indicate that MC's, 9-15's, Pta's, Npa's, and Pfa's showed more anticipation of 
the necessity of preparation for children's reentry than their counterparts in each category. In terms of the category concerning preparation for the present U.S. Iiving situation, the results appeared to indicate people's consistent positive attitude toward the idea of preparation (see Table XXIII) 。

\section{TABLE XXIII}

PERCENTAGE OF SUBJECTS WHO ANSWERED "YES" TO QUESTION 15

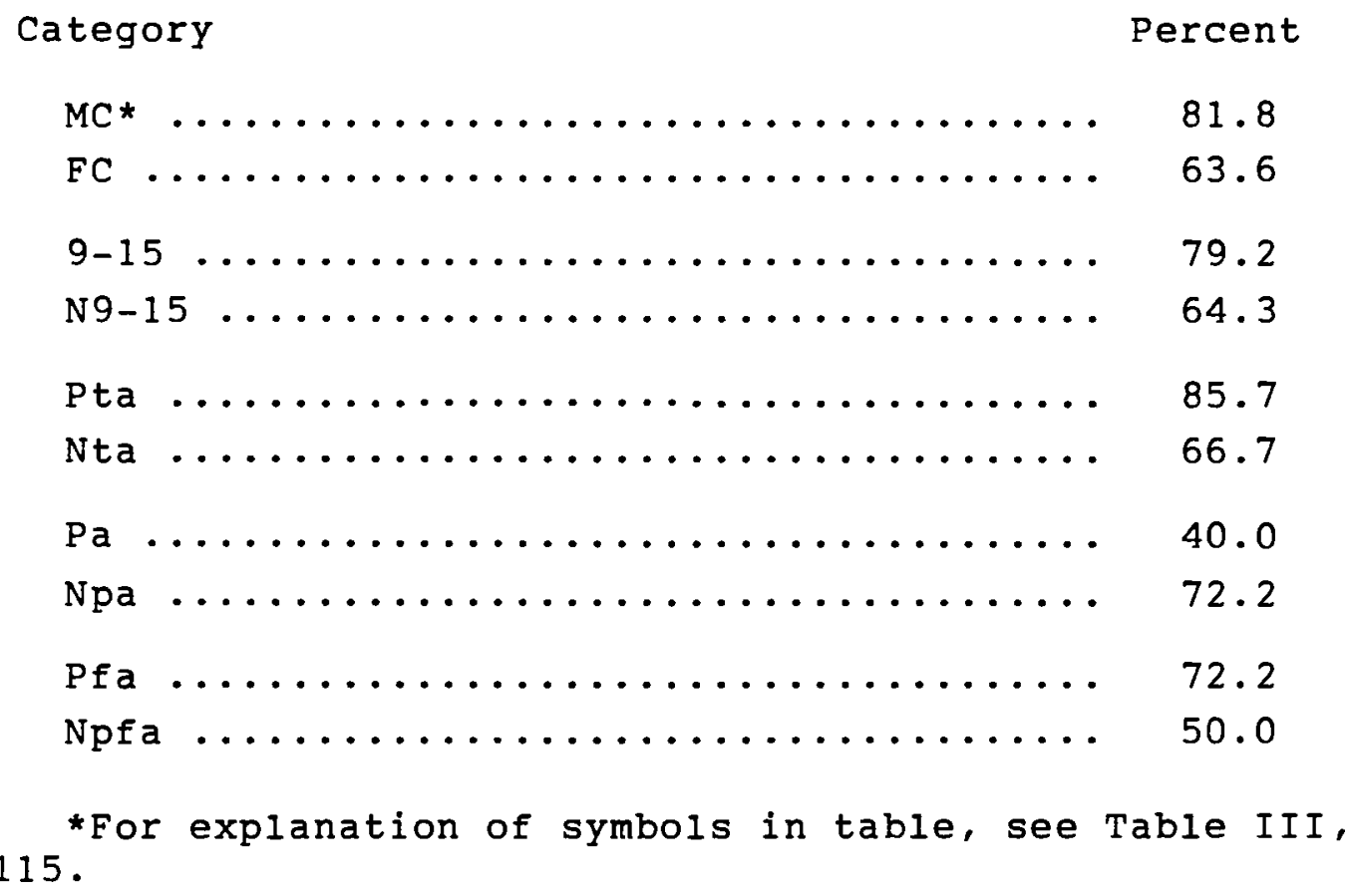

Question 16 asked, "Since you checked that you do believe preparation is necessary for children's reentry to Japan in more than academic areas, please check one or more of the following that apply to you or your children." No subjects chose the item (1), which said, "I have thought about potential reentry problems but have kept these thoughts 
to myself." Five additional possible items were given. First, it was found that 13 out of all the 41 subjects (31.7\%) were preparing their children for their reentry by discussing the issues. The results of the demographic data analysis are shown in Table XXIV. More FC's, 9-15's, Pta's, Npa's, and Npfa's were preparing their children for their reentry by having discussions than their counterparts in each category. Moreover, the differences in terms of children's sex and preparation for the present living situation in the U.S. were smaller than those of the other categories. In this question the result of the demographic category regarding preparation for the present living situation in the U.S. contradicted the people's general positive idea for preparation.

TABLE XXIV

PERCENTAGE OF CHILDREN'S PREPARATION DONE BY THE SUBJECTS

Category

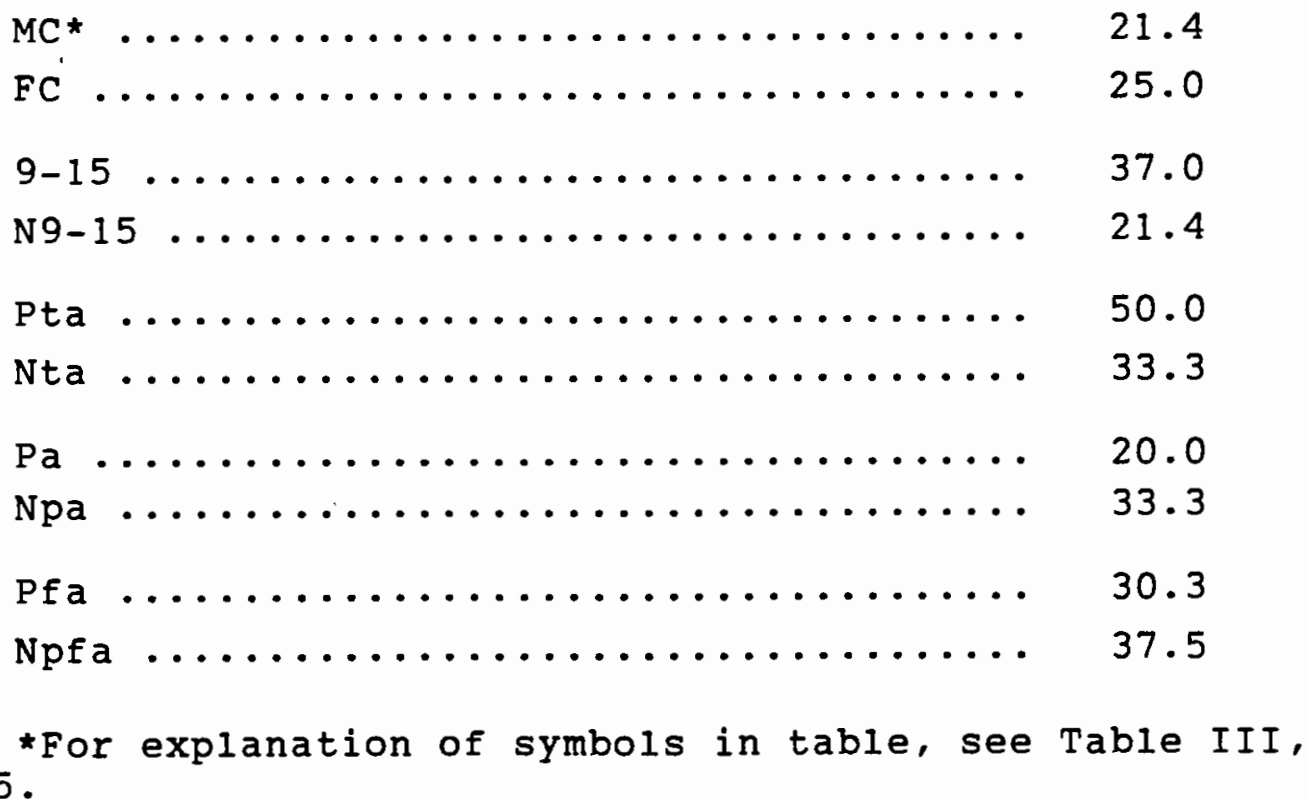

Percent 21.4

148

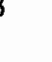


In regard to the mothers' preparation for their children's reentry, it was found that $48.8 \%$ of all the subjects were doing preparation through discussion with their husbands, $43.9 \%$ were preparing through discussion with other Japanese mothers, and $12.2 \%$ were preparing for their children's reentry by attending the program which dealt with the reentry issues. The results of the demographic data analysis are shown in Table XXV.

TABLE XXV

PERCENTAGE OF SUBJECTS MAKING PREPARATIONS FOR THEIR CHILDREN'S REENTRY

Category

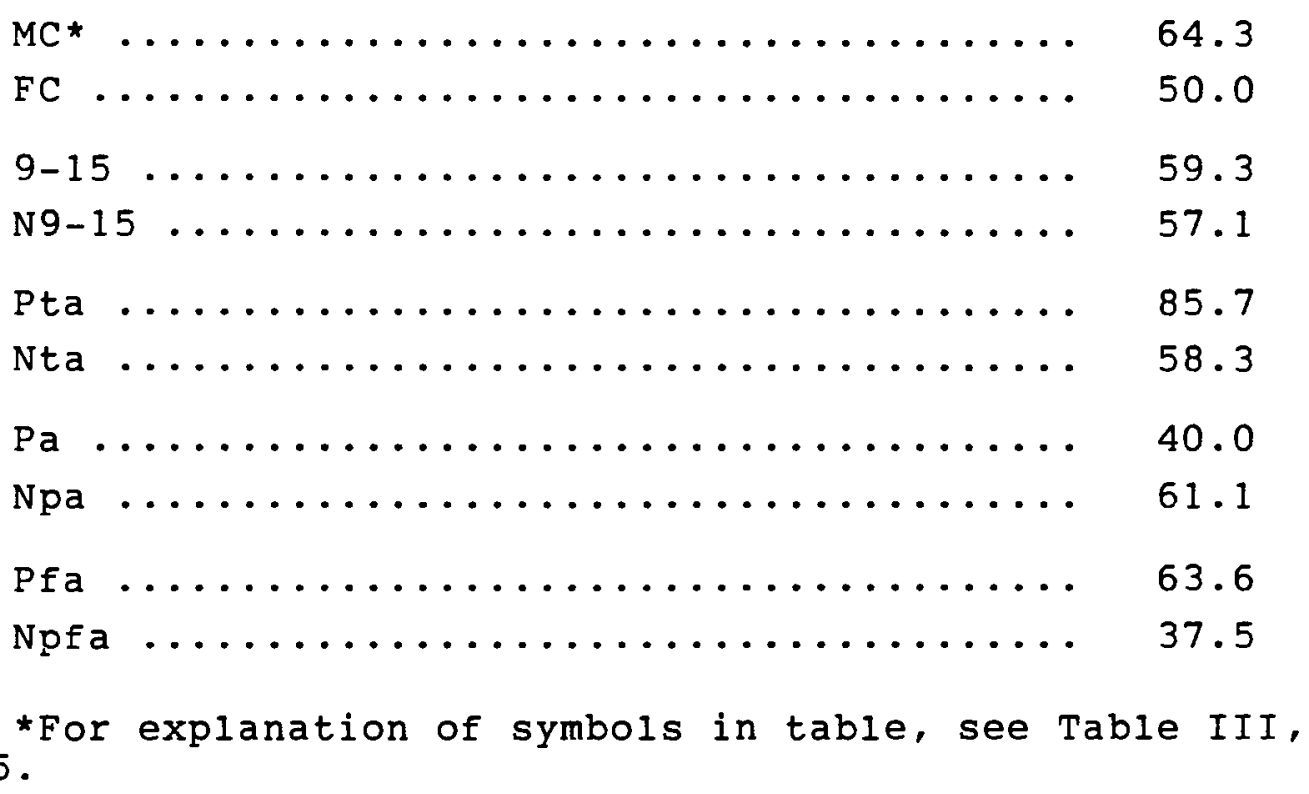

Percent

59.3

85.7

58.3

60

63.6

37.5

p. 115 .

Table XXV indicates that more MC's, 9-15's, Pta's, Npa's, and Pfa's were preparing for their children's reentry than their counterparts in each category. The difference in terms of the children's age was smalier than those of the other 
demographic categories. In this question the result of the demographic category regarding preparation for the present living situation in the U.S. was consistent with the people's general positive idea for preparation.

Two subjects reported other kinds of preparation done by both parents and children which were not described in the above. One subject reported, "My family watched the video tape about the Japanese returnee children entitled 'Bondage'." The other subject reported, "I'm trying to give my child information about Japanese social life and/or other aspects of Japanese culture."

Through the results obtained from questions 11 and 16 , it was found that some mothers were preparing their children for their reentry by encouraging them to speak Japanese at home, by discussing the reentry issues with their children, and/or by showing them books and/or video tapes about Japanese culture. In terms of the mothers' own preparation for their children's reentry, it was found that some mothers were preparing for their children's reentry by discussing the issue with their husbands and/or other Japanese mothers, and/or attending the programs which dealt with the reentry issue. Also, the results showed that mothers were preparing themselves more than preparing their children for their children's reentry issues.

The following questions provided information concerning research questions 1,2 , and 3 in general. Question 24 asked, "Please describe other aspects, if any, you think 
important concerning your children's reentry to Japan." In this open-ended question themes which elicited a response to research question 1 emerged. However, all the themes reported by the subjects were the same as the ones reported in question 17. For example, 5 subjects reported concern for their children's readjustment to the Japanese educational system. Also, 5 subjects reported concern for their children's readjustment to the Japanese ways of $l i f e$, and 2 subjects were concerned with whether their children could get along with the teachers and/or students at school in Japan .

Question 25 asked, "If you have any comments on this questionnaire, please feel free to describe below." Most of the responses were not directly related to the present issue; however, it was noteworthy that 3 subjects reported their feelings about the lack of necessity of preparing for their children's reentry. For example, 1 subject reported, "It is not necessary to be worried about children's readjustment at least at present stage." 
CHAPTER VI

DISCUSSION, LIMITATIONS, AND SUGGESTIONS

FOR FUTURE RESEARCH

\section{DISCUSSION}

In the first part of this final chapter, by referring to the literature review, the researcher will discuss the results in this study, focusing mainly on the results which were considered of major importance by the researcher.

Research question 1 asked whether or not Japanese parents are anticipating the possibility of psychological and communicative problems which their children may face as returnees. The subjects showed higher anticipation of some problems than others. The mean of the 5-point Likert scale concerning the mothers' anticipation of the importance of maintenance of the Japanese language for their children was 4.4. This means that many mothers were aware of the importance of the Japanese language for their children's reentry. The subjects also showed their higher anticipation in terms of changes which happened to their children during their sojourn in the U.S., their children's differences compared with their peer group in Japan, and the influence these differences would have on their reentry to Japan. 
Less than half of the subjects reported social relationships with people at school and/or in the community as being important for their children's reentry. An exception was that $66.7 \%$ of the subjects showed their awareness of the Japanese national characteristics in regard to their children's reentry. However, there was only 1 subject who exactly reported that the nature of Japanese particularism (Japanese people's tendency to not easily accept any differences seen among the Japanese) would become a barrier for their children's reentry. This result was consistent with the subjects' ideas about the importance of "Japaneseness" for their children, which showed that the subjects in this study regarded the importance of "Japaneseness" as above neutral. Moreover, no subjects reported that their children's reduced Japanese language ability would cause the children to suffer from an identity crisis which was one of the problems in regard to language discussed in the literature.

As discussed in the literature review, it is considered that a general Eastern world view expressed as Taoism makes it difficult for the Japanese to look at any situation as a cause-effect relationship. In the case of this study, it could be concluded that the subjects were not aware of the causes for Japanese returnee children's reentry problems. In the Background and Justification section, based on the literature review, this researcher made an assumption that a large number of the parents in this study might be concerned about their children's ability to reenter the 
Japanese educational system. The percentage of the mothers' responses to this issue was not as high as expected. However, since almost $50 \%$ of the subjects showed their concern for their children's academic standing in every open-ended question, it could be said that this theme is important to parents. Also, the fact that the subjects had enrolled their children in the Portland Japanese School shows their concern for this area.

In the separate data analysis, two results attracted the researcher's attention. The first regards the sex of the subjects' children. In most of the questions which were related to children's language issues, the subjects with only male children showed more anticipation of reentry problems than those with only female children. This appears to be consistent with White's (1988) statement that many families feel that girls can afford to be international (p. 101). In a tightly hierarchical society like Japan, men are expected to show their loyalty to the society through devoting themselves to one campany and/or organization in their life, and not to deviate from the main stream of their group. The language plays one of the important roles in Japanese society in this concern. For example, one parent, answering question $10 \mathrm{~b}$, which asked the reason of the importance of the Japanese language for their children, reported, ". . Japanese language is important for my son since unlike my daughter, he will live and work in the Japanese society as a Japanese." 
On the other hand, Japanese women are considered to be able to become more flexible. The more skillful they are in some special fields, the more opportunities they are likely to obtain as a specialist in the job situation, i.e., a specialist in the English language. However, there is a catch when the issue concerns interpersonal relationships. For example, as seen in the result of the question that asked the subjects whether they expected the differences which occurred to their children could cause any difficulties for their reentry to Japan, $88.9 \%$ of the subjects with only female children, compared to $63.6 \%$ with only male children, considered that their children's differences could cause problems in connection with their reentry. This result appears to indicate that there is a stronger social expectation for the Japanese women. The value of suppression and restraint for women in Japanese culture has deep historical roots (Ramsey, 1985), and is a determinant for how a Japanese woman is supposed to behave in the society. For example, if the nonverbal behavior of the Japanese female college student differs from the female returnee student from the U.S., there would be serious consequences for the female returnee student. Ramsey mainly discussed Japanese women's nonverbal behavior, but it can also be applied to their verbal behavior. If the female returnee children behave like an American student in the classroom situation by presenting American nonverbal and/or verbal behavior, they are likely to experience a harder time than male children in regard to keeping 
good social relationships with teachers and/or their peer group. The questionnaire shows that the parents with only female children are more concerned about their children's changes than those with male children. Also, the subjects with only female children showed more anticipation of the importance of maintenance of the children's Japaneseness. The second interesting result was in regard to the children's age. In most of the questions the subjects with children who belonged to the $9-15$ age category showed more anticipation of the issue of the Japanese returnee children's reentry than those of the other age categories. However, a major exception was that $87.5 \%$ of the subjects whose children belonged to the other age categories, in comparison with $76.2 \%$ of those with children in the 9-15 category, showed more anticipation of the negative influence of the children's changes to their reentry to Japan. In considering Minoura's (1987) statement introduced previously, which states that if the children spent their life at the age of 9-15 in America, they tended to be psychologically assimilated to the meanings existing behind the American mode of interpersonal relationship and/or behavior, it could be hazardous that the parents with children in this age category do not anticipate the effect of their children's sojourn in the U.S. on their reentry to Japan.

Research questions 2 and 3 asked about the preparations being made in terms of discussion and other means. As seen 
in the results of question $11,85.4 \%$ of the subjects' children were using only the Japanese language at home. However, it was found that less than half of the mothers (43.9\%) encouraged this. Also, it is not clear whether these mothers encouraged their children as a conscious preparation for their reentry. In considering the fact that $75 \%$ of the subjects reported the necessity of preparation for their children's reentry in question 15 , this number is very low.

In question 16 the researcher asked directly about the subjects' preparation for their children's reentry. Most of the items were related to the subjects' discussion of the issue of the children's reentry since the literature stated the necessity of discussion as a preparation. It was found that only $31.7 \%$ of the subjects were preparing their children for their reentry through discussion. In regard to parents' preparation, it was found that $48.8 \%$ of the subjects discussed the reentry issue with their husbands, $43.9 \%$ discussed it with other Japanese mothers, and $12.2 \%$ of the subjects attended a seminar where reentry problems were dealt with. These results indicate that less than half of the subjects were doing discussion with their husbands and/or children as a preparation for the children's reentry, and this discussion occurred less than once every 3 months. This frequency is lower in comparison with Wallack and Metcalf's (1982) suggestion that parents should provide an opportunity to have a discussion once a week as a preparation for overseas movement. 
In other words, it appears that subjects in the present study did not regard discussion as a part of preparation.

The researcher considers that the above data indicates the Japanese cultural aspect seen in the Eastern world view, and their attitudes toward problem solving. As discussed in the literature review, unlike the traditional Western view of the universe, which tends to rationalize situations and use a dialectic approach, Japanese thought patterns stemming from the Eastern view of Taoism does not follow this kind of approach. In this mode of thinking there exists no dichotomy expressed as such things as right or wrong, black or white, or happiness or sadness. It allows for acceptance of opposites as existing together, and a problem is approached in a more holistic way.

This nondualistic way of thinking affects the Japanese attitude toward problems. As discussed previously, when Americans face a problem, they usually confront the situation and/or people directly, and try to solve the problem, usually through direct open discussion. On the other hand, the Japanese do not approach a problem necessarily as something to be solved. Their attitude is more like "It will work itself out." Also, it is felt that open discussion could lead to criticism of the other person's opinion, which often hinders harmonious interpersonal relationships.

Since this kind of explanation is especially given to the people on the outside of the family (out-group), it may 
or may not be directly applied to the subjects in this study. The researcher considers that Japanese preference for the idea of using intuition or reading nonverbal expressions is related to the present case. As Kunihiro, cited by Ramsey (1985), says, intuitive communication is an important usual method of communication within the family. The researcher considers that this emphasis on intuitive communication led to the small amount of discussion reported in this study. In answering the question which asked the reasons for not discussing the children's reentry issue within the family, a subject reported, "Even if we do not discuss, I know that all of our family have the same opinion." This statement clearly describes the above mentioned Japanese cultural aspect.

If discussion is not regarded as a preparation, it is important to know what kinds of things the present subjects are doing in preparation for their children's reentry. Only $12.2 \%$ of the subjects reported that they had attended a seminar dealing with reentry problems. Only 2 subjects reported that they were showing the children video tapes and/or books on Japan. This indicates that only a small number of the subjects are doing some preparation for their children's reentry except for enrolling them in the Saturday Japanese school to keep them abreast of academic subjects. It is also interesting to compare this result with that of question 7 which asked about the subjects' preparation for the present 
U.S. assignment. The result showed that $63.6 \%$ of the subjects had attended orientation programs for living overseas sponsored by their spouses' company and/or organizations, and $57.6 \%$ of the subjects read a book(s) about the U.S. This different result appears to show the subjects' lesser concern for their children's reentry problems than for their adjustment to the U.S. This is consistent with reentry literature which concludes that unlike culture shock, since reentry shock is totally unexpected, people do not feel the necessity to prepare for their own reentry.

Some results of the demographic analysis regarding the children's age attracted the researcher's attention. It was found that the subjects with children who did not belong to the 9-15 age category had discussions with their husbands and children more frequently than those with children in the 9-15 age category. However, the subjects with children who belonged to the 9-15 category were found to be preparing themselves and/or their children for their children's reentry more than those in the other categories. This appears to reinforce the lack of relationship of discussion to the idea of preparation in the present subjects' case which was described previously.

\section{LIMITATIONS OF THE PRESENT STUDY}

There are some limitations in the present study. First, it can be stated that "there are at least potential communication problems in all cross-cultural research" (Schrest, 
Fay, and Zaidi, 1985, p. 218). A common problem is the necessity to translate from one language to another. Even though reliability of the translation of the questionnaire was checked, there still could be confusion there and with the translation of the responses.

The second limitation is related to the general unfamiliarity of the Japanese with the research procedure. Because of this unfamiliarity, some subjects in the present study might have suspected or misunderstood the questions, and/or even hesitated to return their questionnaire. Moreover, they might have reported what appeared to be the "best" answer rather than their honest feelings.

The third limitation is related to the nature of the mailed survey questionnaire. The following disadvantages of mailed questionnaires described by Bailey (1982) are applicable to the present study.

1. Lack of flexibility. Since there is no interviewer present in the survey questionnaire, there is no variation in questions asked and no probing for a more specific answer if the respondent's first answer is too vague or general to be useful. In the present study some answers in open-ended questions showed irrelevancy to the questions asked. Also, in 5-point Likert-type questions, several subjects used their own scales, not choosing an appropriate answer from already established scales in each question. However, because of the lack of flexibility of mailed questionnaires, the researcher could not 
correct these subjects' misunderstandings, and as a result could not use that data.

2. No control over environment. In a mailed questionnaire study there is no assurance that the respondent will be able to complete the answers in private. In this study the subject's husband or children might have demanded to see the completed questionnaire and censored it.

3. Verbal behavior only. In the descriptive study observation of subjects' nonverbal behavior is one of the important aspects. However, in this study since there is no interviewer present, the researcher could only have access to the mothers' verbal behavior.

Another limitation of the present study is population. Access to subjects was restricted to the parents who enrolled their children in the Portland Japanese School. Because of this necessary selection procedure, not random sampling, the results of this study may not be generalizable to a larger population, e.g., subjects living in the different states in the U.S., or different countries, or even subjects in Portland who do not think it necessary to continue their children's Japanese education while they are an overseas assignment. Also, the number of the subjects in this research was limited particularly for separate demographic data analysis. Those who did not return the questionnaire might be ones who were least active in preparing for reentry and therefore, embarrassed by the questionnaire. However, a $62.6 \%$ response rate 
in this study is considered good by Lin introduced by Tucker, Weaver, and Berryman-Fink (1981).

\section{SUGGESTIONS FOR FUTURE RESEARCH}

This study has collected data which helps to view Japanese mothers' anticipation of the issue of their returnee children, and the kinds of preparation they are doing for the children's reentry to Japan. The researcher focused only on the mothers' anticipation and preparation. This was because mothers are likely to take major responsibility for raising children, especially in Japan. However, since in terms of children's reentry it is very important for both parents to share their anticipation of the issue and cooperate with each other, future research could focus on fathers' anticipation, too. Another suggestion would be to involve future returnee children themselves by investigating to what extent the children's subjective reports of anticipation of their own reentry are consistent with those of their parents. Moreover, as described in the limitations of the present study, future research should be done for a larger population, e.g., Japanese families living in the other states, and countries other than the U.S.

The topic of reentry needs to be treated in a holistic way in the sense that there are both returnees and people who are in the position to accept these people. In order to approach the issue of Japanese returnee children, it is significant to focus on Japanese teachers' anticipation of the 
present issue, and the kinds of preparation they are doing at school so that returnee children can adjust to their school life smoothly in Japan. In doing research in Japan, the following questions could be explored from the perspective of Japanese teachers: (1) What are the difficulties that Japanese returnee students face in the school system? (2) What are the cultural expectations which Japanese returnee students have to meet to readjust to Japanese society? (3) Are the schools which accept Japanese returnee children offering any educational programs which satisfy the needs of those children?

As discussed in the Operational Definitions section of this paper, it is significant to note that the commonly accepted definitions of "reentry" in the field of intercultural communication, which represents the value of individualism, is not applicable to the study of Japanese returnees.

As seen in the case of sojourning abroad, orientation programs play a vitally important role for people's reentry to their home country. In this study only 5 out of 41 subjects reported that they had attended reentry orientation programs, however, the researcher could not clarify where those programs were held, and what kinds of programs they were. Future research should be conducted concerning what kinds of orientation programs are offered at present both in Japan and in the U.S. in terms of children's reentry. 


\section{SUMMARY AND CONCLUSION}

This research project has shown that, in general, the Japanese mothers in this study anticipated some of the potential effects of their children's sojourn in the U.S. on their reentry to Japan, but did not anticipate the causes of those effects, or ways to minimize the problems. It was also found that they were not discussing the issue of reentry with their husbands and/or their children as much as is recommended in the literature. This was explained by the tendency of the Japanese in general not to verbalize theirfeelings. Although many mothers anticipated the necessity to prepare for their children's reentry other than helping their children in the academic areas, most of them did not report any kinds of preparation they were actually doing.

An indirect goal of this research was to alert those Japanese parents and teachers, who might need this study, to the children's reentry issues. It is the writer's hope that in a small way this project will help intercultural communication scholars to design reentry orientation programs specifically for Japanese returnee children since more and more Japanese families are in temporary residence in the U.S. It is also hoped that as viewed in this study, intercultural communication scholars will recognize the need to redefine the terms, such as "reentry," by taking consideration of the cultural context, and design training and coping methods which could be used in reentry orientation programs. 
REFERENCES

Adler, N. (1981). Reentry: Managing cross-cultural transitions. Group and Organization Studies, 6, 341-356.

Adler, P. (1975). The transitional experience: An alternative view of culture shock. Journal of Humanistic Psychology, 15, 13-23.

- (1985). Beyond cultural identity: Reflections on cultural and multicultural man. In L. A. Samovar and R. E. Porter (eds.), Intercultural communication: A reader. 4th ed. Belmont, CA: Wadsworth Publishing Company.

Andersen, J.F. (1985). Educational assumptions highlighted from a cross-cultural comparison. In L. A. Samovar and R. E. Porter (eds.), Intercultural communication: A reader. 4th ed. Belmont, CA: Wadsworth Publishing Company.

Austin, C. N. (Ed.) (1986). Reentry stress: The pain of coming home. In Cross-cultural reentry: A book of readings. Abilene, TX: Abilene Christian University Press.

Bailey, K. D. (1982). Methods of social research. 2nd ed. New York: The Free Press.

Barker, L. L. (1987). Communication. 4th ed. Englewood Cliffs, NJ: Prentice-Hall, Inc.

Barna, L. M. (1983). The stress factor in intercultural relations. In D. Landis and R. W. Brislin (eds.), Handbook of intercultural training. Vol. II. New York: Pergamon Press.

- (1985). Stumbling blocks in intercultural communication. In L. A. Samovar and R. E. Porter (eds.), Intercultural communication: A reader. 4th ed. Belmont, CA: Wadsworth Publishing Company.

- (3 October 1988). Personal interview.

Barnlund, D. C. (1975). Public and private self in Japan and the United States. Tokyo: The Simul Press. 
Barnlund, D. C. and Nomura, N. (1983). Patterns of interpersonal criticism in Japan and United States.

International Journal of Intercultural Relations, 7, $2-17$.

Becker, T. (1968). Patterns of attitudinal changes among foreign students. American Journal of Sociology, 73, $431-442$.

Benedict, R. (1946). The chrysanthemum and the sword. Tokyo: Charles E. Tuttle Company, Inc.

Bennett, M. J. (1986). Towards ethnorelativism: A deve1opmental model in intercultural sensitivity. In M. Paige (ed.), Cross-cultural orientation. New York: University Press of America.

Berger, P. L. and Luckman, T. (1967). The social construction of reality. New York: Anchor Books.

Blackmun, M. ( 3 March 1988). Couple from Japan provide cultural exchange. The Oregonian, p. 2Mp 4M.

Bochner, S., Lin, A., and McLeod, B. M. (1980). Anticipated role conflict of returning overseas students. Journal of Social Psychology, 110, 265-272.

Brislin, R. W. (1974). The establishment of re-entry/ transition seminar of overseas sojourners. Paper presented for the Re-Entry/Transition workshop at Wingspread, Madison, WI.

- (1981). Cross-cultural encounters. New York: Pergamon Press.

Brislin, R. W. and Buren, V. H. (1986). Can they go home again. In C. N. Austin (ed.), Cross-cultural reentry: A book of readings. Abilene, $\mathrm{TX}$ : Abilene Christian University Press.

Brislin, R. W. and Pedersen, P. (1976). Cross-cultural orientation program. New York: Garner Press.

Cantrel1, A. W. (1974). Culture shock and the foreign service child. Foreign Service Journal, 51, 4-8, 28-29.

Condon, J. C. (1984). With respect to the Japanese. Yarmouth: Intercultural Press, Inc.

Condon, J. C. and Yousef, F. S. (1975). Introduction to intercultural communication. Indianapolis: The BobbsMerril Company, Inc. 
Doi, T. (1973). The anatomy of dependence. Translated by $\mathrm{J}$. Bester. Tokyo: Kodansha International Ltd. (original work published in 1971).

Domoto, A. (1987). Student returnees, student misfits. Japan Quarterly, 34, 34-38.

Eakin, B. K. (1979). The real culture shock: Adolescent re-entry to the U.S. Foreign Service Journal, 56, 2022 .

Ehrlick, H. (1973). The social psychology of prejudice. New York: Wiley.

Enloe, W. and Lewin P. (1987). Issues of integration abroad and readjustment to Japan of Japanese returnees. International Journal of Intercultural Relations, 11, 223-248.

Farkas, J. B. and Kono, M. (1987). America no nihonjin seito tachi: Ibunka kan kyoikuron (Japanese students in America: Intercultural education). Tokyo: Tokyo Shoseki, Ltd.

Fontaine, C. M. (1986). International relocation: A comprehensive psychosocial approach. In C. N. Austin (ed.), Cross-cultural reentry: A book of readings. Abilene, TX: Abilene Christian University Press.

Freedman, A. (1986). A strategy for managing cultural transitions: Re-entry from training. In C. N. Austin (ed.), Cross-cultural reentry: A book of readings. Abilene, TX: Abilene Christian University Press.

Gama, E. M. P. and Pedersen, P. (1977). Readjustment problems of Brazilian returnees from graduate studies in the U.S. International Journal of Intercultural Relations, $1,46-59$.

Guither, H. D. and Thompson, W. N. (1986). Return, readjustment and reminiscence. In C. N. Austin (ed.), Crosscultural reentry: A book of readings. Abilene, TX: Abilene Christian University Press.

Gullahorn, J. E. and Gullahorn, J. A. (1963). An extension of the U-curve hypothesis. Journal of Social Issues, $14,33-47$.

Haglund, E. (1984). Japan: Cultural considerations. International Journal of Intercultural Relations, $8, \frac{1}{61-75}$. 
Hal1, E. T. (1959). The silent language. Garden City: Anchor Books.

Harrell, B. (1986). Practical guidelines in the positive adjustment of missionary children. In $C$. N. Austin (ed.), Cross-cultural reentry: A book of readings. Abilene, TX: Abilene Christian University Press.

Hasebe, M. (1985). Kaigaishijo kyoiku manyuaru (Parents' manual for educating children overseas). Tokyo: Foundation of Japanese Overseas Education.

Hoijer, H. (1985). The Sapir-Whorf hypothesis. In L. A. Samovar and R. E. Porter (eds.), Intercultural communication: A reader. 4th ed. Belmont, CA: Wadsworth Publishing Company.

Impoco, J. (July 1988). You think it's bad here. U.S. News \& World Report, 34 .

Irish, D. (1986). Rules for re-entry. In C. N. Austin (ed.), Cross-cultural reentry: A book of readings. Abilene, TX; Abilene Christian University Press.

Ishii, S. (1985). Thought patterns as modes of rhetoric: The United States and Japan. In L. A. Samovar and R. E. Porter (eds.), Intercultural communication: A reader. 4th ed. Belmont, CA: Wadsworth Publishing Company.

Ishii, S. and Bruneau, T. (1988). Silence and silences in cross-cultural perspective: Japan and the United States. In L. A. Samovar and R. E. Porter (eds.), Intercultural communication: A reader. 5 th ed. Belmont, CA: Wadsworth Publishing Company.

Kagitcibasi, C. (1978). Cross-national encounters of Turkish students in the U.S. International Journal of Intercultural Relations, $2,141-160$.

Kelly, T. F. (1973). Who's the kids' advocate? Foreign Service Journa1, 50, 16-19, 32 .

Kim, Y. Y. (1985). Intercultural personhood: An integration of Eastern and Western perspectives. In L. A. Samovar and R. E. Porter (eds.), Intercultural communication: A reader. 4th ed. Belmont, CA: wadsworth Publishing Company.

Kitagawa, T. (March 1982). Kyoiku sodanshitsu (Educational counseling room). Kaigai Shijo Kyoiku (Overseas Children's Education), 34-37. 
Kitashiro, M. (September 1984). Oya ni kaserareta gimu (A duty imposed on the parents). Kaigai Shijo Kyoiku (Overseas Children's Education), 56.

Kobayashi, T. (1981). Kaigai Shijo Kyoiku, kikoku shijo kyoiku (Overseas Children's Education, returning children's education). Tokyo: Yuhikaku.

Koehler, N. (1986). Reentry shock. In C. N. Austin (ed.), Cross-cultural reentry: A book of readings.

Abilene, TX: Abilene Christian University Press.

LaBrack, B. (October 1981). Readjustment problems of students returning from abroad. Eigo Kaiwa II.III

(English conversation II.III), 34-53.

- (September 1983a). Cool welcome home. PHP, 28-37.

. $(1983 \mathrm{~b})$. The reentry process as a cultural universal and the status of "returnee" studies in Japan. In N. Horoiwa and T. Nakazawa (eds.), Meta Report I: Ibasho sagashi to ibunka taiken (The identity search and cross-cultural experiences). Tokyo: Meta Press.

Lambert, W. E. (1967). Social psychology of bilingualism. Journal of Social Issues, 23, 91-109.

Lowenthal, N. P. and Renwick, G. (July 1988). Training in transnational business. Packet used at Summer Institute of Intercultural communication, Portland, OR.

Lundstadt, S. (1963). An introduction to some evolving problems in cross-cultural research. Journal of Social Issues, $19,1-9$.

Martin, J. N. (1984). The intercultural reentry: Conceptua\begin{tabular}{l} 
lization and direction for future research. Inter- \\
national Journal of Intercultural Relations, \\
\hline , $115-$
\end{tabular} 133 .

- (1986). Communication in the intercultural reentry: Student sojourners' perspectives of change in reentry relationships. International Journal of Intercultural Relations, $10,1-12$.

Meinte1, D. A. (1973). Stranger, homecomers and ordinary men. Anthropological Quarterly, 46(1), 47-58.

Ministry of Education (1988). Kaigai Shijo Kyoiku no Genjo (The present situation of overseas children's education). Tokyo: Ministry of Education. 
Minoura, Y. (April 1981a). Kaigai de sodatsu to wa? (What does it mean to grow up overseas?) Kaigai Shijo Kyoiku (Overseas Children's Education), 20-21.

- (August 1981b). Gentenho no shakai nihon (Society of reduction: Japan). Kaigai Shijo Kyoiku (Overseas Children's Education), $4 \overline{5}$.

- (1987). Kodomo no ibunka taiken: Jinkaku keisei katei no shinrijinruigakuteki kenkyu (Intercultural experience of children: Psychoanthropological study of the process of personality formation). Tokyo: Shisakusha.

Mitarai, S. (1981). Transcultural education and JapaneseAmerican relations. Ph.D dissertation, Oregon State University, Corvallis, OR.

Nakane, C. (1984). Japanese Society. Tokyo: Charles E. Tuttle Co.

Naotsuka, R. (1984). Obeigin ga chinmoku suru toki (When the Westerners become silent). Tokyo: Taishukan.

Naotsuka, R. and Sakamoto, N. (1982). Polite fictions. Tokyo: Kinseido.

Nelson, E. T. (1988). The expression of politeness in Japan: Intercultural implications for Americans. Master's thesis, Portiand State University, Portiand, OR .

Ota, A. (5 September 1985). Adjustment of ten troublesome for Japanese in U.S. The Oregonian, p. 2 .

Piet-Pelon, N. J. (1986). Reentry for teens. Foreign Service Journal, 63, 28-30.

Porter, R. E. and Samovar, L. A. (Eds.). Approaching intercultural communication. In Intercultural communication: A reader. 4th ed. Belmont, CA: Wadsworth Publishing Company.

Ramsey, S. (1985). To hear one and understand ten: Nonverbal behavior in Japan. In L. A. Samovar and R. E. Porter (eds.), Intercultural communication: A reader. 4th ed. Belmont, CA: Wadsworth Publishing Company.

Read, R. (12 January 1988). Japanese executives find going home again can be difficult. The Oregonian, p. D8.

Rooks, J. (12 January 1988). A hitch in Oregon can be tough at first. The oregonian, p. D7. 
Schrest, L., Fay, T. L., and Zaidi, S. M. (1985). Problems of translation in cross-cultural communication. In L. A. Samovar and R. E. Porter (eds.), Intercultural communication: A reader. 4 th ed. Belmont, CA: Wadsworth Publishing Company.

Schuetz, A. (1945). The homecomer. American Journal of Sociology, 50, 376-396.

Smith, M. J. (1988). Contemporary communication research methods. Belmont, CA: Wadsworth Publishing Company.

Sobie, J. H. (1986). The culture shock of coming home again. In C. N. Austin (ed.), Cross-cultural reentry: A book of readings. Abilene, $T \bar{X}$ : Abilene Christian University Press.

Stewart, E. C. (1972). American cultural patterns. Pittsburgh: Regional Council for International Education.

Stonequist, E. V. (1935). The problem of the marginal man. American Journal of Sociology, $41,1-12$.

Sussman, N. M. (1986). Re-entry research and training: methods and implications. International Journal of Intercultural Relations, $10,235-254$.

Suzuki, T. (October 1979). Gaikokugo to aidentiti (Foreign language and identity). Kaigai Shijo Kyoiku (Overseas Children's Education), 22-23.

Tai, E. (1986). Modification of the Western approach to intercultural communication for the Japanese context. Master's thesis, Portland State University, Portland, OR .

Tucker, R. K., Weaver, F. L., and Berryman-Fink, C. (1981). Research in speech communication. Englewood Cliffs, NJ: Prentice-Hall, Inc.

Ueda, K. (1974). Sixteen different ways to avoid saying "no" in Japan. In J. C. Condon and M. Saito (eds.), Intercultural encounter with Japan. Tokyo: The Simul Press.

Uehara, A. (1986). The nature of American student reentry adjustment and perception of the sojourn experience. International Journal of Intercultural Communication, $10,415-437$.

Ulrich, K. (1986). Normative teacher and student role behaviors in the U.S. with a contrast to Japan. Master's thesis, Portland State University, Portland, OR. 
Wallack, J. and Metcalf, G. (Summer 1981). Raising children overseas. Bridge, 13-14.

- (1982). Parenting abroad. Foreign Service Journal, $59,20-23$.

Watzlawick, P., Beavin, J. B., and Jackson, D. D. (1967). Pragmatics of human communication: A study of interactional patterns, pathologies, and paradoxes. New York: w. W. Norton \& Company.

Werkman, S. L. (1986). Coming home: Adjustment of Americans. In C. N. Austin (ed.), Cross-cultural reentry: A book of readings. Abilene, TX: Abilene Christian University Press.

White, M. (1988). The Japanese overseas: Can they go home again? New York: The Free Press.

Yanagihara, M. (July 1983). Kikoku shijo: Shakaijin to shite no aidentiti (Returnee children: Identity as a member of the society). Kaigai shijo Kyoiku (Overseas Children's Education), 37. 
APPENDIX A

ANXIETIES HELD BY JAPANESE FAMILIES OVERSEAS 


\section{APPENDIX A}

ANXIETIES HELD BY JAPANESE FAMILIES OVERSEAS (Survey by the Ministry of Education in 1982)

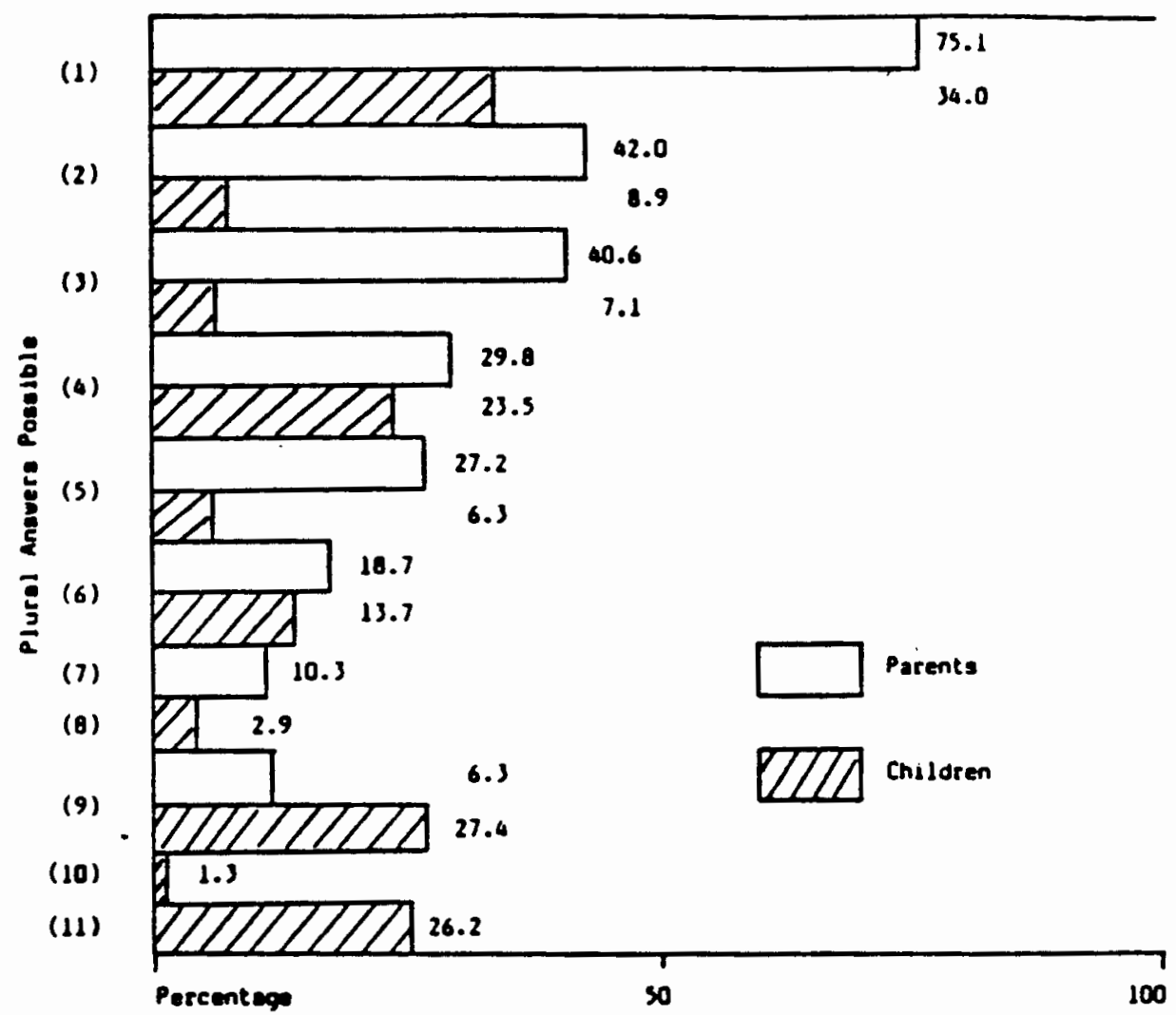

(1) Unether the children cen keep up oith the study after returning to depanese echeol.

(2) Whether the children cen acke friends.

(3) Wether the childten cen reedjust to the clieste and life environments in Jepon.

(4) Whether the childten cen enter the Jepenese high echool or university.

(3) Whether they cen epock lepenese well.

(6) Whether thore are apeciel schools for relurnec childten in the aree there their resily lives ofter returning to jepen.

(7) Wether the chilaten cen got a job ot a Jepenese compeny.

(8) Whether the children cen get a job in mich thay cen anke use of thest overseas emparianco.

(9) other

(10) Whether the children cen stay at a foresgn country without returning to japen.

(11) Thure are no spocial anxieties in returning to japen.

mote: Survey polled 7,000 remilies. 
APPENDIX B

PROBLEMS FACED BY RETURNEE CHILDREN 


\section{APPENDIX B}

PROBLEMS FACED BY RETURNEE CHILDREN

(Survey by the Ministry of Education in 1982)

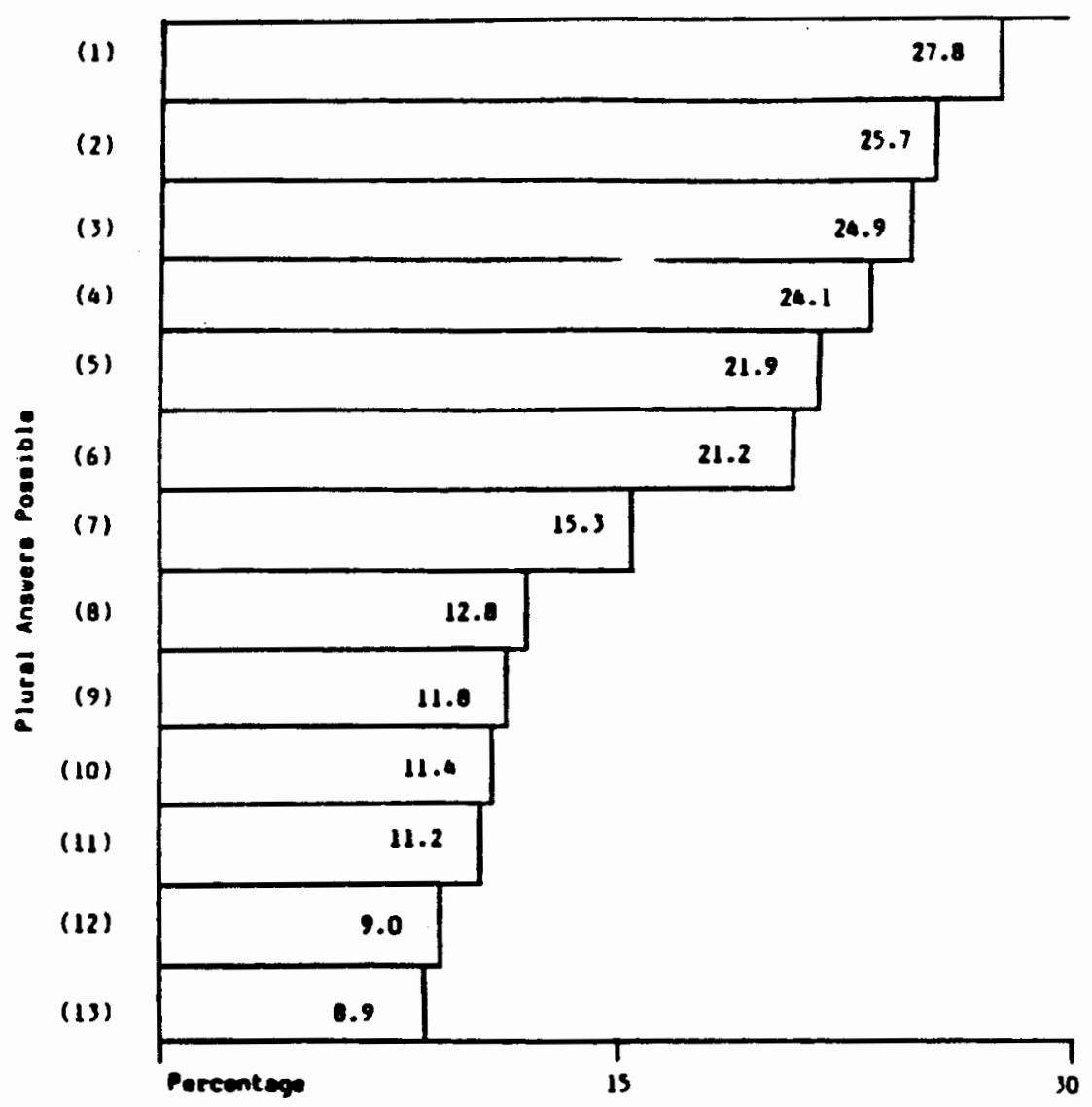

(1) School vecation is thort.

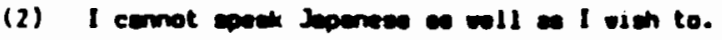

(3) It is difficult to kep exociation oith the friends.

(4) School requlation ore teo strict.

(5) I foel werreaced with the lepenese cuaton and nemmer.

(6) I cemat do wil ot P.E. cleas

(7) I to nat bou now to etudy.

(8) The centente of the cleases ore difficult to follos.

(9) Thare is teo auch homowork.

(10) In ectool is far erey from ay house.

(11) I hove to epend any houra et echool a day.

(12) I cenot underat and lapenese very wll.

(13) Other

noIT: Surver polled 4,000 fanilies. 
APPENDIX C

LIST OF POTENTIAL PROBLEMS FROM THE REVIEW OF

LITERATURE WHICH WILL BE FACED BY THE

JAPANESE RETURNEE CHILDREN 
LIST OF POTENTIAL PROBLEMS FROM THE REVIEW OF LITERATURE WHICH WILL BE FACED BY THE

JAPANESE RETURNEE CHILDREN

\section{Language Issue:}

1. Because of Japan's particularism, returnee children's high English proficiency could become a serious barrier to their readjustment to the schools in Japan.

2. Because of Japan's particularism, returnee children's reduced Japanese ability due to intensive use of English could become a serious barrier to their readjustment to the schools in Japan.

3. Returnee children's reduced Japanese ability could cause an "identity crisis" to the returnee child.

\section{Issues Other than Language:}

4. Losing "Japaneseness" could become a serious barrier to the Japanese returnee children's readjustment to the schools in Japan.

a. Changes in terms of values, ways of thinking, behavioral patterns and communication styles could occur to the person who has sojourned in a foreign country. The Japanese children who have lived out of Japan, especially in the U.S., could be much influenced in terms of these intercultural aspects.

b. Because of Japan's particularism, even subtle differences which occurred in the returnee children could become a serious barrier to their readjustment 
to the schools in Japan partly because of the reaction of their peers and their teachers against it. 
APPENDIX D

THEMES WHICH EMERGED FROM SUBJECTS' RESPONSES 
THEMES WHICH EMERGED FROM SUBJECTS' RESPONSES

Q6b A: Curiosity about overseas living

B: Benefit for family

c: Anxiety

Q9 (Advantage)

A: Social necessity/desirability of knowing English language

B: Academic reasons

C: Cultural enrichment

(Disadvantage)

D: Reduced Japanese language ability

E: Difficulty of maintaining good social relationships with people at school and/or in the community

F: Academic reasons

G: More limited possibilities for occupation

Q10b A: Academic reasons

B: To maintain good social relationships with people at school and/or in the community

C: Japanese national characteristics

Q17 A: Concern for readjusting to the Japanese ways of Iife

B: Academic concerns

C: Concern for maintaining good social relationships with people at school and/or in the community 
D: Concern for Japanese national characteristics

E: Concern for maintaining Japanese language ability

F: Social necessity and/or desirability of knowing English language

Q24 A: Concern for readjusting to the Japanese ways of Iife

B: Academic concerns

C: Concern for maintaining good social relationships with people at school and/or in the community 


\section{APPENDIX E}

\section{HUMAN SUBJECTS RESEARCH REVIEW}

COMMITTEE APPROVAL 


\author{
HUMAN SUBJECTS RESEARCH REVIEW \\ COMMITTEE APPROVAL
}

PORTLAND STATE UNIVERSTTY

MEMORANDUM

HUMAN SUBJECTS RESEARCH REVIEW COMMITTEE

$1987-1988$

DATE: August 30,1988

TO: Noriko Nakagawa, SP

FROM: Robert C. Holloway, Chairperson

Human Subjects Research Review Committee (HSRRC)

RE: HSRRC Approval

In accordance with your request, the Human Subjects Research Review Committee has reviewed your proposal entitled Preparation of Japanese Parents in the U.S. for their Children's Potential Communication Problems in their Reentry to Japan for compliance with DHHS policies and regulations on the protection of human subjects.

The committee is satisfied that your provisions for protecting the rights and welfare of all subjects participating in the research are adequate and therefore the project is approved.

c: Office of Grants and Contracts

$\mathrm{RCH}: \mathbf{a} \mathbf{s m}$ 
APPENDIX F

\section{QUESTIONNAIRE}


ENGLISH VERSION

Demographic Information

1. How long has your family been living in the U.S.? year(s) month(s)

2. Please indicate the number, age, and sex of the children who are living in the U.S. with you.

lst child:

2nd child:

$3 r d$ child:

Age

Age

Male

Male

Male

Female

Female

Age

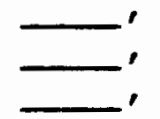

Female

*If you have more than three children, please describe below in the same way.

3. Did either you or your husband spend part or all of your/his childhood (up to high school age) in any country other than Japan?

$$
\text { Yes No }
$$

If 'yes,' please state where you/he lived, how long you/he

(or both) were there, and your/his age at that time.

4. Has your family been assigned overseas previously? Yes No

If 'yes,' please state where you 1 ived, the date and length of time you were there, and whether your children were with you at these times. Also, if your children were school age, what was the language used at that school?

5. Do you expect your family to return to Japan within the next six months? Yes $\quad$ No 
6(a) How did you feel when you heard about this present overseas assignment from your husband?

$\begin{array}{ccccc}1 & 2 & 3 & 4 & 5 \\ \text { very } & \text { somewhat } & \text { neutral } & \text { not } & \text { very } \\ \text { pleased } & \text { pleased } & & \text { pleased } & \text { displeased }\end{array}$

(b) Please describe the reasons for this feeling.

7. Did you do anything in Japan to prepare for living in the U.S.? Please check each of the following that is appropriate, or describe what you did.

(1) Nothing
(2) attended orientation programs for living
overseas sponsored by my husband's company
and/or other organizations.
(3) I read a book(s) about the U.S.
(4) I talked with my acquaintances who had an
experience of overseas assignment in the
U.S.

Parent's Awareness, Communication Behavior, and Preparation for the Children's Reentry:

8. How would you judge your children's English proficiency? 5 very good good fair poor very poor

9. Obviously your children will have better English speaking ability than those Japanese children who have never left Japan. What advantages and/or disadvantages do you believe your children will have after they return to Japan because of this English ability?

10(a) How important do you think it is for your children to maintain and/or improve their Japanese language ability in preparation for return to Japan?

$\begin{array}{ccccc}5 & 4 & 3 & 2 & 1 \\ \text { impory } & \text { important } & \text { neutral } & \begin{array}{c}\text { not so } \\ \text { important }\end{array} & \begin{array}{c}\text { not } \\ \text { important } \\ \text { at all }\end{array}\end{array}$


(b) Please explain why you think this way.

11 (a) What language do your children usually speak in your home in the U.S.? Japanese English Both

(b) Why do you think they use this language at home? Please check appropriate number(s) below.

(1) They are used to speaking Japanese more than English.

(2) Most of their playmates use Japanese.

(3) I encourage them to use Japanese.

(4) They are used to speaking English more than Japanese.

(5) Most of their playmates use English.

(6) I encourage them to use English.

(7) Other (please describe)

12. Have you ever discussed such language issues as those mentioned in Q9-Q11 with your husband?

$54 \quad 4 \quad 3 \quad 2$ $\begin{array}{cccc}\text { once a } & \begin{array}{c}\text { once a } \\ \text { meek }\end{array} & \begin{array}{c}\text { once every } \\ \text { month }\end{array} \text { three months } & \text { never }\end{array}$

13. Have you ever discussed these same language issues with your children?

$\begin{array}{ccccc}5 & 4 & 3 & 2 & 1 \\ \begin{array}{c}\text { once a } \\ \text { week }\end{array} & \begin{array}{c}\text { once a } \\ \text { month }\end{array} & \begin{array}{c}\text { once every } \\ \text { three months }\end{array} & \begin{array}{c}2 \\ \text { seldom }\end{array} & \text { never }\end{array}$

14. If you do not discuss language issues with your husband and/or children, please check appropriate number (s) below.

(1) It never occurred to me to do so.
- (2) I do not think that it is important.
(3) Discussion would not accomplish anything.
(4) Since they are busy in working and/or
studying, we do not have enough time for
(5) Othersion.


15. Do you feel parents need to prepare themselves and/or their children for their children's return to Japan besides helping them keep up with their studies? Yes No

If 'no,' please skip to Question 18 .

16. Since you checked that you do believe preparation is necessary for children's reentry to Japan in more than academic areas, please check one or more of the following that apply to you or your children.

(1) I have thought about potential reentry problems, but have kept these thoughts to myself .

(2) I have discussed potential reentry problems with my husband.

(3) I have discussed potential reentry problems with other Japanese mothers.

(4) I have discussed potential reentry problems with my children.

(5) I have attended classes or programs in Japan and/or the U.S. where reentry problems were discussed.

(6) Other (please describe)

17. Please describe the types of problems that concern you.

18. How important do you think it is for your children to maintain their "Japaneseness"?

$\begin{array}{ccccc}5 & 4 & 3 & 2 & 1 \\ \begin{array}{c}\text { very } \\ \text { important }\end{array} & \text { important } & \text { neutral } & \begin{array}{c}\text { not so } \\ \text { important }\end{array} & \begin{array}{c}\text { not } \\ \text { important } \\ \text { at al1 }\end{array}\end{array}$

19. Are you aware of any changes in your children since they arrived in the U.S. in regard to their values, ways of thinking, and behavioral patterns?

Yes No 
20. If you checked 'yes' to $Q 19$, do you believe that these changes are or will be strong or serious enough to make your children appear different from those Japanese children who have never lived outside of Japan? Yes No

21. If you checked 'yes' to $Q 20$, do you expect these differences to cause any difficulties for your children's reentry to Japan? Yes No

22. Have you ever discussed such issues as those mentioned in Q18-Q21 with your husband?

5

once a

43

2

21

week month three months

23. Have you ever discussed these same issues with your children?

5

once a

4

once a

month

once every seldom

never

week

24. Please describe other aspects, if any, you think important concerning your children's reentry to Japan?

25. If you have any comments on this questionnaire, please feel free to describe below.

I appreciate your cooperation by answering this survey Please let me repeat that your response is vital to the succesful completion of my research and your answers will remain anonymous and confidential. If you have any questions, please feel free to call me. 
JAPANESE TRANSLATION

$$
\text { アンクート }
$$

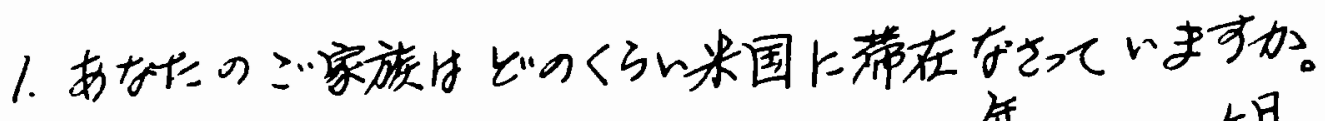
年—5月

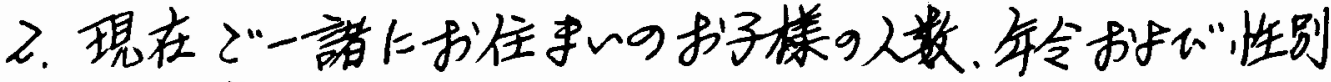
を书書を下さい。

$$
\begin{aligned}
& \text { 第一子:(年令)—才，(性别)—男，一女 } \\
& \text { 第二子:(脌令)—才，(性别)—男，一- } \\
& \text { 第三子:(铃)—才（性别) 一男，一女 }
\end{aligned}
$$

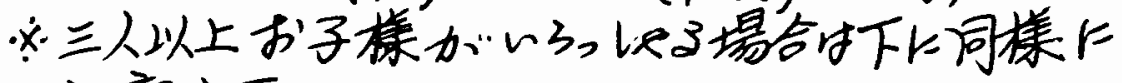

$$
\begin{aligned}
& \text { で記入下さ的。 }
\end{aligned}
$$

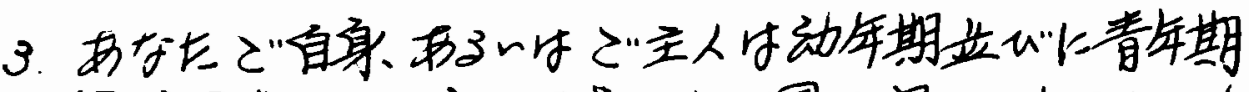
(高校卒業時末で)を棟以外の国で過己゙て小たてとが

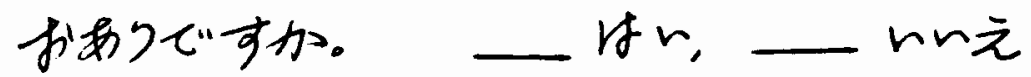

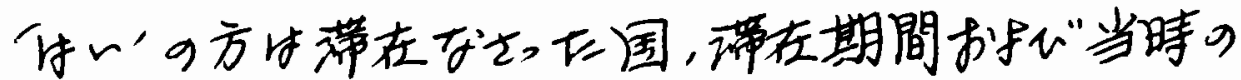
笭をで記入下をい。

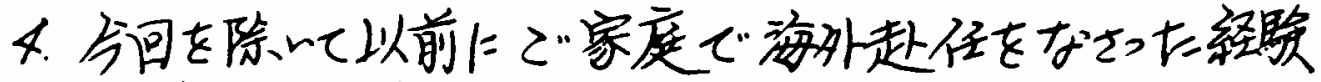
がおめ放ですか。 将， 一n之

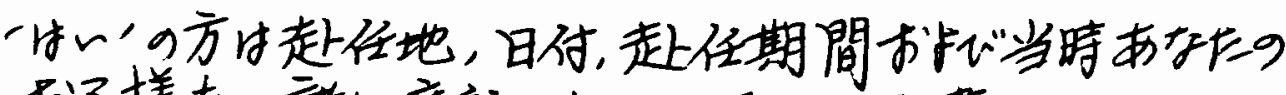

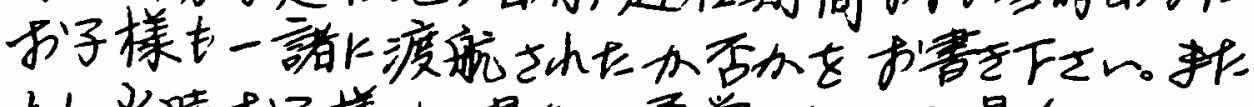
古し当時お子样办現地て通学されていた場合的 その学校で㹬小れていた棓け后じレたか。 
193

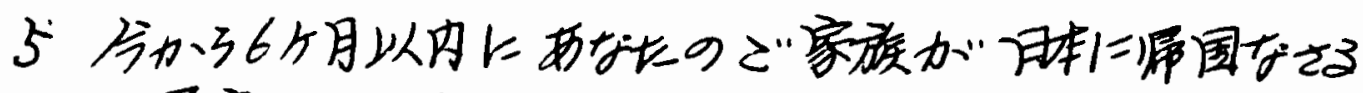

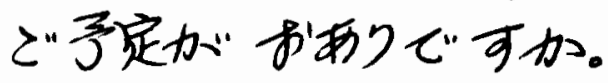

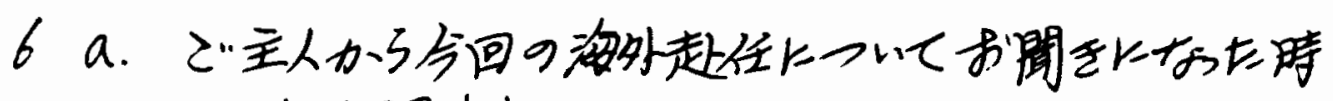
どの护思汃ましたか。

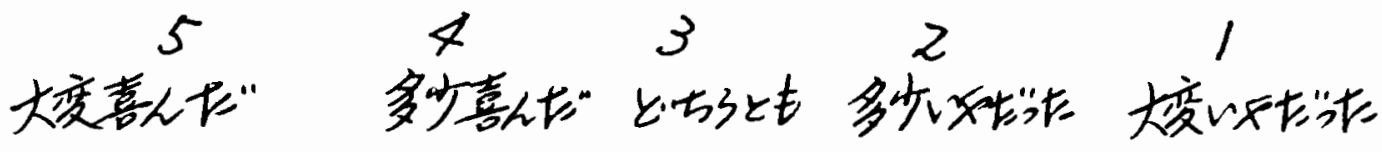

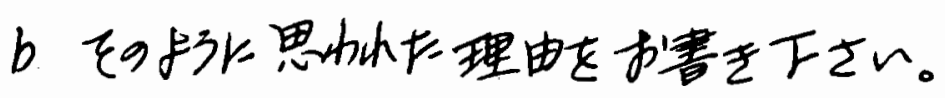

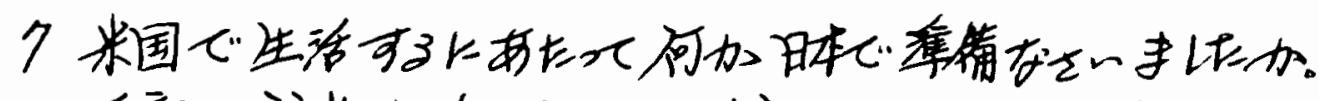
下記の該当するもの(いくでも)ににはをっけて下さい。 あるレ生何をなをったが䛌入下さい。

—(1) 何もしなか力た

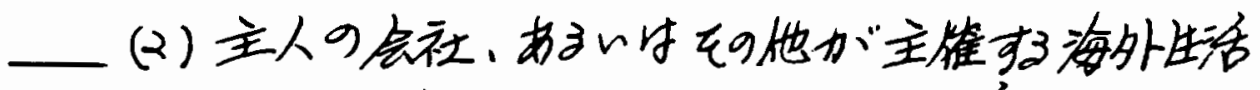
のための才师シテーショレプログラムに参加レた。

—(ヨ)米国に閣する本を䛃んだ。

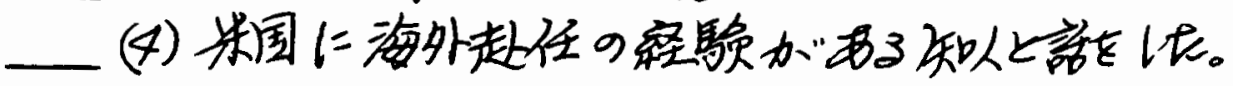

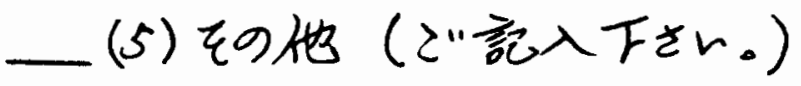

8、あけたのお子样の英語力トつレてどのように思小执ますか。

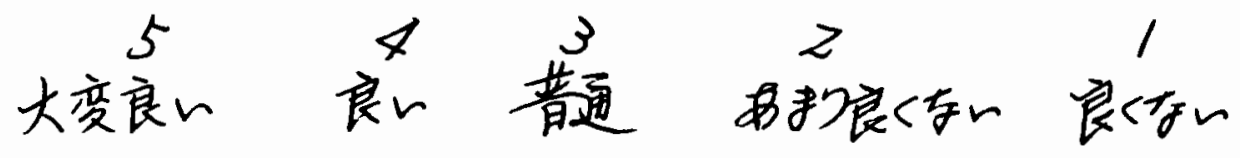


194

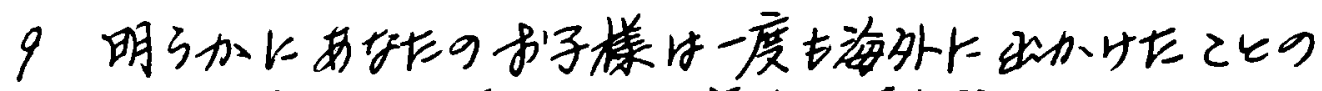

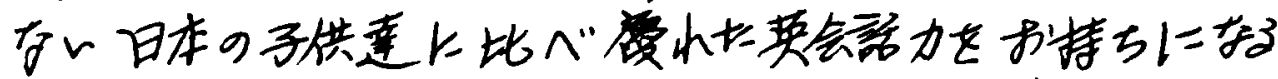

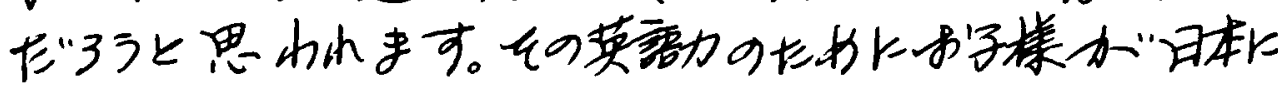

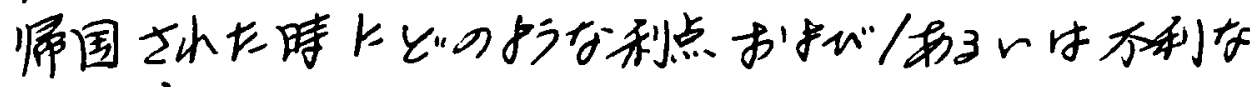
点を受りるとお'思レトななりすか。

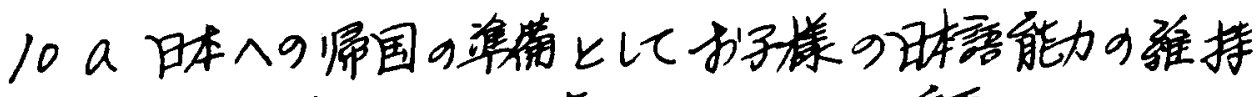

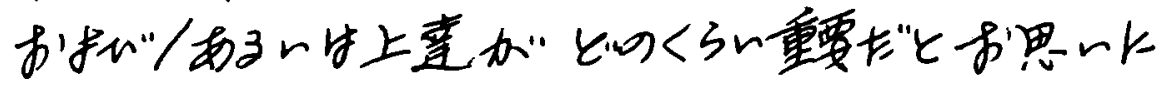
なりま可力。

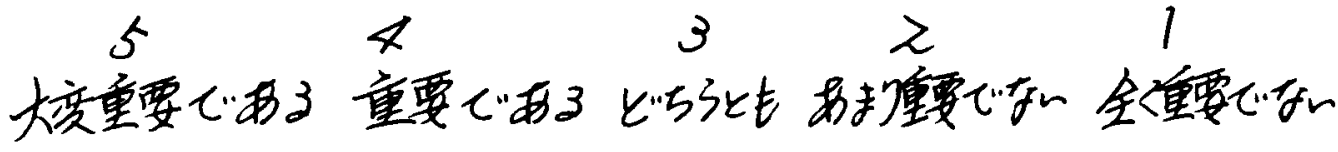

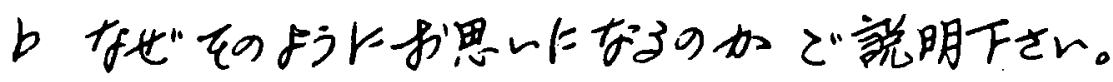

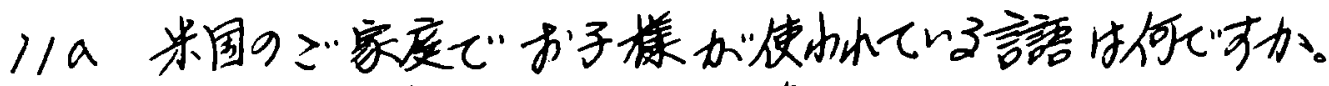

日本害 英語

两方

bなぜお子样はての語をで家庭でお゙使いけなると

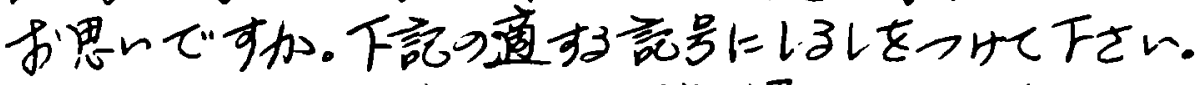

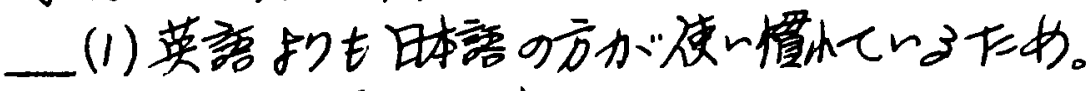

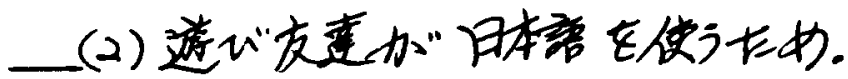

—(3）日本語を使うおうに私が初めるため。

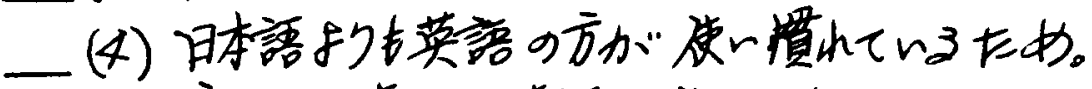

—(5)遮心゙友走が英語を使亏ため

—(6)英語を使う抮私が娾めるため。

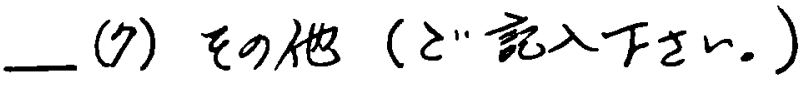


195

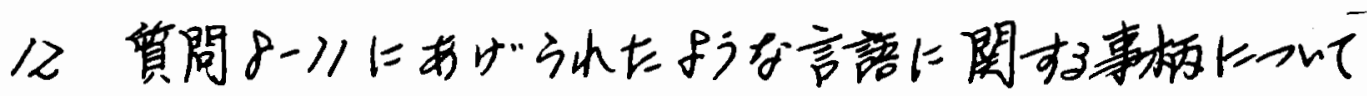
今までにで主人と䃞されたてとがお和ですか。 5

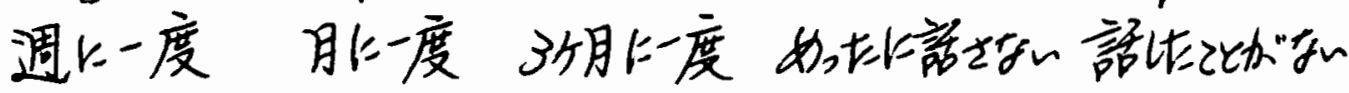

乃工記と同じ語に関する事柄についてお子样と話て山た てとがおおりですか。

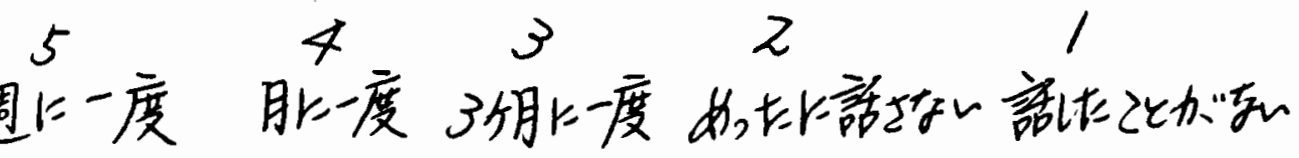

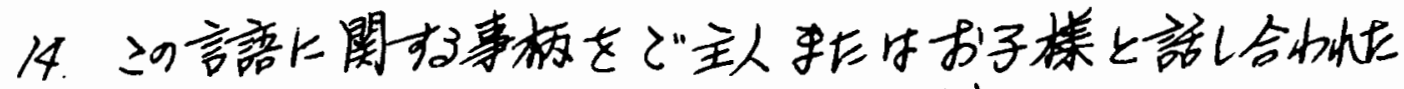
てとのない方け、をの理由にっいて下の該当するものたレるしを フサて下さい。

一(1)弦まで考えたてとがなかった。

一(マ)重要なてとだとは思小ない。

一(話レ合ても意味がな゙ロと思う。

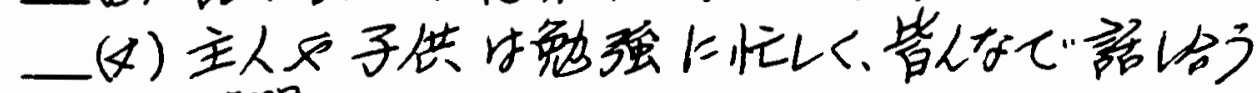
時間がな的。

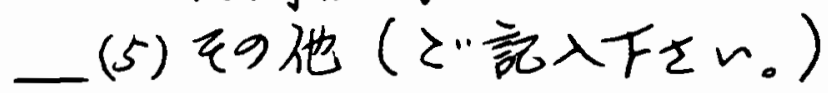

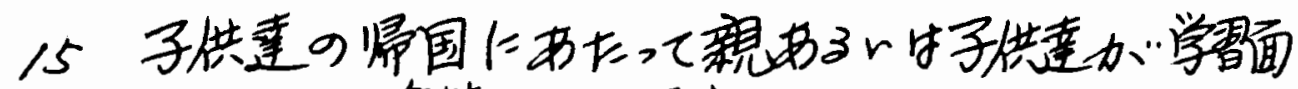

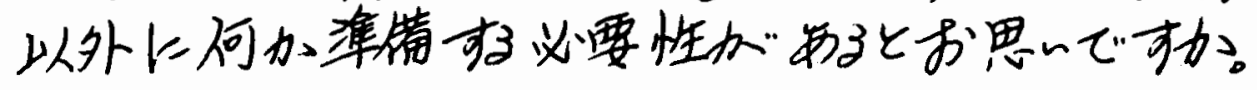

_ Vr

- $u n \bar{z}$

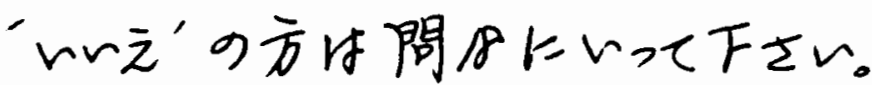




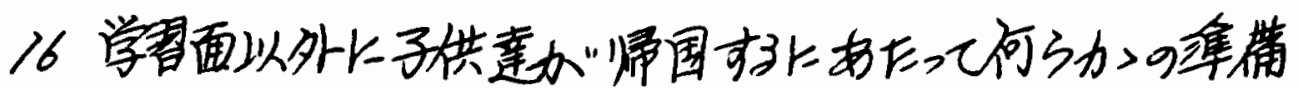

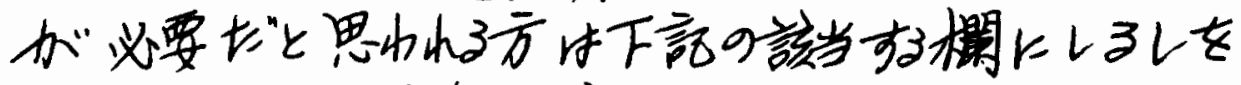
フタて下之レ。(複数可)

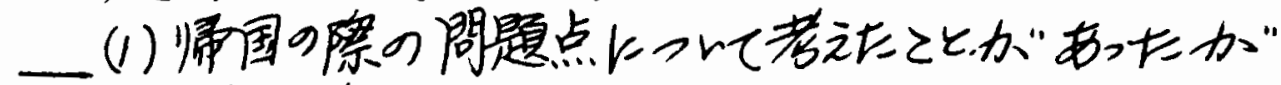
自分の胸のラちトレまっていた。

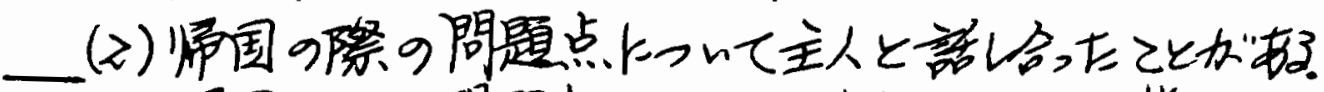

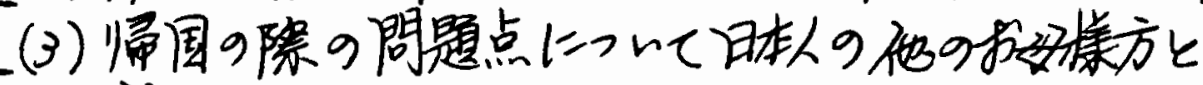
話し合、たてとがある。

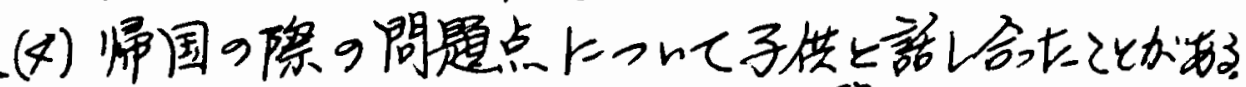

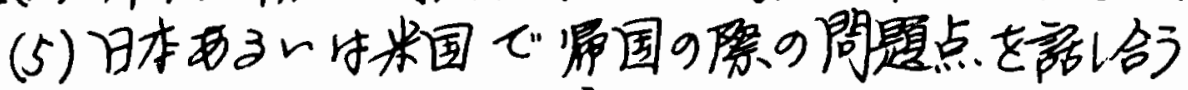
クラスメプログラムト参加したてと办める。 (6)その他(乙゙記入下さr。)

クあなたが関心を特ちたなっている师国後の閣题点 にっルてで記入下さい。

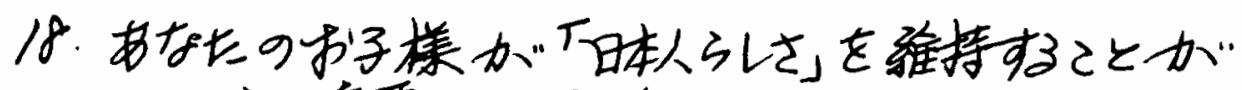
どのくく的重要だとお゙考之じすか。

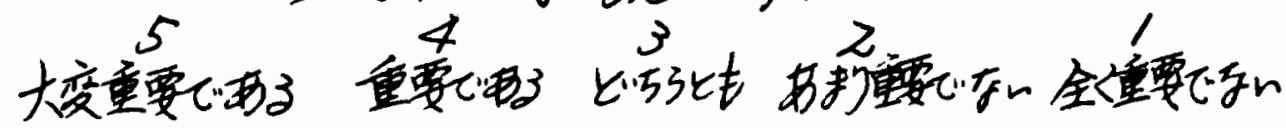

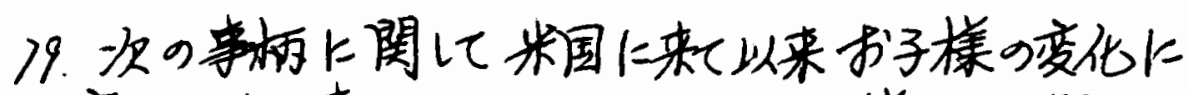

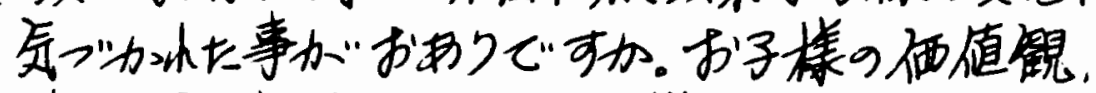

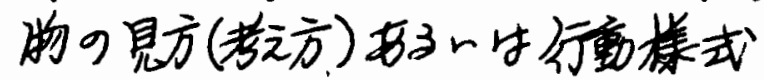

$$
\text { - Hr - rri }
$$


197

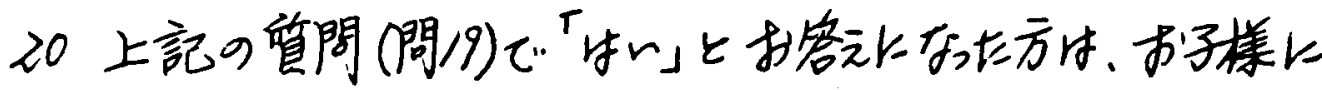

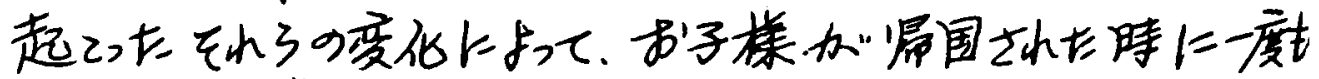

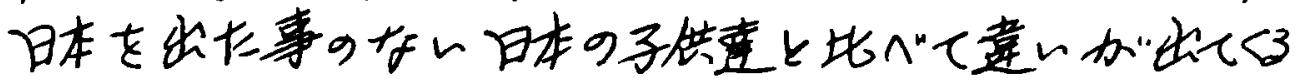
阮お思的ですか。

一 村

- nn之

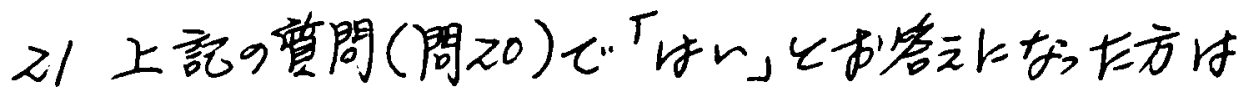

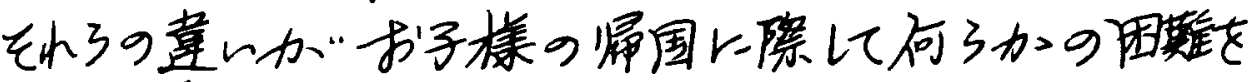

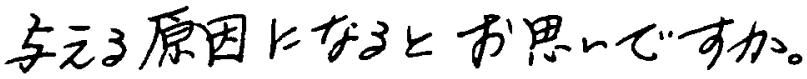

一将 $n \sim \bar{z}$

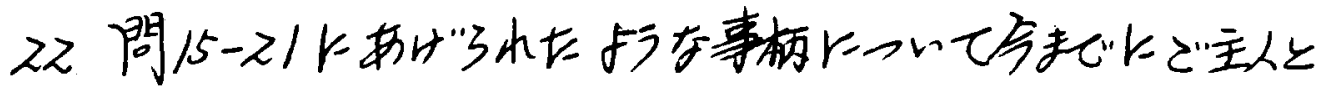

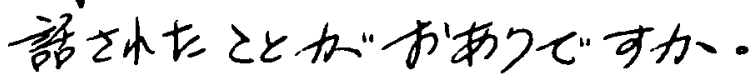

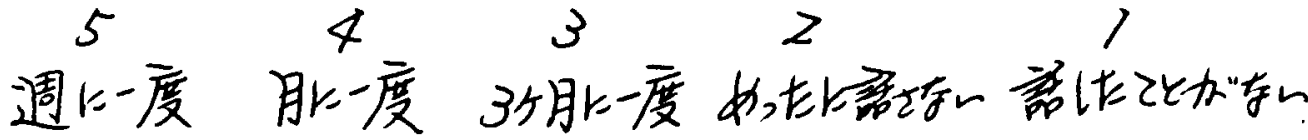

23 上記飞同样の事板につルてお子样と話と小たてとが お車りですか。

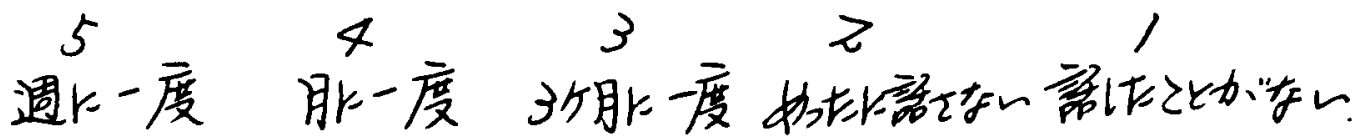

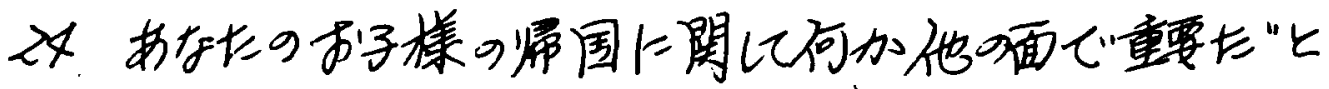

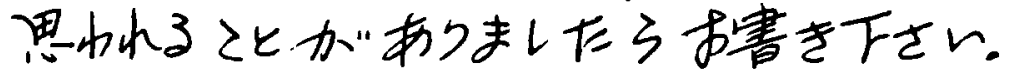

25 てのアンケートトつきまにて局かコメントがあうましたう，

で自由にお書きたさい。 
198

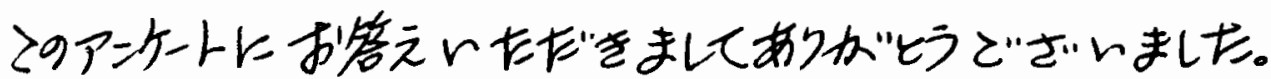

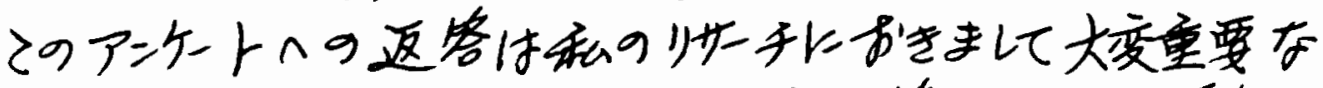
ものであり、まにただきました各返答はすべてて医名。

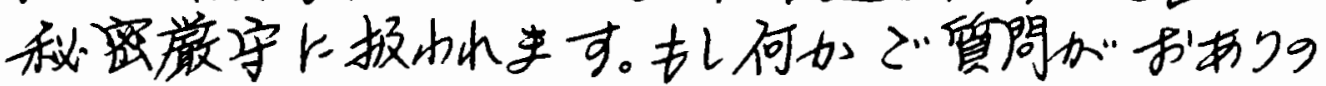

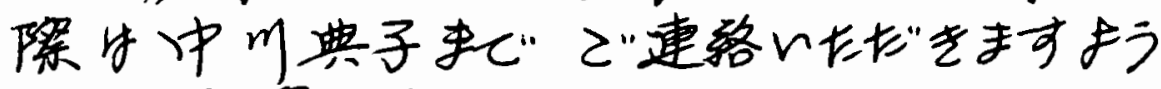

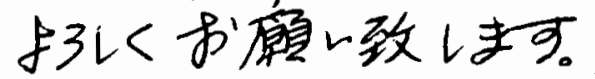


APPENDIX G

PILOT STUDY QUESTIONNAIRE 
ENGLISH VERSION

\section{DEMOGRAPHIC INFORMATION}

1. How long has your family been living in the U.S? year(s) month(s)

2. Please indicate the number, age, and sex of the children who are living in the U.S. with you.
lst child:
Age
2nd child:
Male
Male
Female
3rd child:
Age
Age
Male
Female
Female

*If you have more than three children, please describe below in the same way.

3. Did either you or your husband spend part or all of your/his childhood (up to high school age) in any country other than Japan? Yes No

If 'yes,' please state where you/he lived, how Iong you/he (or both) were there, and your/his age at that time.

4. Has your family been assigned overseas previousiy? Yes No

If 'yes,' please state where you lived, the date and length of time you were there, and whether your children were with you at these times. Also, if your children were school age, what was the language used at that school?

5. Do you expect your family to return to Japan within the next six months? 
6(a) How did you feel when you heard about this present overseas assignment from your husband?

$\begin{array}{llll}1 & 2 & 3 & 4\end{array}$ very somewhat neutral pleased pleased $\begin{array}{cc}\text { not } & \text { very } \\ \text { pleased displeased }\end{array}$

(b) Please describe the reason for this feeling.

7. Did you do anything in Japan to prepare for living in the U.S.? Please check each of the following that is appropriate, or describe what you did.

(1) Nothing

(2) I attended orientation programs for living overseas sponsored by my husband's company and/or other organizations.

(3) I read a book(s) about the U.S.

(4) I talked with my acquaintances who had an experience of overseas assignment in the $\mathrm{U} . \mathrm{S}$.

(5) Other (please describe)

Parents' Awareness, Communication Behavior, and Preparation for the Children's Reentry

8. How would you judge your children's English proficiency?

$\begin{array}{ccccc}5 & 4 & 3 & 2 & 1 \\ \text { very good } & \text { good } & \text { fair } & \text { poor } & \text { very poor }\end{array}$

9. Obviously your children will have better English speaking ability than those Japanese children who have never left Japan. What advantages and/or disadvantages do you believe your children will have after they return to Japan because of this English ability?

10(a) How important do you think it is for your children to maintain and/or improve their Japanese language ability in preparation for return to Japan?

$\begin{array}{ccccc}5 & 4 & 3 & 2 & 1 \\ \text { very } & \text { important } & \text { neutral } & \text { not so } & \text { not } \\ \text { important } & & & & \begin{array}{c}\text { important } \\ \text { at all }\end{array}\end{array}$


(b) Please explain why you think this way.

11 (a) What language do your children usually speak in your home in the U.S.?

Japanese English

Both

(b) Why do you think they use this language at home?

Please check appropriate number (s) below.

\begin{tabular}{l} 
(1) They are used to speaking Japanese more \\
than English. \\
(2) Most of their playmates use Japanese. \\
(3) I encourage them to use Japanese. \\
(4) They are used to speaking English more than \\
(5) Mapanese. \\
(6) I encourage them to use English. \\
\hline
\end{tabular}

12. Have you ever discussed such language issues as those mentioned in Q9-Q11 with your husband?

$54 \quad 4 \quad 3 \quad 2$

$\begin{array}{cccc}\begin{array}{c}\text { more than } \\ \text { once a } \\ \text { week }\end{array} & \begin{array}{c}\text { once a } \\ \text { week }\end{array} & \begin{array}{c}\text { once a } \\ \text { month }\end{array} & \text { seldom never } \\ & & & \end{array}$

13. Have you ever discussed these same language issues with your children?

$\begin{array}{ccccc}5 & 4 & 3 & 2 & 1 \\ \begin{array}{c}\text { more than } \\ \text { once a } \\ \text { week }\end{array} & \begin{array}{c}\text { once a } \\ \text { week }\end{array} & \begin{array}{c}\text { once a } \\ \text { month }\end{array} & \text { seldom } & \text { never } \\ & & & & \end{array}$

14. If you do not discuss language issues with your husband and/or children, please check appropriate number (s) below.

(1) It never occurred to me to do so.

(2) I do not think that it is important.

(3) Discussion would not accomplish anything.

(4) Since they are busy in working and/or studying, we do not have enough time for discussion.

(5) Other (please describe) 
15. Do you feel parents need to prepare themselves and/or their children for their children's return to Japan besides helping them keep up with their studies? Yes No

If 'no,' please skip to Question 18 .

16. Since you checked that you do believe preparation is necessary for children's reentry to Japan in more than academic areas, please check one or more of the following that apply to you or your children.

(1) I have thought about potential reentry problems, but have kept these thoughts to myself.

(2) I have discussed potential reentry problems with my husband.

(3) I have discussed potential reentry problems with other Japanese mothers.

(4) I have discussed potential reentry problems with my children.

(5) I have attended classes or programs in Japan and/or the U.S. where reentry problems were discussed.

(6) Other (please describe)

17. Please describe the types of problems that concern you.

18. How important do you think it is for your children to maintain their "Japaneseness"?
5
4
3
2
very
important important neutral
not so important important at a 11

19. Are you aware of any changes in your children since they arrived in the U.S. in regard to their values, ways of thinking, and behavioral patterns? Yes No

20. If you checked 'yes' to $Q 19$, do you believe that these changes are or will be strong or serious enough to make your children appear different from those Japanese children who have never lived outside of Japan? Yes No 
21. If you checked 'yes' to $Q 20$, do you expect these differences to cause any difficulties for your children's reentry to Japan? Yes No

22. Have you ever discussed such issues as those mentioned in Q18-Q21 with your husband? 5 4 3 2

\begin{tabular}{|c|c|c|}
\hline & week & month \\
\hline
\end{tabular}
week

23. Have you ever discussed these same issues with your children?

$\begin{array}{ccccc}5 & 4 & 3 & 2 & 1 \\ \begin{array}{c}\text { more than } \\ \text { once a } \\ \text { week }\end{array} & \begin{array}{c}\text { once a } \\ \text { week }\end{array} & \begin{array}{c}\text { once a } \\ \text { month }\end{array} & \text { seldom } & \text { never } \\ & & & \end{array}$

24. Please describe other aspects, if any, you think important concerning your children's reentry to Japan?

25. If you have any comments on this questionnaire, please feel free to describe below.

I appreciate your cooperation by answering this survey . Please let me repeat that your response is vital to the successful completion of my research and your answers will remain anonymous and confidential. If you have any questions, please feel free to call me. 
JAPANESE TRANSLATION

$$
\text { アンクート }
$$

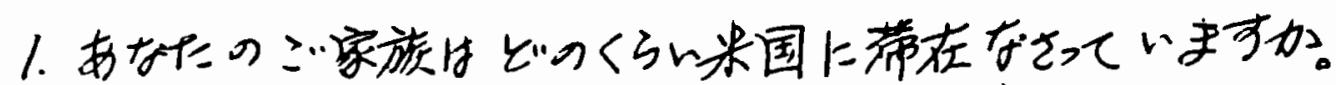

$$
\text { - 年—5月 }
$$

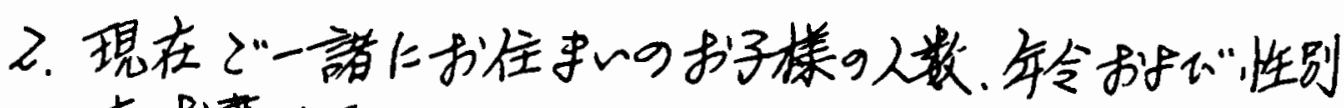
を书寒を下さい。

$$
\begin{aligned}
& \text { 第一子:(䍅)—才，(性别)—男，一女 } \\
& \text { 第二子:(年令)—才，(性别)—男，一女 } \\
& \text { 第三子:(年令)—才（性别)—男，一女 }
\end{aligned}
$$

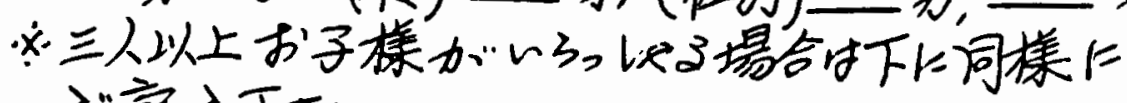
で記入下てい。

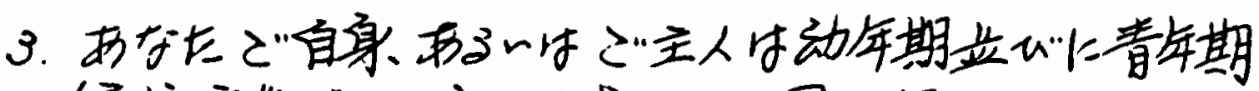

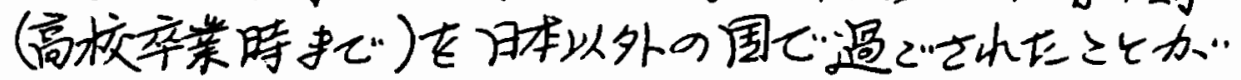

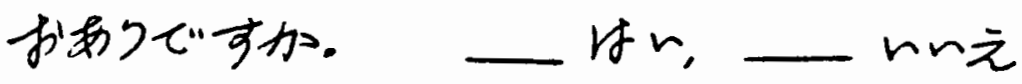

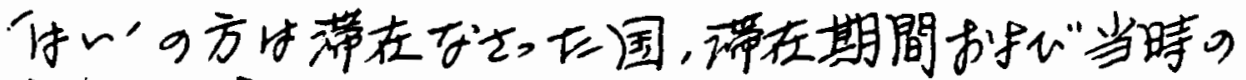
䍅をで記入下さい。

4. 兮句を除的て以前にで家庭で海外赴任をなさた経娩

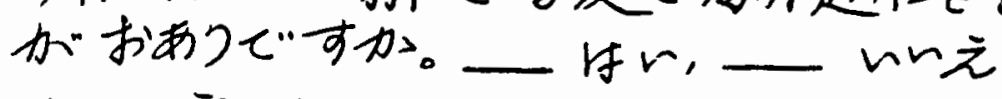

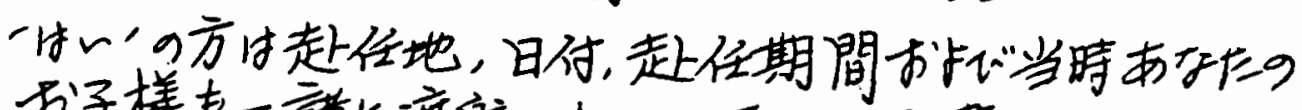

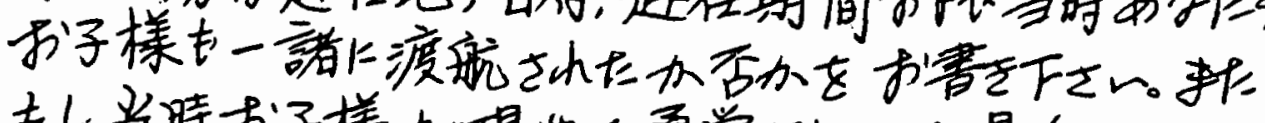
もし当時お子样办現地飞”通学されていた場合时 その学校で㹬かれていた棓け后でしたか。 
206

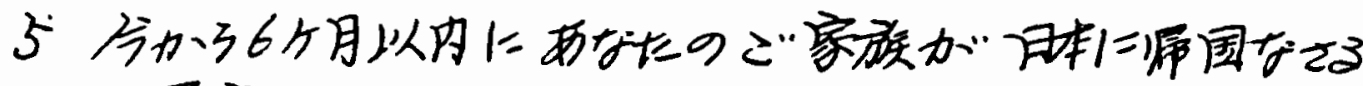

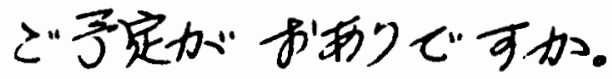

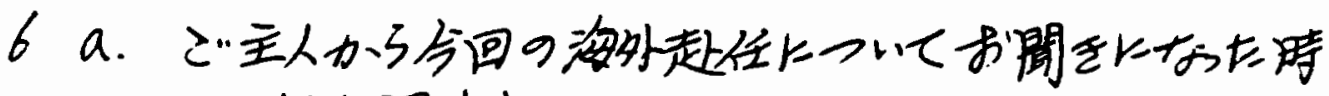
どの㧍に思力れ手した。

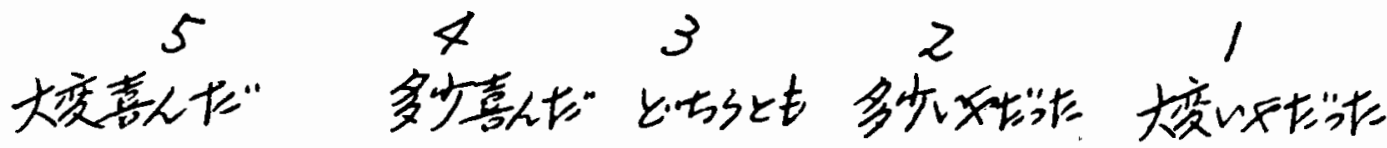

bとの8ラト思似た理由をお害を下さい。

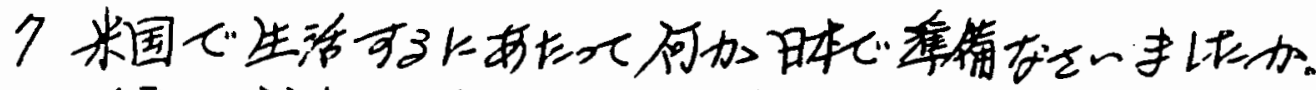
下記の該当するもの(いくでも)ににはをっけてたさい。 好レ性砢をなをったかで語入下さい。

一(1) 何もしな加た

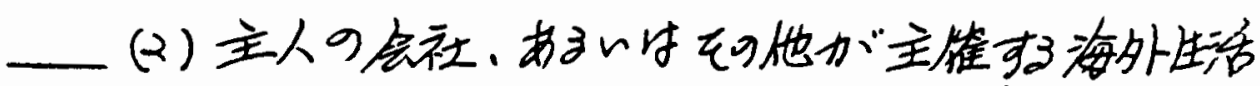
のための才师ンテーショレプロブラムに参加Vた。

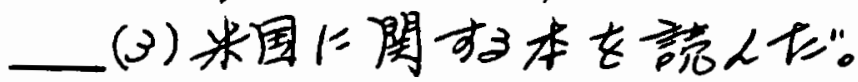

-(4) 米国に海外赴任の経䮖办”成子知人と話飞怅。

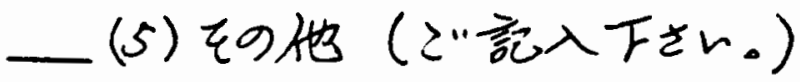

8、あなたのお子样の英語カにっレてどのように思小水ますか。

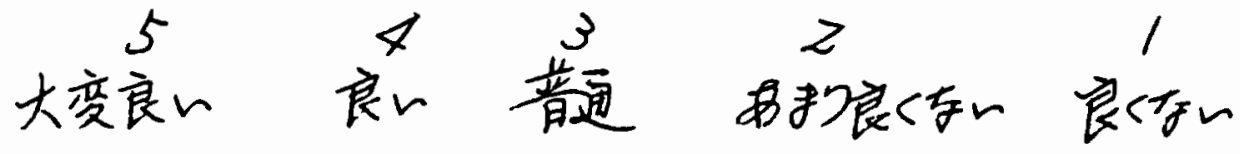


207

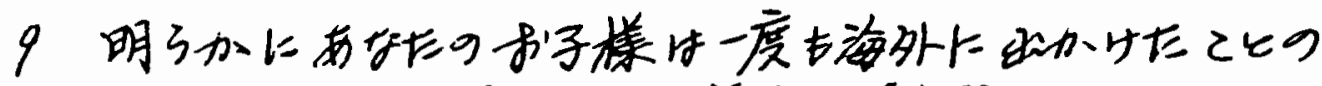

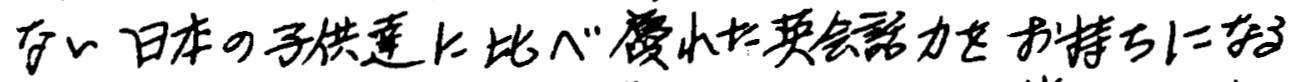

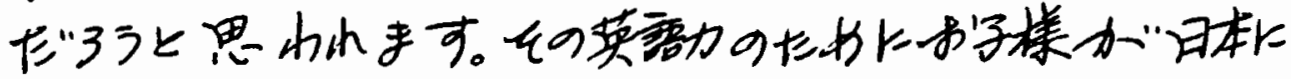

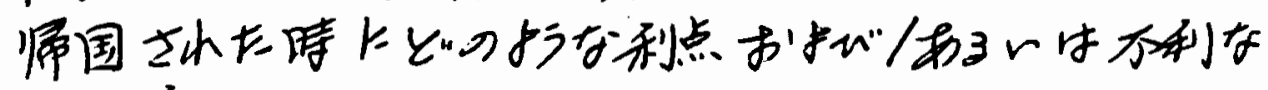
点を受りるとお'思レトなりますか。

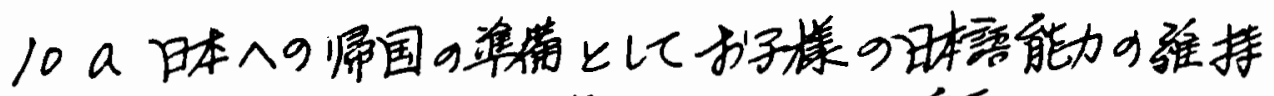

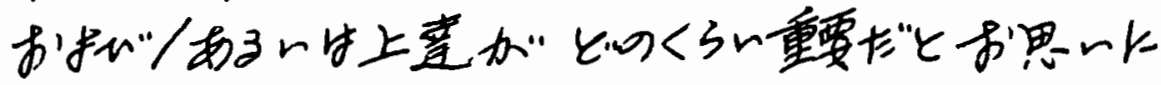
なりますか。

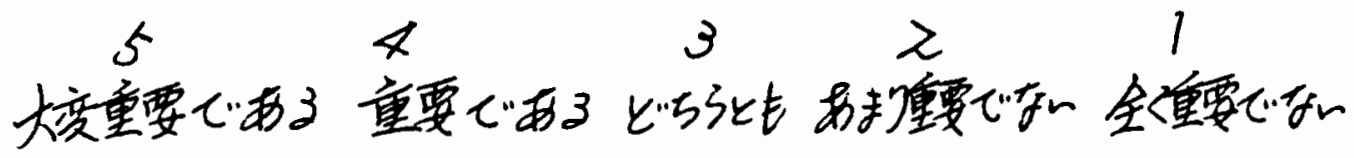

りなぜをのようケお思レにするのかで説明下ざ。

1/a米国のざ家庭でお子样が使小れている棓け何ですか。

日本棓

英語

两方

bなぜおる样けての語をで家庭でお゙使いたな゙ると

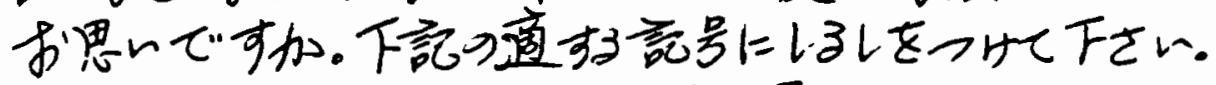

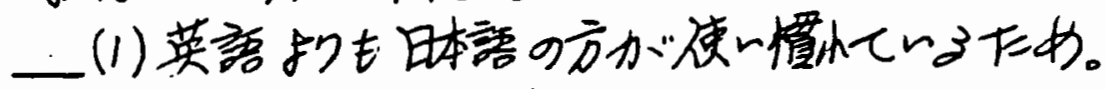

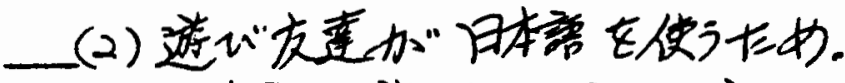

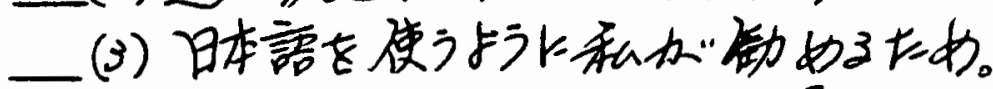

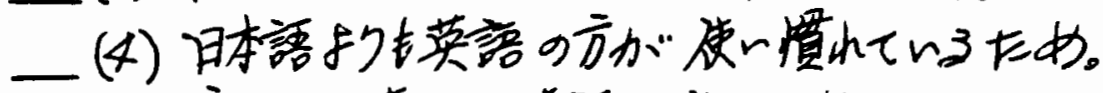

一(5)遮心゙友奠が英語を使うため

—(6)英語を使う拉私が謜めるため。

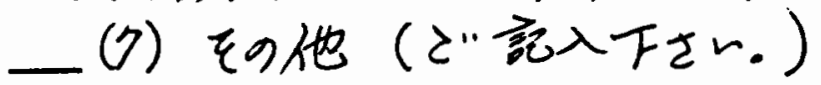


208

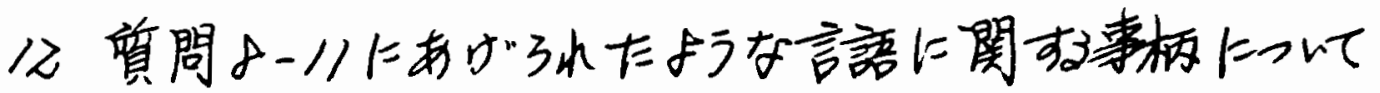

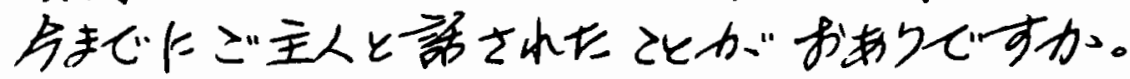
5

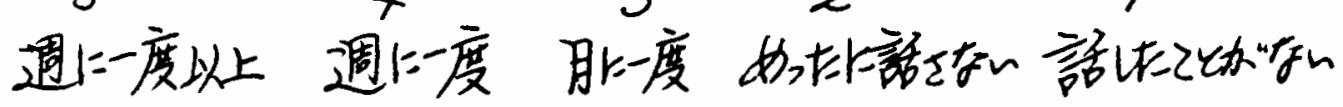

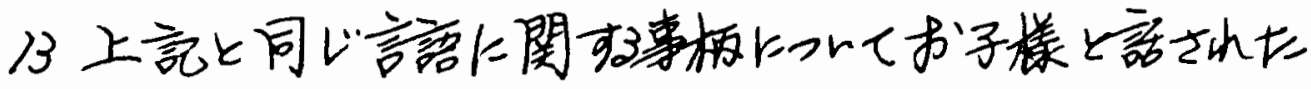

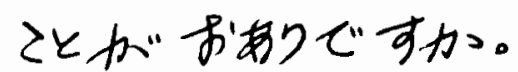

5

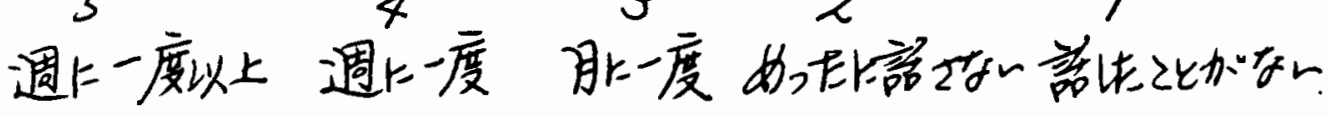

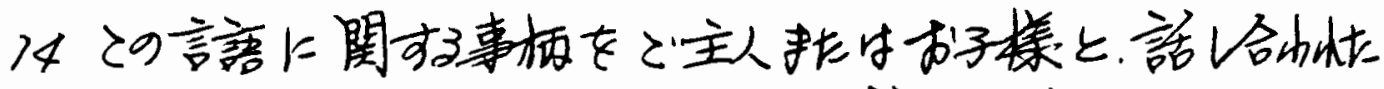

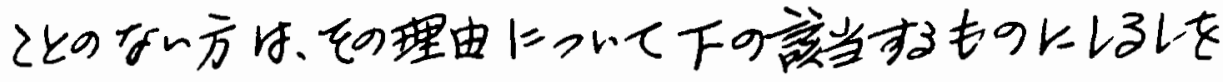
カリててさい。

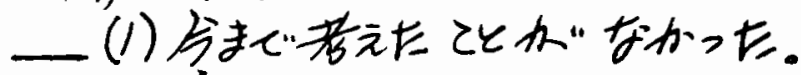

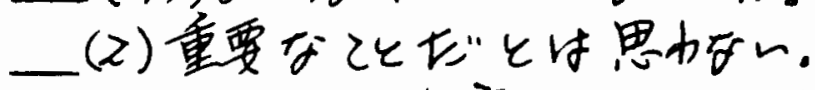

—(や)話レ合っても意味がないと思う.

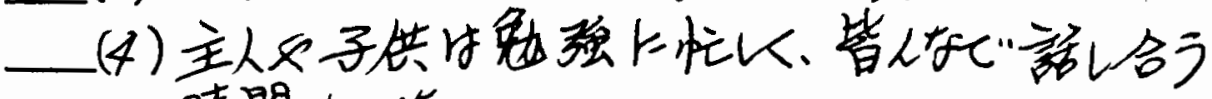
時間方的。

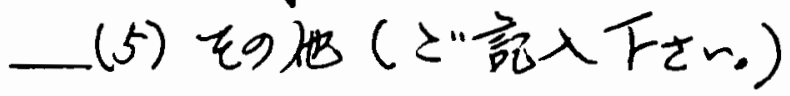

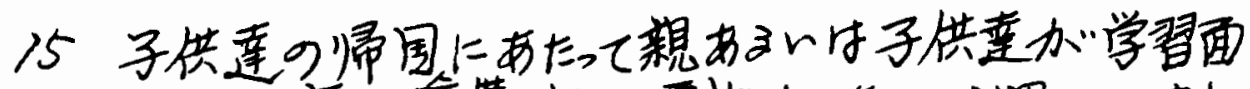
以外何加潗物する必要性があるとお思的ですか。

— Yr —urz

‘レ゙え’の方时䦓/8にレって下さい。 
209

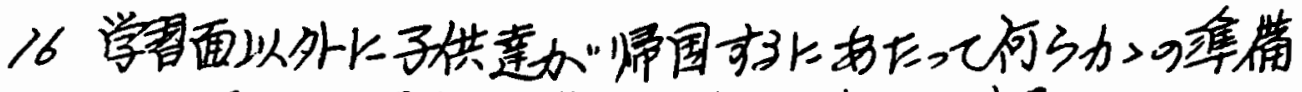
が必要だと思小水る方け下記の該当する相にレるレを

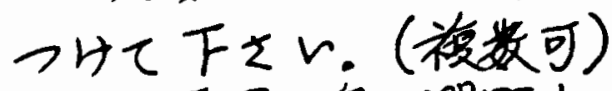

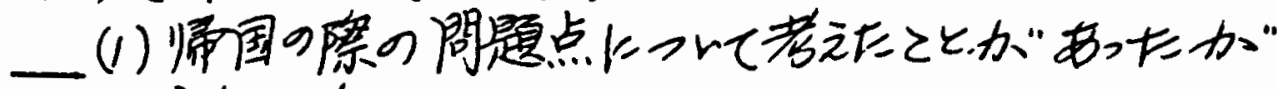
自分の胸のうちにレまっていた。

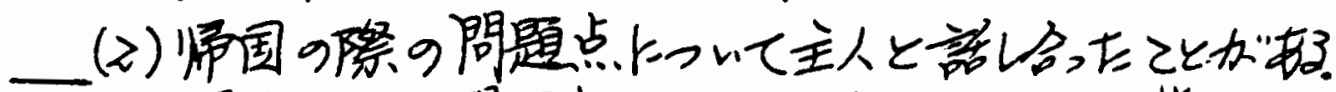

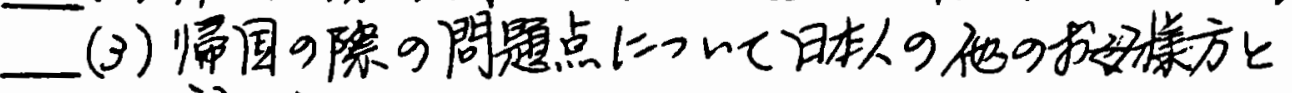
話し合ったてと办ある。

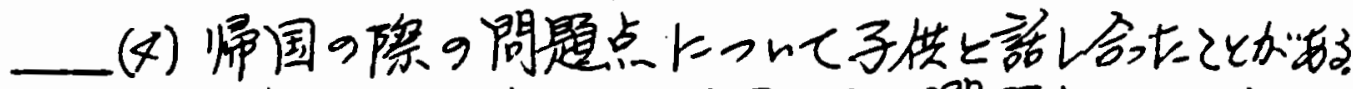

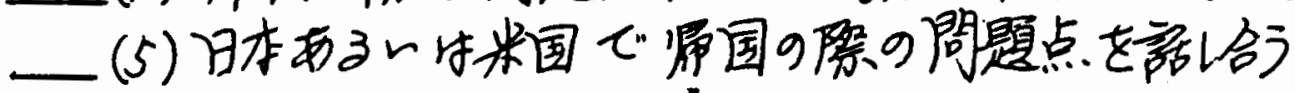
クラスメプログラムに参加したてと办ある。

一(6) その他（で記入下亡r。）

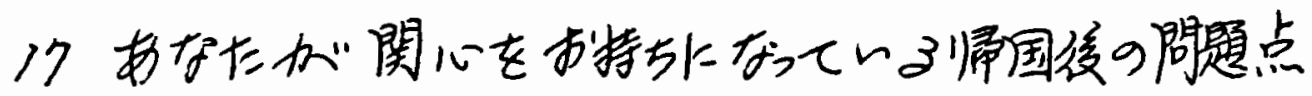
にっルてで記入テさい。

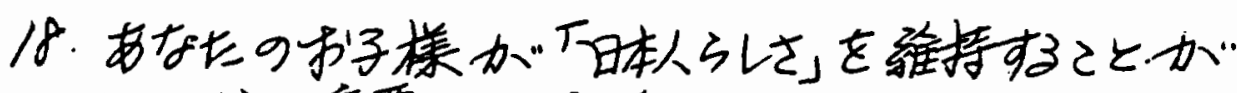
どのくら熏要だとお考えじ可加。

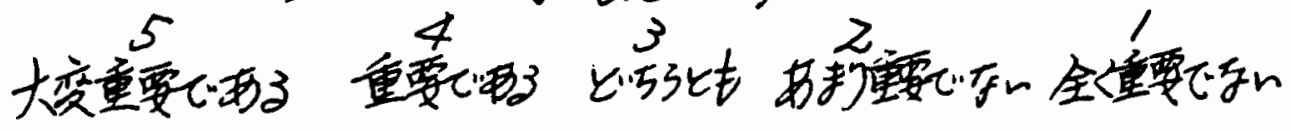

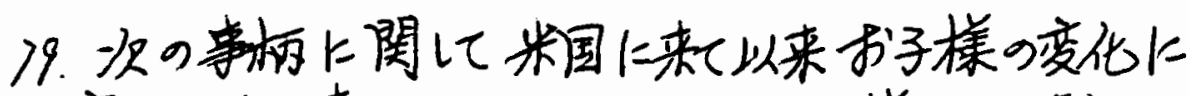

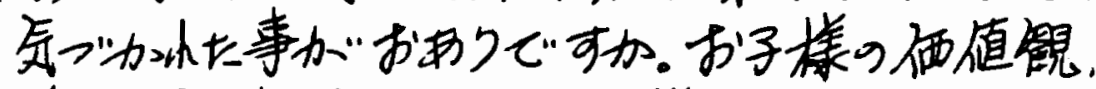

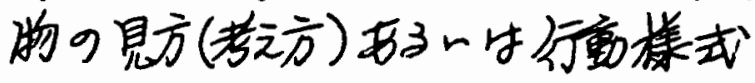

- Hr - rri 


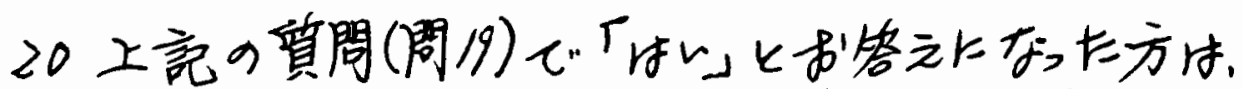

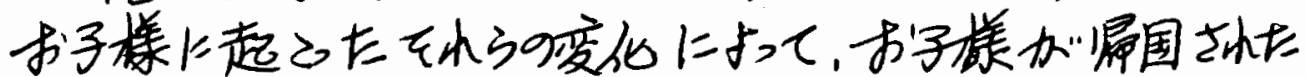

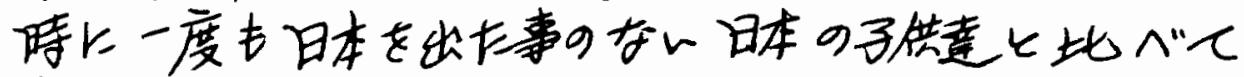

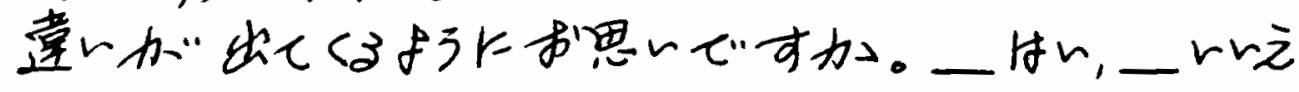

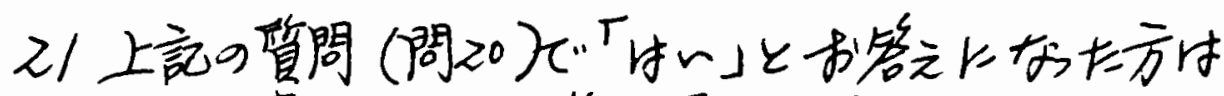

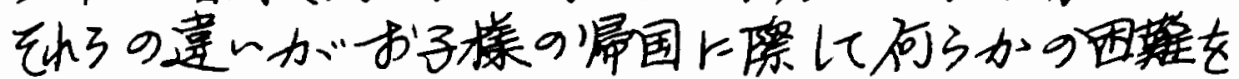

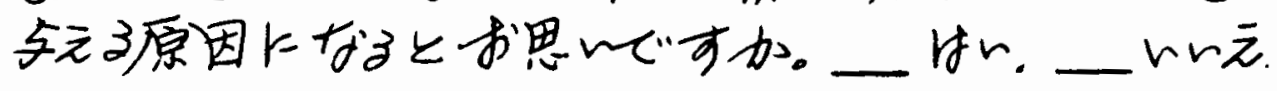

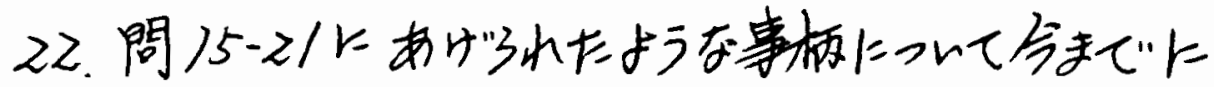
之゙主人と話されたてとがお物りですか。 $54 \quad 3 \quad 2 \quad 1$

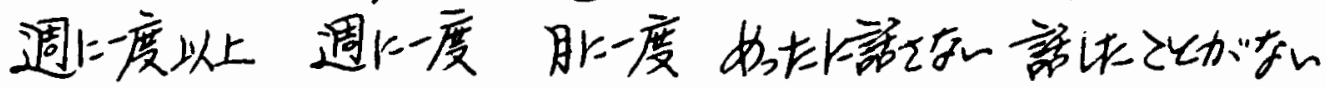

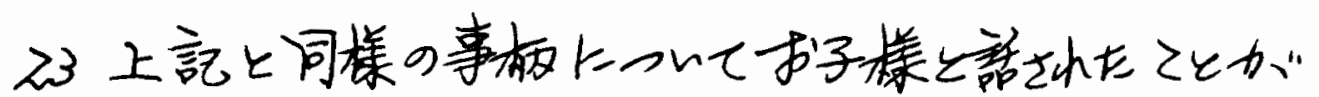
おおりですか。

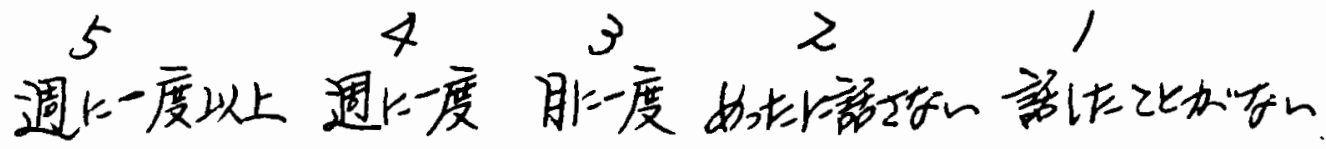
24 あ大たのお子样の师国上開儿何加他の面で重要だと

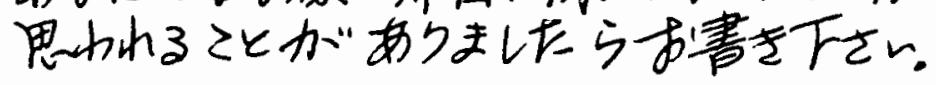

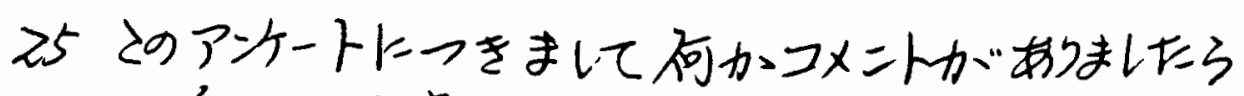
で自由にお害きてさい。 


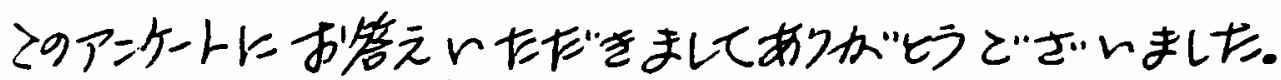

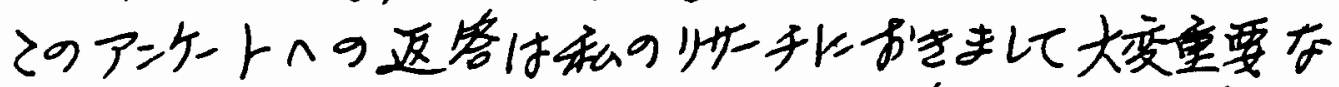
ものであク、またいただきました各返答はすの゙てて医名。

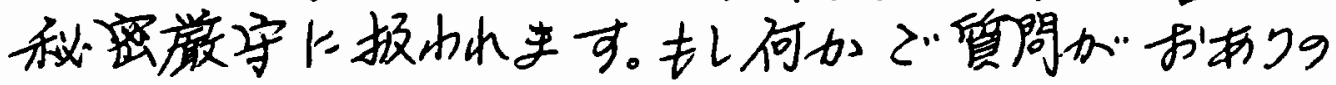

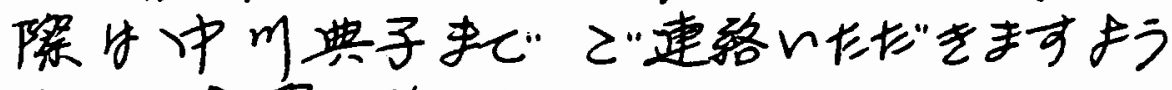
お3しくお㟲致にます。 
APPENDIX $\mathrm{H}$

LETTER OF INTRODUCTION 


\section{APPENDIX H}

\section{LETTER OF INTRODUCTION \\ (Japanese Version)}

书样方へ：

1/月P日

持店

私时ポートランド州立大学格士染程スピーチ・コミュニケーショ2

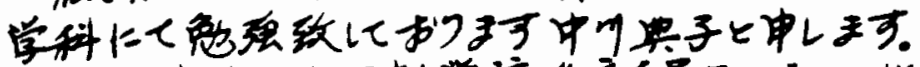

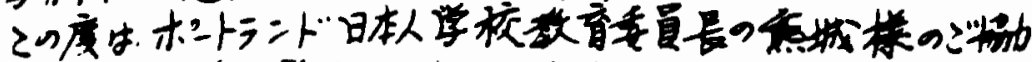

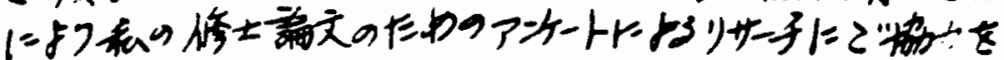

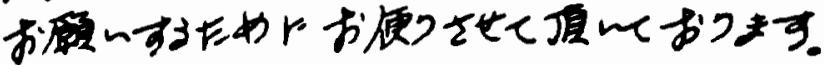

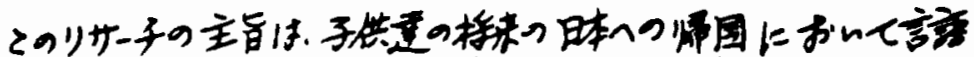

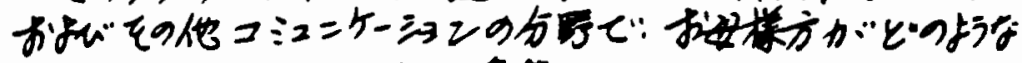

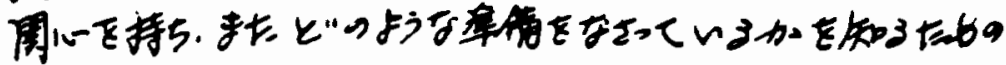
まのびす。

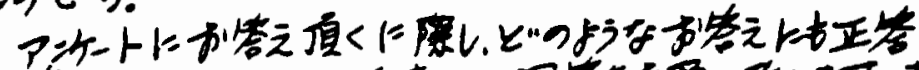

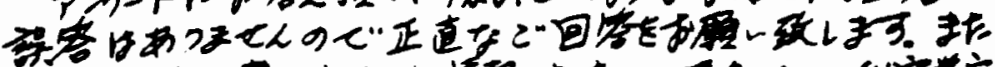

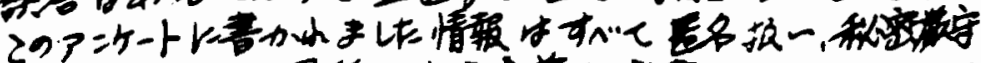

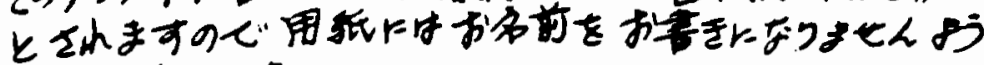
お展的します。

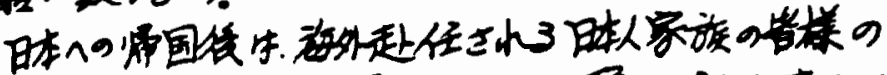

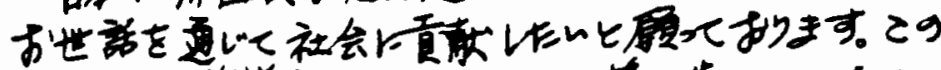

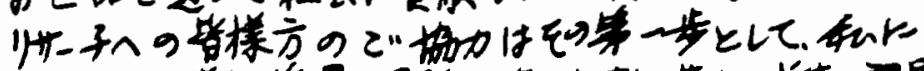

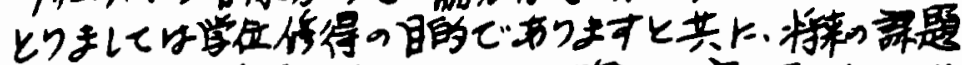

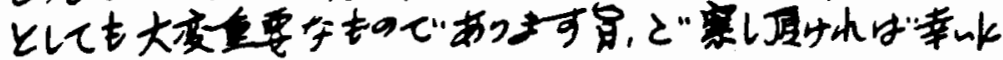
存じるす。

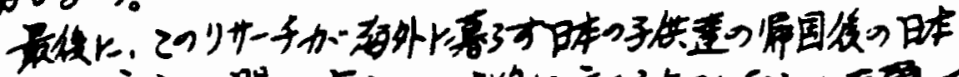

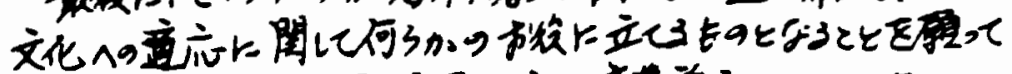

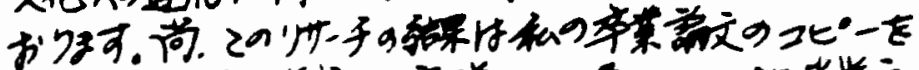

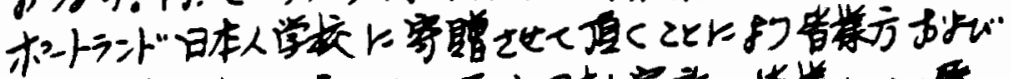

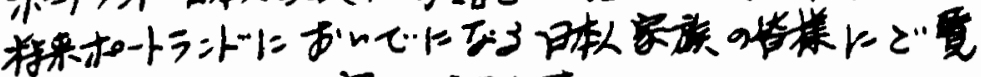

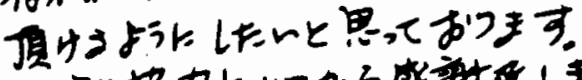

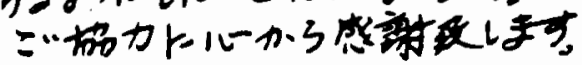

具 
ENGLISH TRANSLATION

November 8,1988

Dear Mothers:

My name is Noriko Nakagawa. I am a graduate student in Speech Communication at Portland State University. With the assistance of $\mathrm{Mr}$. Kumashiro, chairperson of Educational Board at the Portland Japanese school, I am writing this letter to ask for your cooperation in the survey questionnaire for my Master's thesis.

The purpose of this research is to discover what kinds of concerns mothers have, and what kinds of preparations they are doing regarding the language and other aspects in the field of communication in terms of their children's future return to Japan.

Since there are no right or wrong answers for this questionnaire, please give your honest responses. Also, please do not write your name as every information given to this questionnaire remains anonymous and confidential.

After returning to Japan, I wish to dedicate myself to the service of Japanese families who will be assigned overseas. I appreciate if you would understand that your cooperation in this research is vitally important not only for the acquisition of my degree, but also for my future career.

I am hoping that this research will be beneficial for readjustment of the Japanese children living abroad to the Japanese culture upon their return to Japan. I would like the Japanese families who will be assigned to Portland in the future to review my thesis, a copy of which will be donated to the Portland Japanese school.

I sincerely appreciate your cooperation.

Sincerely yours, 
APPENDIX I

PERMISSION LETTER 
APPENDIX I

\author{
PERMISSION LETTER \\ (English Version)
}

COLLCE OF

LIBERAL ARTS ANO SCIENCES

DEPARTMENT OF

SPEECH COMMUNICATION

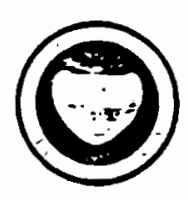

PORTLANO

STATE

UNIVERSITY

PO BOX 751

pontlato. uRecon

9;20:

503.229.3531

Novenber 7, 1988

Deat Parent:

This letter is being witten to ask for your osoperation in a research study that is being conducted by Miss Noriko Nakagawa, tho is a graduate student in the Dept. of speech Comminication at Portland State university. Her program emphasis is Intercultural comminication, wich includes the study of problems of adjustment to Hving in a foreign country and to the difficulties that might be encountered upon reentry to one's home country. Miss kakagawa has successfully completed all required courses for the Master of Art's degree except for her thesis research and witing.

Because of the increasing numbers of Japanese families who are temporarily living outside of Japan, Miss Nakagawa and I believe that it is important to have more information about Japanese children's reentry to Japan. The specific purpose of her thesis study is to dicoover to what extent Japanese parents in the U.S. are aware of, and are preparing to cope with, poychological and commication problews thich their children might encounter when they return to Japan. only when this is known can intercultural comminication specialists design assistance program in both the U.S. and Japan.

Miss kaleagawa has a strong grasp of the subject of Intercultural comminication, and her research is being conducted for a purrely academic purpose. I believe that it will be beneficial for both you and the Japanese families who will be assigned overseas in the future. I also understand that Miss Nakagaw intends to dedicate herself to the servioe of Japanese returnee children and their families after she grachates.

As Miss Nakagawa's academic and thesis adviser, may I thank you in advance for your support and your copperation. We need to have you complete and return the enclosed questionnaire in the stamped, addressed ervelope. You do not have to sign your name. All data will be reported anconmously. If a sufficient number of questionnaires are retirned atre will be able to ochiplete her research study.

We appreciate your kind assistance.

sincarely yours,

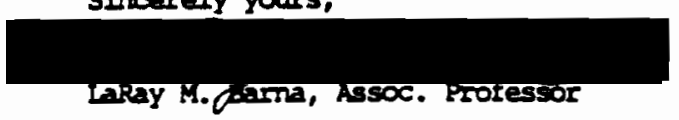


PERMISSION LETTER (Japanese Translation)

\section{》月ク日}

书然㥞方八:

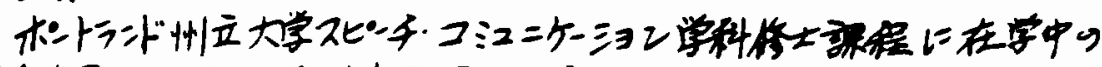

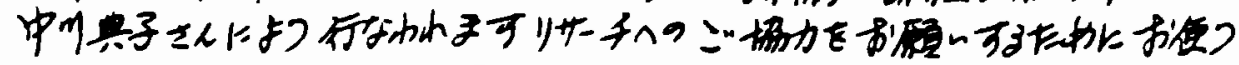

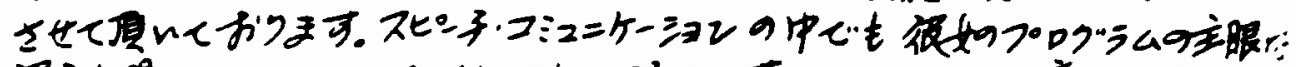

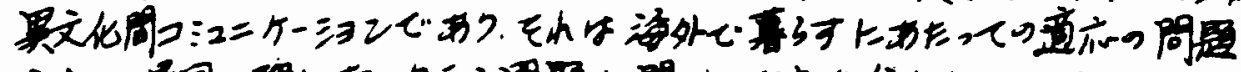

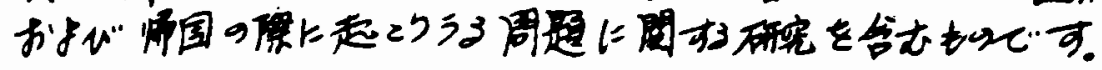

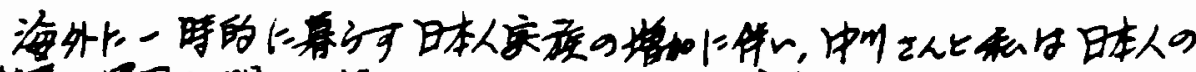

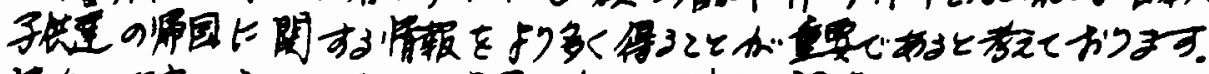

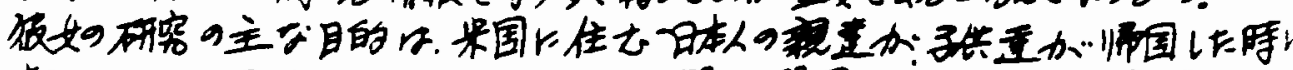

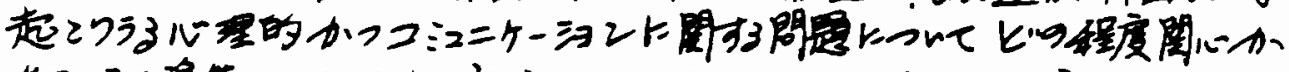

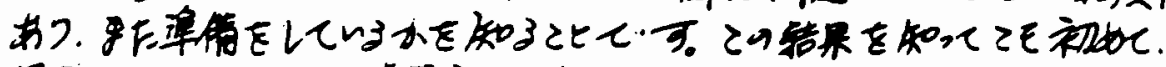

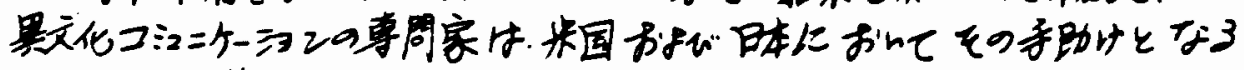
プログラムを作るてとができる切です。

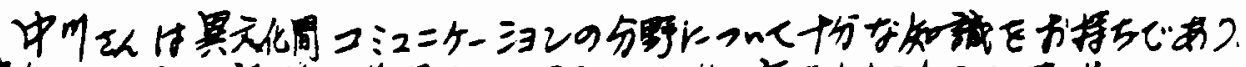

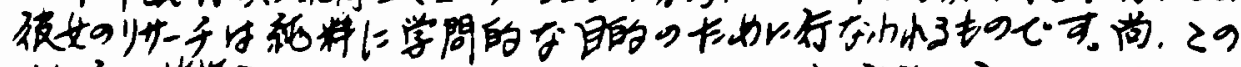

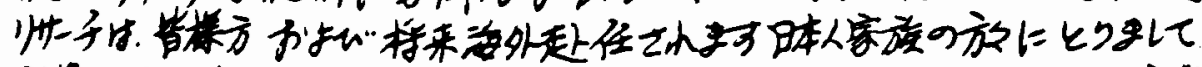

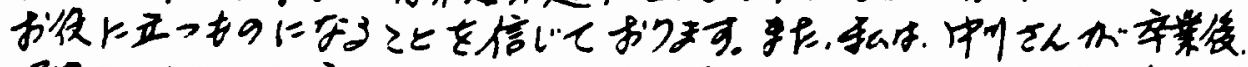

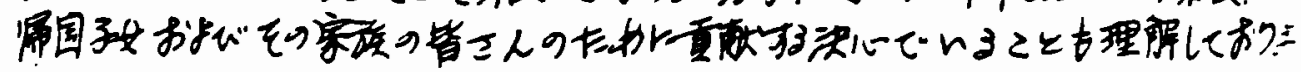

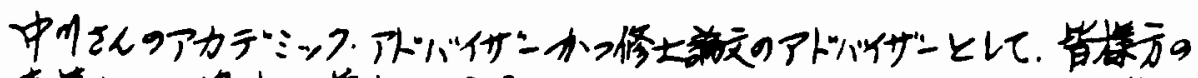

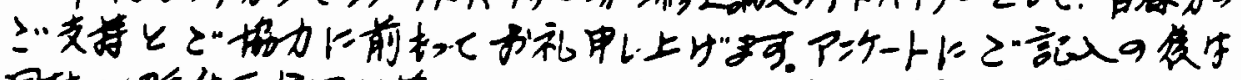

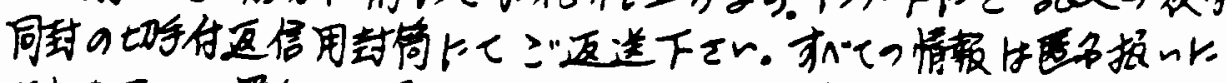
てんま可ので署名心必要けざごいません。汾な数のアンケートが

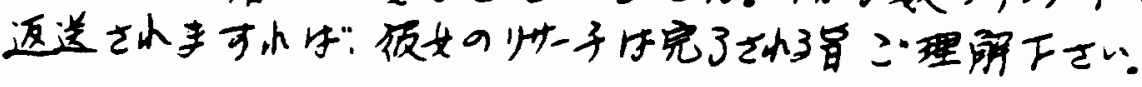

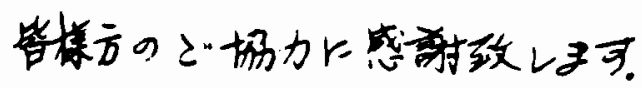

歌具 哮授 タイイ、バーナ 
APPENDIX J

APPROVAL IETTER 


\section{APPENDIX J}

APPROVAL LETTER

(Japanese Version)

ALA ATAKA LUMBER AMERICA, INC. One Main Place - Suite 1450 101 S.W. Main Street, Portland, Oregon 97204

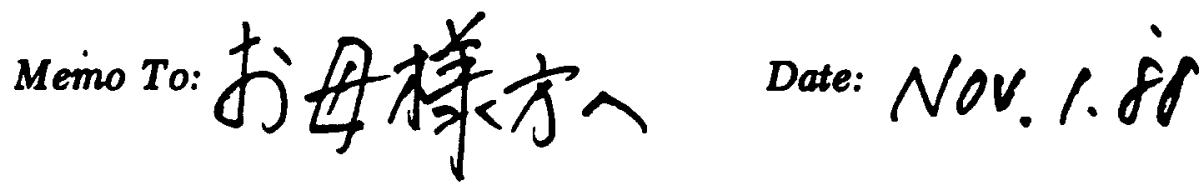

同封の中川典子こんのアンケート はポート3ンド日本人学校にと, 毛有意義学结果が却思い

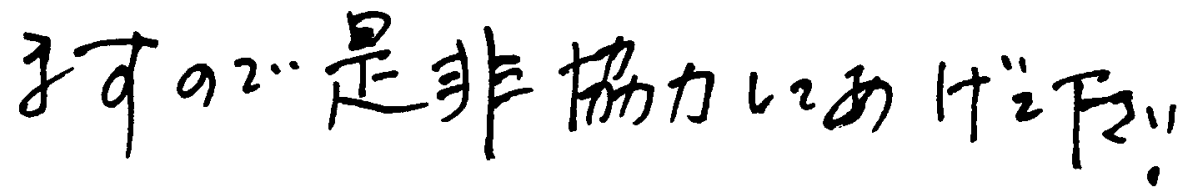
故育委真夏 熊城忠一 


\section{ENGLISH TRANSLATION}

November 1, 1988

Dear Mothers,

I would like to ask for your cooperation in the enclosed questionnaire which is conducted by Miss Noriko Nakagawa. This research will be beneficial for the Portland Japanese School.

Sincerely yours,

Chairperson of the Educational Board at the Portland Japanese School

Tadakazu Kumashiro 
APPENDIX K

FOLLOW-UP LETTER 


\section{APPENDIX $\mathrm{K}$ \\ FOLIOW-UP LETTER \\ (Japanese Version)}

お婪样方へ:

12839

前略

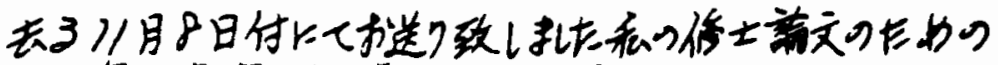

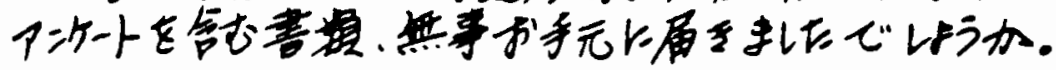

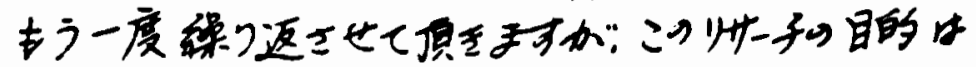

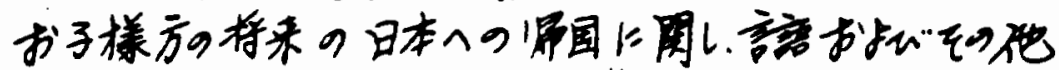

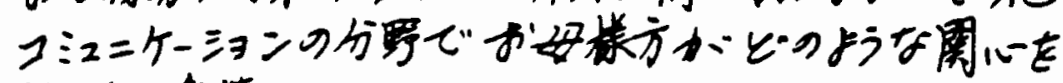

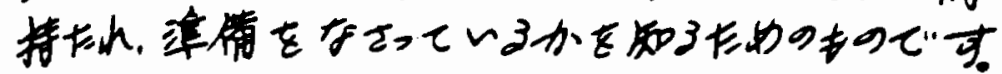

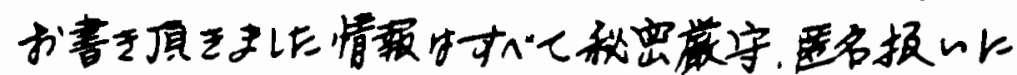

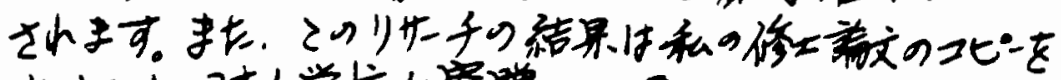

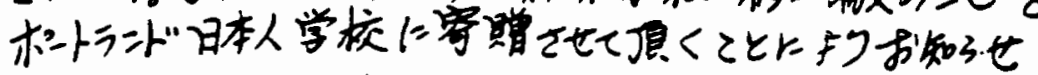
するっちでずります。

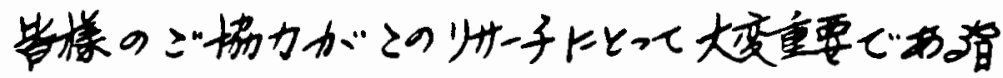
ン゙理解頂け小げ幸いです。

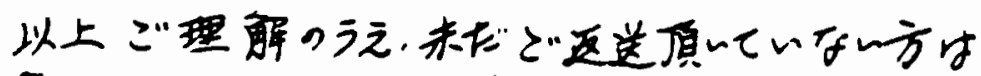

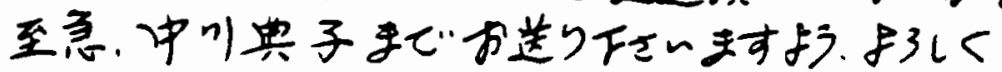
お殿し致レます。

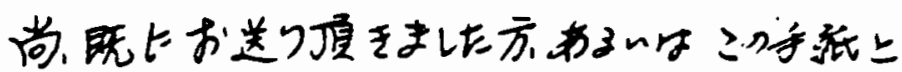

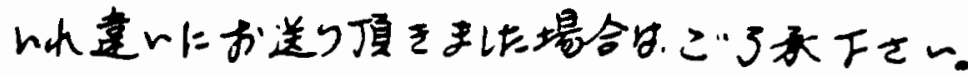

草

种典子 
ENGLISH TRANSLATION

December 3, 1988

Dear Mothers,

I hope that you have received my letter dated November 8 with the enclosed survey questionnaire for my Master's thesis.

Please let me repeat that the purpose of this research is to discover what kinds of concerns mothers have, and what kinds of preparations they are doing regarding the language and other aspects of the communication field in terms of their children's return to Japan.

Every information given to the questionnaire will remain confidential and anonymous. I am going to inform you of the results of this research by donating a copy of my thesis to the Portland Japanese School.

I appreciate if you would understand that your cooperation is vital to this research.

If you have not returned your questionnaire yet, please mail it to Noriko Nakagawa as soon as possible. If you have already mailed it, please disregard this notice letter.

Sincerely yours,

Noriko Nakagawa 